\title{
Urban regulation and diverse housing supply: An Investigative Panel
}

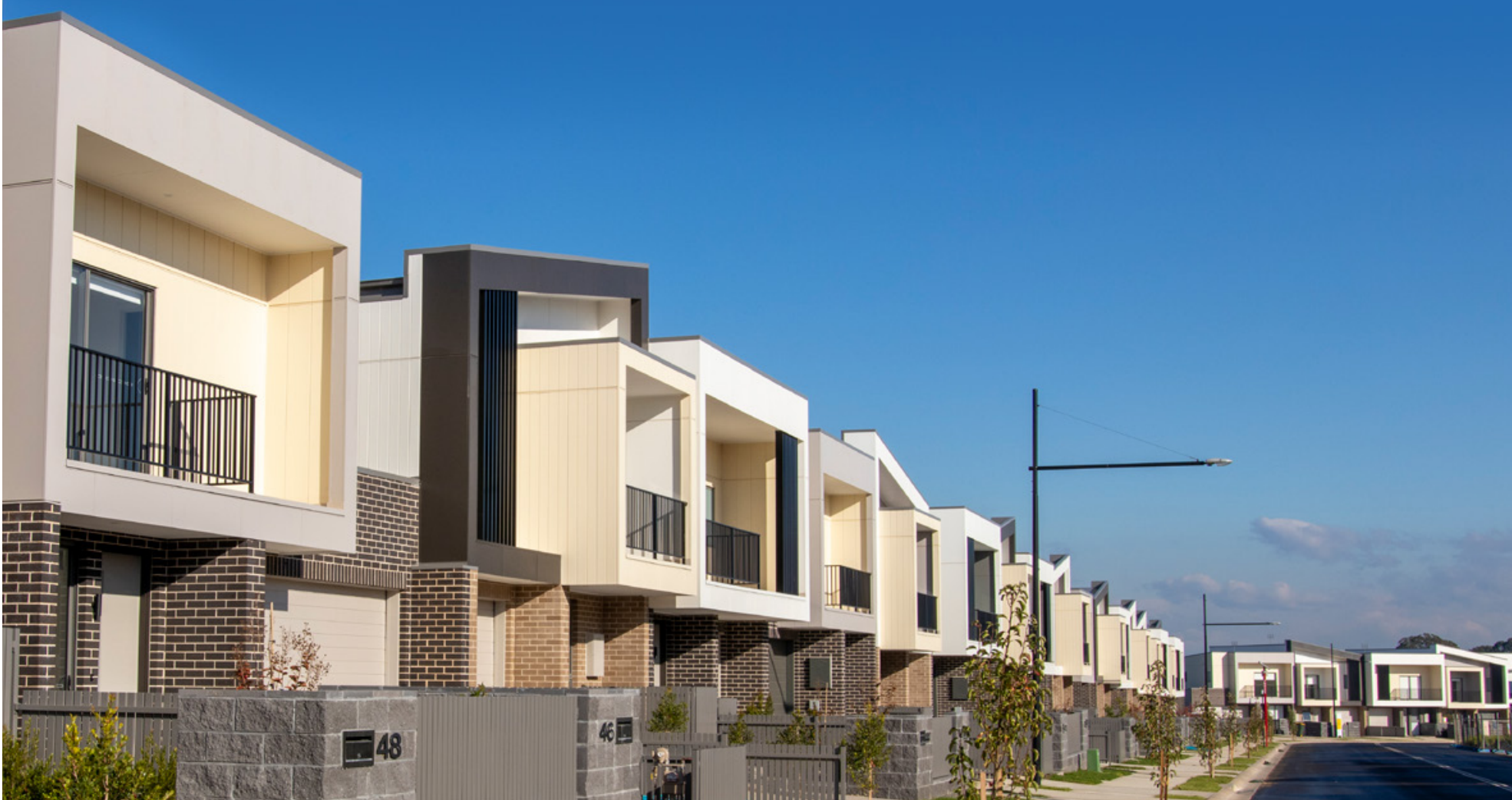

Authored by

Catherine Gilbert, The University of Sydney

Steven Rowley, Curtin University

Nicole Gurran, The University of Sydney

Chris Leishman, The University of Adelaide

Mike Mouritz, Curtin University

Katrina Raynor, The University of Melbourne

Christen Cornell, The University of Sydney
Publication Date December 2020

DOI 10.18408/ahuri7321501

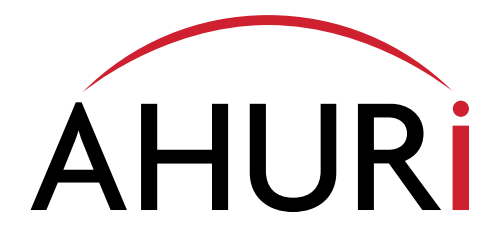


Title

Urban regulation and diverse housing supply: An Investigative Panel

\section{Authors}

Catherine Gilbert, The University of Sydney

Steven Rowley, Curtin University

Nicole Gurran, The University of Sydney

Chris Leishman, The University of Adelaide

Mike Mouritz, Curtin University

Katrina Raynor, The University of Melbourne

Christen Cornell, The University of Sydney

\section{ISBN}

978-1-922498-15-1

\section{Key words}

Urban planning and housing; supply and demand for social and affordable housing; financing social and affordable housing; home ownership; private rental market.

\section{Series}

AHURI Final Report

\section{Number}

349

\section{ISSN}

1834-7223

\section{Publisher}

Australian Housing and Urban Research Institute Limited Melbourne, Australia

\section{DOI}

10.18408/ahuri7321501

\section{Format}

PDF, online only

\section{URL}

https://www.ahuri.edu.au/research/final-reports/349

\section{Recommended citation}

Gilbert, C., Rowley, S., Gurran, N., Leishman, C., Mouritz, M., Raynor, K. and Cornell, C. (2020) Urban regulation and diverse housing supply: An Investigative Panel, AHURI Final Report No. 349, Australian Housing and Urban Research Institute Limited, Melbourne, https://www.ahuri.edu.au/research/final-reports/349, doi: 10.18408/ahuri7321501.

\section{AHURI}

AHURI is a national independent research network with an expert not-for-profit research management company, AHURI Limited, at its centre.

AHURI's mission is to deliver high quality research that influences policy development and practice change to improve the housing and urban environments of all Australians.

Using high quality, independent evidence and through active, managed engagement, AHURI works to inform the policies and practices of governments and the housing and urban development industries, and stimulate debate in the broader Australian community.

AHURI undertakes evidence-based policy development on a range of priority policy topics that are of interest to our audience groups, including housing and labour markets, urban growth and renewal, planning and infrastructure development, housing supply and affordability, homelessness, economic productivity, and social cohesion and wellbeing.

\section{Acknowledgements}

This material was produced with funding from the Australian Government and state and territory governments. AHURI Limited gratefully acknowledges the financial and other support it has received from these governments, without which this work would not have been possible.

AHURI Limited also gratefully acknowledges the contributions, both financial and in-kind, of its university research partners who have helped make the completion of this material possible.

\section{Disclaimer}

The opinions in this report reflect the views of the authors and do not necessarily reflect those of AHURI Limited, its Board, its funding organisations or Inquiry Panel members. No responsibility is accepted by AHURI Limited, its Board or funders for the accuracy or omission of any statement, opinion, advice or information in this publication.

\section{AHURI journal}

AHURI Final Report journal series is a refereed series presenting the results of original research to a diverse readership of policy-makers, researchers and practitioners.

\section{Peer review statement}

An objective assessment of reports published in the AHURI journal series by carefully selected experts in the field ensures that material published is of the highest quality. The AHURI journal series employs a double-blind peer review of the full report, where anonymity is strictly observed between authors and referees.

\section{Copyright}

(C) Australian Housing and Urban Research Institute Limited 2020

This work is licensed under a Creative Commons Attribution-NonCommercial 4.0 International License, see http://creativecommons.org/licenses/by-nc/4.0/. 


\section{Contents}

List of tables

List of figures $\quad$ iv

List of boxes

Acronyms and abbreviations used in this report iv

Glossary

Executive summary

1. Introduction

1.1 Policy context

1.2 Diverse housing and supply barriers $\quad 12$

1.2.1 What is diverse housing?

1.2.2 Barriers to diverse housing supply

1.2.3 Role of government in supporting change and innovation in housing supply 18

1.3 Research methods $\quad 19$

1.3.1 Research aims and questions 19

1.3.2 The Investigative Panels

1.3.3 Other data collection and analysis

2. Recent regulatory reforms and programs to support diverse housing models in Canada and the UK 23

2.1 Background $\quad 24$

2.2 Planning policies to support alternative housing tenures in Vancouver, Canada 25

2.2.1 Purpose-built rental housing 25

2.2.2 Below-market-rate housing and innovative models to support long-term affordability for moderate income groups

2.2.3 Affordable housing for higher need groups

2.3 Policies and programs to support alternative housing tenures and new housing models in the UK 28

2.3.1 Diversifying housing tenures $\quad 29$

2.3.2 Purpose-built rental housing 29

2.3.3 Community-led housing development

2.4 Summary and policy development implications

3. Current planning policies and programs to support diverse housing supply in Sydney, Melbourne and Perth

\begin{tabular}{l}
3.1 Background \\
\hline
\end{tabular}

3.2 Sydney

3.2.1 Support for diverse housing supply in metropolitan strategic planning

3.2.2 Planning-based incentives for lower cost market and affordable rental housing 36

3.2.3 Medium density in greenfield and infill contexts 37

3.2.4 Inclusionary planning mechanisms

3.2.5 Evidence of outcomes of policies to support diverse housing supply 38

$\begin{array}{ll}3.3 \text { Melbourne } & 39\end{array}$

3.3.1 New planning objectives and strategies to support diverse housing supply

3.3.2 Diverse housing types in greenfield and infill contexts 39 
3.3.3 Inclusionary planning mechanisms for affordable housing

3.3.4 Affordable homeownership

3.4 .1 Support for diverse housing in strategic planning

3.4.2 Planning and other policy reform

3.4.3 Joint ventures and government leadership

3.4 .4 Affordable homeownership

3.5 Summary and policy development implications $\quad 43$

4. Diversifying housing supply in Sydney, Melbourne and Perth: views from the Investigative Panels 45

4.1 Background

4.2 Dimensions of diversity and housing stock gaps

4.2.1 Dimensions of diversity

4.2.2 What housing is missing and who is missing out?

4.2.3 Features of a more diverse housing system 49

4.3 Barriers and challenges for delivering diverse housing supply $\quad 50$

4.3.1 Zoning, development control policies and developer contributions 50

4.3.2 Development assessment processes

4.3.3 Development financing and taxation settings

4.3.4 Land costs and acquisition 56

4.3.5 The housing development industry and housing market factors

$\begin{array}{ll}4.4 \text { Summary and policy development implications } & 58\end{array}$

5. Potential levers for government to support more diverse housing supply: views from the Investigative Panels

$\begin{array}{ll}5.1 \text { Land } & 63\end{array}$

5.2 Leadership, demonstration and education $\quad 66$

5.3 Reform to zoning and statutory planning rules

5.4 Reform to development assessment processes $\quad 71$

5.5 Funding affordable housing and supporting the not-for-profit housing sector 72

5.6 Data collection, reporting and monitoring

5.7 Summary and policy development implications $\quad 74$

6. Policy development options $\quad 76$

6.1 Why is more diverse housing supply needed and what are the opportunities to diversify housing in Australian cities?

6.2 What are the major barriers for increasing the diversity of new housing supply?

6.3 How can governments better enable diverse housing supply? $\quad 79$

6.4 Conclusion

References $\quad 82$

Appendix 1: Built-environment and housing industry experts $\quad 90$

Appendix 2: Housing market trends and housing stock in Sydney, Melbourne and Perth

Appendix 3: Investigative Panel question prompts and key terms and definitions 94 


\section{List of tables}

Table 1: Elements of housing diversity with potential to support more affordable housing supply 14

Table 2: State planning policies relevant to housing diversity in NSW 36

Table 3: Comparison of reforms and policy efforts to encourage diverse housing supply 43

Table 4: Overview of key barriers and challenges for delivering diverse housing supply 60

Table A1: Comparison of housing stock: dwelling types (2016) 93

Table A2: Comparison of housing stock: number of bedrooms and average household size (2016)

Table A3: Comparison of housing tenure and select household characteristics (2016)

\section{List of figures}

Figure A1: Residential property price index:

Sydney, Melbourne and Perth

Figure A2: Median price at transfer (unstratified) of detached dwellings 92

Figure A3: Median price at transfer (unstratified) of attached dwellings

\section{List of boxes}

Box 1: Master planned redevelopment on underutilised government land (Montario Quarter) 65

Box 2: Master-planned development on underutilised government land (Edmonson Park and Ed.Square) 65

Box 3: Communicating housing need (Moreland Council)

Box 4: Government demonstration (White Gum Valley) 68

Box 5: South Australia's statewide inclusionary zoning scheme

Box 6: Structural and tenure diversity through a state-led masterplan (Thornton)

Box 7: Mixed-tenure housing project delivered by a CHP (Macarthur Gardens)

\section{Acronyms and abbreviations used in this report}

ABS

Australian Bureau of Statistics

AHURI Australian Housing and Urban Research Institute Limited

ARHSEPPAffordable Rental Housing State Environmental Planning Policy

BTR Build to Rent

CBD central business district

CHP community housing provider

DCL development cost levy

EPA Act Environmental Planning and Assessment Act 1979 (NSW)

GFC global financial crisis

JDAP Joint Development Assessment Panel

LDAP Local Development Assessment Panel

LEP local environmental plan

LGA local government area

LIHTC Low Income Housing Tax Credit Scheme (US)

NHFIC National Housing Finance and Investment Corporation

NRAS National Rental Affordability Scheme

NSW New South Wales

PRS Private Rented Sector

SEPP State Environmental Planning Policy

STIR Short Term Incentives for Rental

UK United Kingdom

ULI Urban Land Institute

US United States

VAHA Vancouver Affordable Housing Agency

VPA Voluntary Planning Agreement

VPP Victoria Planning Provisions

WA Western Australia

\section{Glossary}

A list of definitions for terms commonly used by AHURI is available on the AHURI website www.ahuri.edu.au/research/glossary. 


\section{Executive summary}

\section{Key points}

- Diversifying housing supply in response to changing demographic profiles and declining housing affordability has become a significant policy aspiration in Australia's major cities.

- However, despite this aspiration, the majority of housing is delivered in the form of detached housing in greenfield locations and, to a lesser extent, high-rise apartments, both of which are sold at market rates to owner-occupiers and small-scale buy-to-let investors.

- In this context, this study engaged the expertise of 50 housing and built-environment professionals in Sydney, Melbourne and Perth on Investigative Panels to examine barriers and challenges within the housing system for delivering housing supply that is more diverse in terms of size and built form, tenure, development model and, importantly, affordability level.

- Across these three cities, the housing industry and built-environment experts who took part in the study perceived a need for: greater diversity in housing types and sizes, particularly in lower-density suburban areas; medium- and higher-density housing forms able to accommodate a wider variety of household types and lifestyle preferences; rental housing that can offer greater security of tenure; and, more housing supply across tenures that is affordable to very low to moderate income households. 
- In addressing these gaps, panellists saw a need for more mediumdensity housing such as townhouses and other attached housing types with ground access; dwelling designs that cater to different household needs and preferences (in terms of size, facilities, adaptability, etc.), and alternative processes for developing new supply, including deliberative development models managed by future residents/owners. Panellists also emphasised the importance of affordable home ownership and rental housing options and increased supply of social housing.

- The Investigative Panels revealed that these types of projects can face a range of development challenges. In terms of the planning system, challenges can include difficulty accessing sites where medium- and higher-density built form is permitted and financially viable; lack of clarity as to the permissibility of unconventional housing or development types within land-use zones; lack of flexibility in development controls to allow for design innovations, such as reduced car parking; and uncertainty around the time frame and outcome of development assessment decisions.

- Uncertainty has a particular impact on less conventional developments with tight development margins, which are less able to cope with unexpected costs associated with time delays. At the same time such projects-often lower cost rental or home ownership developments -can also face greater community opposition in established areas, potentially prolonging assessment processes and uncertainty regarding an application outcome. 
- Other important challenges relate to factors beyond the planning system. These include high urban land costs; challenges obtaining development finance; and a lack of appropriate skills and expertise in the housing industry.

- Competing for access to land and finance can be particularly difficult for housing projects that do not constitute highest value land use and that are initiated by start-up organisations and small developers without significant balance sheets or development track records.

- Projects designed for long-term affordability and affordable housing projects by not-for-profit housing providers face additional economic viability challenges, while subsidies to support project viability are limited and inconsistent.

- The drive for innovation in new housing supply must ultimately come from the private housing development industry, which currently produces more than 97 per cent of Australia's new homes.

- However, all levels of government can play a role in de-risking and supporting the viability of diverse housing projects through subsidies in the form of land, grants, and access to special mortgage products for purchasers of diverse housing products; as well as through access to development finance, and special development assessment pathways.

- State and local governments can ensure that land-use zoning allows for or requires a range of dwelling densities in different locations. Zoning rules can also be designed to limit competition from higher value land uses where a particular form or tenure of housing is desired. 
- Flexibility and concessions on development requirements and fees and charges, where appropriate, could also help to support the viability of diverse housing projects.

- While planning-based interventions can play an important role in supporting the permissibility and viability of projects delivering diverse housing dwelling types and sizes, tenures and development models, deeper forms of subsidy are required to support significant supply of housing that is affordable to low-income groups.

- All levels of government can play an important role in communicating the need for more diverse housing supply and enabling more diverse housing supply through strong leadership. In addition to Commonwealth financial support, state governments should take a leadership role in establishing targets and strategic directions for increasing diversity of housing supply; and supporting innovation through demonstration projects that can be replicated across the industry. Local governments have a crucial role in building support for housing designed to meet the full spectrum of needs in their communities, and in helping developers and community organisations interested in delivering diverse types and tenures of housing and development models to navigate the planning system. 


\section{Key findings}

\section{Dimensions of housing diversity that are lacking in Australia's major cities}

There has long been concern that new housing supply is failing to meet the changing needs of Australia's diverse population. Diversifying housing stock has become a goal of metropolitan region planning in the context of demographic changes; increased barriers to home purchase; growth in private renting; and concerns about the environmental and social performance of Australian homes and communities.

Dimensions of housing diversity include not only built form, but factors such as tenure and price/ affordability. The need for diverse housing supply reflects not only varying capacities to pay for housing, but housing and lifestyle preferences across age cohorts and household types.

The built-environment and housing industry experts involved in this study emphasised that housing diversity embraces a wide range of factors relating to dwelling size and design; tenure and governance arrangements; construction method; and the development and financing model. In the three cities that were the focus of the research, they perceived a need for:

- More diversity in dwelling types and sizes, particularly in lower-density suburban areas characterised by detached houses.

- Medium and high-density housing forms that can better accommodate resident design and lifestyle preferences.

- Rental housing that can offer increased security of tenure compared to the private rental sector which, in Australia, is dominated by small-scale buy-to-let investors.

- Housing across tenures that is affordable to very low to moderate income households.

Panel participants saw a role for different housing types and sizes, tenures and development models that are generating policy and industry interest in Australia-and, in some cases, have been demonstrated on a small scale - in addressing these gaps if able to be scaled up. In terms of the lack of diversity in built form in new and established lower-density areas, built-environment and housing industry experts saw a need for more mediumdensity housing forms which, in the Australian context, include terraced and semi-detached homes and twostorey apartment buildings. These were seen as important for enabling downsizing among older households within their local areas, as well as offering more affordable entry points for first homebuyers. However, it was recognised that medium-density housing forms delivered by private housing suppliers are not always more affordable than other products in a local market. Deliberative and non-speculative development models were seen to offer potential to deliver medium-density and higher-density housing forms that better meet the needs and lifestyle preferences of different household types, while community-led development models oriented to long-term affordability, shared ownership housing, and the scaling up of more traditional affordable and social rental housing provision are needed to address persistent unmet affordable housing need.

If delivered on a wider scale, panel participants pointed out that these housing types, tenures and delivery models - which can be considered diverse in the Australian context-could allow for greater mobility within the housing system, enabling households to better match their housing with their needs, aspirations and capacity to pay for housing across life stages. 


\section{Barriers and challenges for delivering diverse housing}

International research, particularly from the US, has found that planning systems can reinforce patterns of housing supply that are dominated by single family homes and biased towards home ownership. In Australia, previous research has demonstrated similar concerns from developers about planning system barriers to innovation.

However, there is evidence-particularly over the past five years-both of new development types emerging in Sydney, Perth and Melbourne, and of ongoing reforms to metropolitan planning frameworks to support more diverse housing supply. In this context, the Investigative Panels examined the extent to which planning systems in Sydney, Melbourne and Perth remain barriers to the implementation and scaling up of diverse housing types and tenures and new development models, as well as other important housing system factors that impact the financial viability and overall feasibility of different housing models in the Australian context.

A range of challenges for delivering diverse sizes, designs and tenures of housing, and for the scaling up of deliberative and non-speculative development models were identified through the Investigative Panel deliberations. Some of the issues raised are also relevant for the feasibility more conventional housing projects, including the high cost of land, inflexible development controls or requirements, and uncertainty regarding the timing and outcome of development assessment processes. However, projects that deliver housing that differs to the majority of housing stock can face additional challenges as they move through the development process as a result of tighter development margins, lack of precedence both in terms of planning permissibility and valuation for financing and lack of industry experience. Particularly for projects delivering housing for lower income groups, and additional barrier is the need for subsidy for projects to be viable.

\section{Planning}

Across Sydney, Melbourne and Perth, land-use zoning is the primary means of development control. Zones specify maximum residential densities as well as land uses that are potentially permissible with development consent. The built-environment and housing industry experts who took part in the panels explained that local land-use zoning can have a significant impact on whether diverse housing types are permitted in residential areas, as well as whether medium-density housing is financially viable. They argued that medium-density and higher-density housing forms are often not permitted in established residential areas. Where zoning allows for apartment buildings, land prices are typically higher, meaning that medium-density housing forms, including townhouses, are not financially viable. While some specific housing types, such as boarding or rooming houses and secondary or ancillary dwellings are now specified as potentially permissible uses in some land-use zones, many other types of residential development are not specifically named-meaning that their potential permissibility is unclear.

Particularly in infill development contexts where there are potential impacts on surrounding lower-density land uses, projects with medium- and higher-density built forms can face increased community opposition. That opposition can be stronger where projects are also delivering affordable housing. As panel participants explained, that can lead to prolonged development application processes and increase uncertainty as to whether a project will be approved. They explained that projects that have tighter development margins, particularly non-speculative and affordable housing projects, are less able to cope with additional costs of attaining development approval and may become unviable if processes are drawn out.

\section{Land}

The high cost of land, particularly in accessible locations that are well suited to medium and higher-density built form and non-speculative and affordable housing projects, presents as a significant challenge for site acquisition. As panel participants explained, land vendor expectations typically reflect the highest and best economic use value of land. This means that the projects that are best able to compete for sites are those that maximise density allowances and deliver housing for sale at market rates. The high cost of land also makes it difficult to amalgamate sites in order to undertake larger-scale, planned redevelopment to include a variety of residential densities and housing tenures. 


\section{Finance}

Access to finance and finance costs were also identified as a particular challenge for projects that include unique housing products or tenure arrangements, or that are delivered through an alternative development model, as lenders perceive them to be higher risk. Lack of comparable dwelling types can also be a problem for accurately valuing diverse housing products.

A further challenge for obtaining finance is that developers and organisations looking to develop medium-density infill housing and non-speculative and community-led housing projects are often small scale and in some cases start-up organisations that do not have a development track record or significant balance sheets. Projects delivering housing for low-income households also need additional subsidy to be financially viable, but sources of subsidy are limited and inconsistent.

\section{The development industry}

Barriers to innovation also exist within the housing development industry itself. Panel participants pointed out that the larger developers who dominate the development industry can be averse to economic risk and slow to change their housing products. Smaller developers may be more agile in terms of the housing products they can produce, but can face challenges in scaling up their production. Innovation is also hindered by lack of necessary skills and experience within the housing development industry. This can include lack of knowledge or lack of experience with different housing delivery models, building forms and dwelling configurations, as well as building materials and construction methods.

\section{Enabling diverse housing supply: policy development options}

There are significant opportunities for governments to support more diverse housing supply in Australian cities. Although important, particularly in terms of the permissibility of different housing types, planning reform alone is unlikely to 'unlock' innovation or support significant scaling up of diverse housing supply. In part, this is because important barriers and challenges to delivering diverse housing relate to factors beyond the planning system. There is an opportunity for governments to initiate and extend more holistic approaches, including:

- leadership in articulating the need for different dwelling types, housing tenures, development models and pricepoints

- guidance and support for suppliers interested in delivering diverse housing products

- proactive measures to subsidise and de-risk projects that deliver affordable housing for low-income and moderate-income groups

- engaging in potentially replicable projects that demonstrate diverse housing types, tenures and delivery models.

\section{Reforms to planning}

State and local government can support diverse housing supply and innovative housing projects through regulatory reforms to:

- Ensure land-use zoning allows for medium-density and higher-density land uses in a range of locations. This could extend to permitting rental housing or affordable housing tenures in appropriate non-residential zones where land-use conflicts can be managed-for example, affordable 'live/work' precincts in light industrial zones.

- Ensure that diverse housing types and models are named in state planning strategies and in statutory planning instruments, and that their permissibility (with consent) is clear.

- Require a mix of housing types and tenures, including lower cost or affordable housing as part of significant new residential development projects. 
- Expedite or provide priority development assessment processes for projects that can demonstrate an affordability outcome or address an identified unmet housing need.

- Allow concessions such as waived development application fees, council taxes, and development contribution requirements, as appropriate, for projects that can demonstrate an affordability outcome or address an identified unmet housing need.

\section{Scaled subsidy}

Projects delivering housing at below-market rates for those on lower incomes require additional subsidy-beyond what can be generated from sales or rents-to be financially viable. All levels of governments could support the viability of projects that deliver housing that is affordable for low-income and moderate-income groups through:

- provision of government land-through discounted sale, long-term lease or through joint ventures

- access to special loans for developers and purchasers

- grants to support the development of new sectors within the housing industry, particularly organisations interested in undertaking non-speculative and community-led development, as well as funding to support demonstration projects

- long-term sources of funding to support not-for-profit housing developers to deliver new affordable housing supply, in addition to funding from the National Housing Finance and Investment Corporation (NHFIC).

\section{Government leadership}

Apart from regulatory reform and subsidies, governments have an important role to play in developing the strategic framework in which to situate policies and programs to support diverse housing supply and in demonstrating diverse housing projects. Key areas for government leadership include:

- Communicating the need for diverse housing supply to communities, government agencies and the housing development industry.

- Establishing targets and strategic directions for increasing the diversity of housing supply.

- Making detailed data available and undertaking or commissioning detailed research on housing needs, preferences and housing supply.

- Helping community organisations interested in developing housing and affordable housing developers to navigate the planning system.

- Supporting innovation through projects that demonstrate demand for-and potential profitability of-diverse housing products, and that work through development challenges.

\section{Industry innovation}

The drive for housing innovation, however, also needs to come from industry. This includes developing understanding of new models, working through feasibility challenges and developing skills in alternative construction methods and building styles appropriate to diverse housing delivery. 


\section{The study}

The research captured the perspectives of 50 built-environment and housing industry experts through six Investigative Panels held in Sydney, Melbourne and Perth between 21 November and 2 December 2019, as well as through four separate interviews. Focussing on these three cities enabled exploration of the opportunities and challenges for delivering diverse types and tenures of housing and development models within different planning system and housing market contexts. Two 3-hour panels were run consecutively in each city. Panellists were invited to participate in the Investigative Panels based on their professional expertise and familiarity and experience with diverse housing types and development models. The first session (morning) focussed on the perspectives of housing, development and finance professionals and researchers. The second session (afternoon) focussed on the perspectives of planners, urban policy makers and financial regulators. The discussion was guided by a common set of questions, with slight modifications across morning and afternoon sessions to account for different professional experience and expertise.

The question prompts and discussion focussed on:

- dimensions of diversity and gaps within the current housing stock of Australian cities

- diverse types and tenures of housing and development models emerging in industry and potential opportunities and barriers for their scaling in Australia

- specific aspects of the planning system that inhibit or challenge diverse housing production

- broader factors inhibiting diverse housing production, including those internal to the construction industry

- how all levels of government could better enable diverse housing supply.

Transcripts of the Investigative Panels were analysed and key ideas and text coded against the series of questions outlined in the discussion paper. Transcripts for each city were analysed separately, and then the results were compared.

In addition to the Investigative Panels, the research team examined select international practice in Canada and the UK in enabling new diverse housing types and development models. This was done through a desk-based review of research findings, policy and program documents and program evaluation materials, accompanied by a small number of interviews. Current policy settings, programs and initiatives in Sydney, Melbourne and Perth to support diverse types and tenures of housing were also examined as background to the Investigative Panels.

The analysis focussed on identifying high-level institutional factors that impact the supply of diverse housing, and potential for regulatory changes and other interventions by government to better enable diverse housing supply across a range of housing types and development models. 


\section{Introduction}

- Australia's housing stock lacks diversity in terms of dwelling type, tenure and-most importantly-affordability.

- Despite strategic planning goals to diversify housing stock in Australia's major cities-and growing interest by policy makers and the housing development industry in new types and tenures of housing and development models-the majority of new housing supply continues to be in the form of detached housing in suburban and city fringe locations and high-rise apartments in inner city areas, both of which are sold to owner-occupiers or small-scale investors at market prices. This is, in part, due to a lack of diversity in the way house building and home purchase is financed.

- The research explores how a wide range of factors impact on the diversity of new housing supply, including planning policies and processes for obtaining development approval; requirements for development financing; and the housing development industry itself.

- The project engaged 50 built-environment and housing industry experts through six Investigative Panels in three cities (Sydney, Melbourne and Perth) and four separate interviews. 


\subsection{Policy context}

Australia's housing system, which has traditionally been characterised by high rates of homeownership, a private rental sector intended as a transitional tenure, and a very small social housing sector, is under significant strain following over a decade of rapid house price growth and declining housing affordability, particularly in the major cities (Australian Bureau of Statistics [ABS] 2019b). Significant affordability barriers to ownership have resulted in unprecedented growth in private rental (38\% between 2006 and 2016), with many households now never becoming homeowners (Hulse, Parkinson and Martin 2018). The pace of growth of the sector is significantly exceeding household growth (Hulse, Parkinson and Martin 2018). While the private rental sector offers a viable alternative to homeownership for some households, low-income households, in particular, face access and affordability barriers (Parkinson, James and Liu 2018), while many renters face short tenancies (6-12 months) and potentially rising housing costs. An increasing proportion of young adults are living with their parents despite aspiring to live independently and for home ownership (Parkinson, Rowley et al. 2019). To access homeownership, there is evidence that some households are moving to city fringe and outer urban locations and commuting long distances to work (Gurran, Gilbert, Zhang et al. 2018). Older, lower income households in the private rental sector are particularly vulnerable and in need of increased tenure security (James, Rowley et al. 2018). More broadly, the growth in older person households suggests a need for increased supply of smaller, lower maintenance dwellings designed with ageing in mind (James, Rowley et al. 2018; James, Rowley et al. 2020).

This context of persistent undersupply of affordable housing relative to needs, demographic change, and growing spatial inequity in access to jobs and services presents major challenges for government. As a result, diversifying Australia's housing supply has become an important objective of metropolitan region planning. In Sydney, increasing the supply of diverse and affordable housing to meet housing needs across the housing continuum is a stated objective of the Metropolis of Three Cities strategy (Greater Sydney Commission 2018). Likewise, Plan Melbourne identifies a need for more affordable housing and for housing that caters for different household types and lifestyles, as well as a need to increase the supply of medium-density and high-density housing that is close to employment opportunities, transport networks and civic activities (State Government of Victoria 2017). Perth continues to face an expanding urban perimeter despite evidence that many people moving to the new outer suburbs would prefer to live close to the city centre if they could afford housing in that location (Department of Housing and Western Australian Housing Commission 2013). In 2018, the Perth and Peel@3.5million strategy (State Government of Western Australia 2018) was introduced with a focus on 'limit[ing] unsustainable urban sprawl and encourag[ing] greater housing diversity to meet changing community needs' (Department of Planning Lands and Heritage 2020b).

Despite the recognised need for more diverse housing stock, higher-density apartments have become the primary mode of new supply within the inner cities, particularly in Sydney and Melbourne, but detached dwellings prevail in suburbs and regional areas, with medium-density options such as townhouses and villas failing to gain significant traction (Rowley, Gilbert et al. 2020). This ‘missing middle' represents a significant gap in Australia's housing supply, with studies showing that many people would choose medium-density living if options were available (Kelly, Weidmann and Walsh 2011; Department of Housing and Western Australian Housing Commission 2013), particularly those seeking long-term residency or ownership (Raynor 2018). The higher-density housing delivered in central areas of the major cities in recent years, despite introducing smaller homes to the housing stock, has not improved high rates of rental stress or declining rates of homeownership (Ong, Dalton et al. 2017; van den Nouwelant, Crommelin et al. 2016). At the same time, dedicated inclusionary planning mechanisms-which are common in global cities internationally - have resulted in very few affordable homes (Gurran, Gilbert, Gibb et al. 2018). Overall, Australia's housing system is failing to deliver diverse sizes, designs and tenures of housing across a range of pricepoints despite more than a decade of urban and housing policy reform targeted at addressing declining housing affordability. 
New alternative housing types and development models have potential to address some of these gaps. There has been an increase in interest in purpose-built rental housing models and shared equity ownership, particularly in the context of declining home-purchase affordability and insufficient rental supply (Thompson, Macdonald and Moullakis 2017; Tan 2018). In some cities, other models are emerging as alternatives to mainstream market offerings, including:

- cohousing-where households occupying more modest private spaces share purpose-designed and managed facilities and common spaces.

- deliberative development models-where groups of households work directly with architects and builders to manage a multi-unit housing development project for their own occupation.

These approaches differ to speculative housing development, and can better align design with occupant needs and lifestyle preferences. However, these models remain small in scale.

Governments have also enacted regulatory changes through the land-use planning system - such as changes to zoning and development control-to support the delivery of medium-density housing in established suburbs as well as in greenfield areas. However, diversifying the housing stock within existing residential areas, and in new communities where market preferences have traditionally focussed on detached dwellings, is a complex challenge. There is a need to better understand the barriers faced by private as well as not-for-profit producers in diversifying housing development and potential opportunities for implementing and scaling up the delivery of alternative housing types and delivery models.

In recent years, governments in nations with comparable housing systems-including Canada and the United Kingdom (UK) - have faced similar challenges, introducing regulatory reforms and incentives. These interventions have sought to diversify both the design of new housing and housing tenure, and have provided support for new development models that can offer improved affordability. These offer potential lessons for Australia on potential for regulatory reforms and government leadership and initiatives to support increased diversification of housing supply.

\subsection{Diverse housing and supply barriers}

\subsubsection{What is diverse housing?}

Delivering diverse forms of housing to meet the spectrum of community needs has become a normative goal of planning. In theory, communities that include a diversity of individuals across the spectrum of age, wealth and cultural background are seen to offer:

- enhanced human experience

- greater social equity, as they allow different social groups access to city resources and avoid concentrated disadvantage

- economic advantages stemming from closer exchange and matching of people and jobs (Talen 2006).

The physical environment plays an important role in supporting this diversity (Talen 2006), with housing being a key element. Recent research in the United States has found that communities characterised by greater housing diversity remained more stable, with fewer foreclosures, during the global financial crisis (GFC). This is largely because those communities, which include housing at a variety of pricepoints, enable households to access their preferred location, close to employment and amenities at costs they can afford (Chakraborty and McMillan 2018). 
However, while there is a strong theoretical rationale for housing diversity, what constitutes diverse housing is often poorly defined, as well as being context-specific. Typically, the notion implies housing that differs in size and built form or tenure to the majority of housing stock, or housing that is delivered in a way that is different to the mainstream mode of provision, with implications for design, lifestyle and costs. Thus, diverse housing can encapsulate:

- dwelling size and built form (Paulsen 2012; Les and Maher 1998)

- housing tenure-the legal arrangements around occupancy

- modes of financing and delivery (Crabtree 2018).

In policy terms, diverse housing typically refers to housing types that are appropriate to a range of household types in terms of size, design and affordability, but are underprovided in the housing market. A key driver of increasing diversity in Australian cities is the need for housing that is affordable and appropriate to households across the whole income spectrum, including across market and affordable tenures (Gurran, Phibbs et al. 2015). Other drivers include urban policy imperatives around containing development to maximise access to jobs and transport, making efficient use of infrastructure, and preserving rural and conservation lands.

In discussing housing needs, policy makers and researchers often refer to a housing continuum, along which different housing needs -including capacity to pay for housing-and appropriate housing tenures to address these needs are situated (Housing WA 2010; Greater Sydney Commission 2018; Gurran, Rowley et al. 2018). In terms of housing tenures, the continuum extends from crisis accommodation or social housing at one end-which have the lowest costs for occupant households but require the highest level of subsidy - to private housing forms, ending in unassisted home ownership, appropriate for above moderate income households. On the middle rungs are affordable rental tenures (such as discounted market rental) and assisted and lower cost home ownership.

The vast majority of new housing in Australia is delivered by private housing developers for purchase in the private market, either for owner-occupation or investment purposes, and is targeted at moderate-income and high-income earners (Rowley, Gilbert et al. 2020). Alternative housing types and tenures that meet the needs of lower-income earners such as lower cost ownership and rental projects and subsidised rental and purchase options are few and far between as delivery has implications for private sector profitability.

Diverse housing might therefore be defined as any housing type that differs to the majority of housing stock in terms of its:

- size and built form - it offers an alternative to detached housing or high-rise apartments

- development model-it differs to the mainstream speculative land and development model

- tenure-it is situated in the middle of the housing continuum, offering an alternative to traditional ownership and rental tenures.

These elements can have implications for affordability.

Table 1 provides an overview of these different elements of housing diversity, including examples applicable to Australian cities. In practice, housing projects may combine these elements. 
Table 1: Elements of housing diversity with potential to support more affordable housing supply

\begin{tabular}{|c|c|c|}
\hline Element of diversity & Examples & Potential benefits \\
\hline $\begin{array}{l}\text { Diverse housing form or } \\
\text { development models (how housing } \\
\text { is designed, developed and built) }\end{array}$ & $\begin{array}{l}\text { - Apartments } \\
\text { - Townhouses / terraces } \\
\text { - Other forms of medium density } \\
\text { - Deliberative development } \\
\text { - Cohousing } \\
\text { - Other forms of non-speculative } \\
\text { community-led development }\end{array}$ & $\begin{array}{l}\text { - Can support downsizing (smaller, lower } \\
\text { maintenance housing options) } \\
\text { - Can be more affordable than detached homes } \\
\text { due to small size and lower land take, but } \\
\text { unlikely to be affordable to low and moderate } \\
\text { income groups in high-value markets. } \\
\text { - Opportunity to design housing to better } \\
\text { meet the needs and lifestyle preferences } \\
\text { of different households } \\
\text { - Can provide affordable housing options for } \\
\text { low to moderate income groups if project has } \\
\text { an affordability aim or is designed to secure } \\
\text { long-term affordability }\end{array}$ \\
\hline $\begin{array}{l}\text { Diverse housing tenures (occupancy } \\
\text { arrangements) }\end{array}$ & $\begin{array}{l}\text { Occupancy arrangements, including: } \\
\text { - long-term secure rental } \\
\text { - shared equity } \\
\text { - below-market rental / discounted } \\
\text { market rent } \\
\text { - social rental }\end{array}$ & $\begin{array}{l}\text { - Can offer longer-term security of tenure than } \\
\text { available in the private rental market } \\
\text { - Affordable to very low to moderate income } \\
\text { households }\end{array}$ \\
\hline
\end{tabular}

Source: Authors.

\subsubsection{Barriers to diverse housing supply}

The planning system has a strong influence on the potential form (structure and design) that a housing development can take, as it:

- defines what uses are permitted on land - such as whether a site can be used for housing

- sets parameters around built form — such as the height, mass and overall density of a building

- sets parameters around building design—such as the extent of open space and landscaping required.

All of these factors can have implications for housing tenure (Gilbert and Gurran 2018).

However, in a market-based system of housing delivery, in addition of whether a particular project is permissible, key determinants of new supply are financial viability and the ability of development to generate a reasonable return for the developer and landowner. This means that the balance between the revenue that can be generated from the development of a site and the cost to develop it needs to deliver a profit sufficient to compensate for the risk of undertaking the development, while still generating sufficient revenue to purchase a site. This balance between risk and return is critical. 
When undertaking a residual valuation to determine whether a project is financially viable, a developer will consider the balance of all sources of revenue, mainly what can be generated from the completed product (dwellings, land, etc.), but also any relevant capital grants, if available, minus all costs. The costs include construction and finance costs and development contribution requirements and fees. A developer will also make assumptions about the timing of these main financial inputs and revenue (Morley 2002; Crosby, McAllister and Whitehead 2013) utilising a cashflow-based approach to estimate returns-usually through an internal rate of return or a return on equity invested. Where the price of land is known - that is, set by the landowner-the developer will determine whether a project can generate a sufficient developer return to compensate for the risks of undertaking development. Where a land price is not known, feasibility modelling will deliver a residual value that is the amount that can be paid for land (Morley 2002; Crosby, McAllister and Whitehead 2013) while delivering a predetermined level of developer profit. In competitive land markets, developers are more likely to be successful in acquiring sites for projects that generate the highest residual land value.

The subsections that follow discuss in more detail how different zoning rules and development control policies influence the potential permissibility of different types and tenures of housing, and how aspects of the development process more broadly have been found to impact the viability of different types of housing development.

\section{Zoning and development controls}

There is a significant body of research that has examined the effects of specific planning policies on housing supply, as well as differences in the regulatory restrictiveness of different jurisdictions. In planning systems that use zoning as the primary means of development control, residential densities are constrained by zoning that only permits single, detached dwellings; low height limits; and requirements for large minimum lot sizes or open space (Glaeser and Ward 2009; Glaeser, Gyourko and Saks 2005; Zabel and Dalton 2011). Where decisions about whether to grant development approval are made by determining authorities on a more discretionary basis, the stance of local governments (and their constituents) towards new development is seen to be an important factor in rates of development approval. This can also apply to decision about whether to rezone land to allow for higher densities (Gabbe 2018b; Whittemore and BenDor 2019). Density limits and car parking requirements are particularly significant in the viability of higher-density development (Gabbe 2018a).

At the extreme end, research suggestions that communities may enact planning controls that are purposely designed to exclude higher-density housing forms and rental tenures as a means of excluding lower income groups (Fischel 2004). This practice, which was originally conceptualised in the US, is referred to as exclusionary zoning.

However, from the 1970s, planning-based strategies collectively defined as 'inclusionary housing' mechanisms have sought to address exclusionary practices (particularly in the US), as well as to achieve more economically mixed communities, and to involve the private sector in the provision and funding of a more diverse range of affordable housing products (Calavita and Mallach 2010). These mechanisms can either be enabled for optional local government use or mandated through state/provincial or national legislation.

\section{These mechanisms include:}

- incentives such as density bonuses or concessions on car parking, development contributions or fees for developers who include non-market-rate housing in their developments

- mandatory requirements for developers to include non-market-rate housing in their developments or to contribute financially towards provision elsewhere.

Some US states have also enacted legislation giving developers of high-density residential projects that include affordable housing a pathway to bypass local development controls in jurisdictions where there is an identified need for affordable housing (Fisher and Marantz 2014; Marantz and Zheng 2020). 
Inclusionary planning mechanisms are a potentially important planning tool to support diverse housing supply, by requiring developers to contribute to delivering below-market-rate housing as part of new developments. However, these models have struggled to gain policy traction in Australia (Gurran, Gilbert, Gibb et al. 2018). US-based research suggests that state policies to allow developers of higher-density, mixed-income housing projects to bypass local development control policies have been effective in overcoming regulatory barriers to this type of supply (Marantz and Zheng 2020). However, inclusionary housing policies on their own have not generally resulted in sufficient affordable housing supply to address the scale and spectrum of housing need. Even in locations where inclusionary zoning is widespread, such as in the US, inclusionary zoning policies and other related requirements for jurisdictions to deliver their regional fair share of affordable housing have not produced sufficient affordable housing to meet the needs of those on low incomes (Freeman and Schuetz 2017). In this context, researchers have pointed to the need for increased public and private funding and political leadership to increase the supply of different types of affordable housing in high-value, high opportunity areas and to improve the quality of existing lower cost accommodation, while maintaining affordability (Freeman and Schuetz 2017; Been, Gould Ellen et al. 2019). Moreover, inclusionary planning models tend to work best in buoyant market conditions, so they are less helpful during periods of high housing need but low development activity (Morrison and Burgess 2014).

Even where a diverse housing project is permissible in terms of the built form, specific aspects of regulation may inhibit development. For example, research in Sydney found that even where small-scale cohousing designs for two or three homes complied with planning controls in terms of size and density, legislation prohibiting multiple occupancies was a barrier to their development (Bay and Lehmann 2017). This also suggests that where development control policies and other aspects of regulation are not designed with specific diverse housing types in mind, there may be incongruencies in planning and building regulation that have not been identified or worked through, resulting in unforeseen regulatory barriers.

\section{Development application processes}

The requirement to get approval to undertake development, typically from a local government authority, can impact financial viability through timing - via holding costs and finance costs - and uncertainty regarding whether a project will be permitted. While developers will estimate the time required to get development approval in their viability modelling, time frames can vary significantly in practice (Crosby, McAllister et al. 2013). Research in the US has found that the time required to obtain development approval is a more significant factor for housing suppliers than the overall costs of fees and charges, with the latter having the benefit of being predictable and able to be costed in a financial viability assessment (Mayer and Somerville 2000). Extended planning processes can push developments into the wrong part of the market cycle, affecting revenues. However, the reverse is also true, with some developers benefiting from delay in a rising market. There is also no guarantee that developers will proceed to deliver housing projects once approval is granted (Adams, Leishman and Moore 2009).

The timing and outcome of development approval can relate to a range of factors, including whether a project strictly complies with planning rules and objectives. Particularly where assessment authorities must exercise discretion over whether or not to approve development, research suggests that community and local political attitudes towards new development can influence rates of approval (Bramley and Watkins 2014). Strong community opposition may also present a risk that development will not be able to proceed as planned, or that requirements for design modifications following assessment will increase development costs (Rowley and Phibbs 2012). These risks can be particularly significant for non-speculative housing projects and those delivering lower cost housing due to lower development margins. In case studies of nine deliberative development projects in Melbourne, Sharam (2020) finds that building delays as a result of awaiting planning application decisions and the need to appeal was financially detrimental for some projects, either resulting in termination of the project or leaving participants with large debts (Sharam 2020). 
Beyond planning

Research also shows that there are a range of factors beyond the planning system that impact the viability of housing development (Rowley, Ong et al. 2017). For housing provided by the private development sector, a key factor is economic conditions that affect consumer demand-and therefore the price consumers will pay for a product (Rowley and James 2017). From an investor perspective, demand will also determine the level of rent and therefore the level of rental return. On the supply side, competing local developments can suppress prices in times of low demand and the level of local, established stock can also reduce demand for new-build products if such stock offers cheaper alternatives to new-build.

On the cost side, the price of materials and cost of labour can render a development unprofitable and so can the cost of the land-particularly if landowner expectations do not match reality. For example, qualitative research with residential developers in New Zealand has found that the main barriers to the industry delivering smaller, more affordable homes include:

- the high cost of land

- limited supply of sites

- the high cost of construction (Tucker and Ryland 2014).

The cost and availability of finance is also crucial. While developers obtain finance in different ways, small to medium sized developers require project-specific finance-which means that they rely heavily on lenders such as banks, which weigh up the risk of the development (Rowley, Costello et al. 2014). If lenders have no appetite for residential development-or a particular type of residential development-then finance is either unavailable or lending conditions will be unacceptable to the developer. Infrastructure costs are a critical component of total costs and the requirements of utility companies and local governments can render a project economically unviable (Rowley and Phibbs 2012). Government regulations and taxes also add to costs and can be the difference between an acceptable profit and no development. In the New Zealand research discussed earlier, dwelling-based development contribution charges were also found to be a factor in the different viability of projects constituting smaller versus larger homes (Tucker and Ryland 2014).

Specific challenges for affordable housing

Affordable housing can be defined as housing provided subject to access and affordability requirements set by government. This includes:

- rental housing priced at below-market rents and earmarked for eligible low-to moderate-income households

- owner-occupied housing for eligible low to moderate income households that is provided under a subsidised loan or shared equity arrangement, or is legally encumbered with covenants that impose an affordability requirement (Rowley, James et al. 2017).

Affordable housing differs to housing that can be offered at a lower pricepoint than other housing in a location due to its design, size or amenity (Gurran, Gilbert, Gibb et al. 2018). Affordable housing provision requires a form of subsidy. This subsidy can come through:

- direct government provision of public housing

- funding of provision through the community housing sector

- tax incentives to deliver subsidised rental housing, such as those under the former National Rental Affordability Scheme (NRAS)

- through low-deposit loans, which require a government to take on an element of risk. 
Such provision is costly, so governments are increasingly looking to partner with the private sector to share some of the cost of provision (Rowley, James et al. 2017). The community housing sector is a key player in affordable housing delivery. In Australia, funding from the National Housing Finance and Investment Corporation (NHFIC) is designed to lower the costs of finance and support delivery.

Delivery of affordable housing at below-market levels (for sale or rent) by the private sector, particularly in the absence of subsidies, reduces development revenues and therefore the economic viability of a project. However, the negative impact on revenue can potentially be offset by:

- allowing the developer to replace the lost revenue through density bonuses

- intervening at a cost level_for example, subsidising the cost of the land or fast tracking development approvals.

These offsets may be possible on government-owned land but are more problematic when it comes to privately owned sites, while the value of density bonuses is dependent on housing market conditions.

\subsubsection{Role of government in supporting change and innovation in housing supply}

While new housing models that demonstrate alternative housing sizes and designs, tenures, financing and development arrangements, and potential for increased affordability seem to offer an opportunity to diversify housing supply in Australian cities, many models remain aspirational or have only been demonstrated on a small scale. As Raynor points out, specific housing projects may be able to demonstrate innovation in the housing system by overcoming project-specific obstacles and bringing together different resources. But institutional change is typically needed for scaling of these innovations (Raynor 2019).

Research suggests that governments can address a number of issues that often prohibit the generation and scaling of housing innovation, including

- lack of resources

- regulatory barriers

- lack of partnerships across sectors

- lack of 'safe spaces' for testing new models.

In the Australian context, research by Rowley, James et al. (2017) has shown the importance of federal-level programs such as the NRAS and the Nation Building Social Housing Initiative in supporting the growth of the affordable housing industry and seeding new partnerships and housing models in Australia. These large-scale and relatively consistent funding streams played an important role in addressing the 'funding gap' between the rents or purchase prices payable by lower income households and the cost of building and maintaining housing (Randolph, Troy et al. 2018). This is particularly relevant in an industry typified by small, ad hoc funding sources and resource-scarcity that often substantially reduces momentum in the scaling of innovation (Raynor 2019). In the US, the long-running Low Income Housing Tax Credit program, funded by the federal government, has resulted in the development of almost 3 million affordable homes, and has supported the establishment of cross-sectoral partnerships (Scally, Gold and DuBois 2018). 
While research suggests that long-term consistent funding is most effective in supporting affordable housing innovation (Rowley, James et al. 2017), governments can also provide once-off support for specific projects. This support may take the form of financial support or land contributions. Recent examples in Australia (Raynor 2019), Canada and the US (Whitzman 2018) have shown the value of governments either leasing or selling their land or airspace to organisations delivering diverse housing products aimed at vulnerable members of the community. Not-for-profit housing associations often layer land contributions with other funding streams to deliver affordable housing projects. Similarly, the redevelopment of large government-owned land parcels often involves the subsidised lease or sale of land to private or not-for-profit sector actors in return for affordable housing inclusion (Milligan, Gurran et al. 2009).

Governmental regulation is also an important factor in supporting housing diversity, either by mandating certain design outcomes or providing incentives for voluntary contributions. Local governments may waive specific planning requirements to encourage housing diversity or address exclusionary zoning standards that constrain housing innovation (see earlier discussion in this chapter). For example, higher-density developments such as those in the Nightingale Village in Melbourne have been partially made possible by construction cost savings realised by the waiving of car parking requirements.

Governments can also support housing innovation through knowledge sharing, design competitions or the creation of 'protective spaces'-often referred to as a 'niche' (Smith and Raven 2012). For example, Housing Expositions have been used extensively internationally-especially in Europe-to provide a platform for stimulating housing innovation (Newton, Gilzean et al. 2015). Development WA's Innovation by Demonstration program, run by Western Australia's central development agency, has provided a stimulus for multiple, innovative and sustainable housing projects across the state (Development WA 2020a). As housing innovation inevitably involves the testing of new business models and heightened levels of market risk, governments can also support housing variety by demonstrating viability on their own sites or addressing planning risk on significant projects (van den Nouwelant, Davison et al. 2015). Research by Rowley, James et al. (2017) on government-led innovations in affordable housing supply found that demonstration projects were important in showing the private sector what can work, and creating new models of delivery, such as micro-lots (Rowley, James et al. 2017). Government partnerships with private developers and Community Housing Providers (CHPs) play an important role in supporting innovation and Rowley, James et al. found that the private sector was prepared to work with government to deliver affordable housing if the policy settings were right.

\subsection{Research methods}

\subsubsection{Research aims and questions}

This research examines the opportunities and regulatory barriers and other challenges in Australian cities for delivering diverse housing supply. The aim of the research is not to capture detailed information on the regulatory constraints impacting specific housing models, but rather to examine how broader, institutional factors may prohibit or disincentivise supply diversity. This includes barriers to the implementation and scaling up of diverse types and tenures of housing and development models that have attracted industry and policymaker interest in recent years.

Participants in the study emphasised that housing diversity embraces a wide range of factors including dwelling size and design; tenure and governance arrangements; development model and price. In this project we define 'diverse' housing supply to mean a variety of dwelling sizes, designs and tenures delivered through different development models and available at different pricepoints, reflecting the continuum of community needs. By identifying and understanding institutional and systemic barriers, the research also aimed to identify how governments, in their leadership and regulatory roles, can better enable diverse housing supply in Australian cities. 
The research addresses four key questions:

1. How does urban regulation enable or constrain diverse housing types and tenures?

2. What other factors, such as taxation or financial arrangements, and market conditions, enable or constrain the supply of diverse housing?

3. What models for alternative types and tenures of housing are being developed by industry and what are the opportunities and barriers to delivery at scale?

4. How might regulatory and other barriers be overcome so that urban regulation and other policy settings can support and enable diverse housing supply?

\subsubsection{The Investigative Panels}

The main research method for this project was Investigative Panels that involved 46 practitioners, policy makers and researchers with diverse expertise across housing development and planning in Australia. Six Investigative Panel meetings were held in Sydney, Melbourne and Perth between 21 November and 2 December 2019. The three cities were selected for analysis in order to explore opportunities and challenges for delivering diverse types and tenures of housing and development models in:

- different housing market and planning system contexts

- cities with different densities of existing housing stock and patterns of new supply.

(See Appendix 2 for a comparison of the housing market and housing stock in Sydney, Melbourne and Perth.)

The panel meetings brought together members of the academic research team with practitioners, policy makers and researchers who were invited to take part in the panels because of their expertise in housing, residential development, finance and planning, as well as their experience with diverse housing models. Two 3-hour panel meetings were run consecutively in each city, with each meeting consisting of between eight and 13 panellists. The morning panel meetings captured the perspectives of housing, development and finance professionals and researchers with expertise in diverse housing types and development models-especially experience designing, financing and implementing diverse housing projects. The afternoon panel meetings focussed predominantly on the perspectives of planners, urban policy makers and financial regulators. Housing economist Professor Ken Gibb (University of Glasgow) took part in the Sydney panel meetings and shared examples of recent initiatives to support the implementation and scaling of new housing tenures in the UK, with a particular focus on Scotland where there has been significant innovation.

The morning and afternoon panel discussions were guided by the same set of questions (see Appendix 3 ). However, panellists in the morning session were asked about the characteristics of housing projects they had been involved in and what most significantly impacted project viability, while panellists in the afternoon session were asked for examples of planning reforms, policies, incentives, demonstration projects or programs that government or related organisations had implemented to support diverse housing in their jurisdictions. This approach of running two shorter panel meetings enabled more built-environment and housing industry experts to contribute to the panel deliberations, while keeping the time commitment short and allowing for smaller groups and detailed discussion around particular areas of expertise and experience.

The format of the panels and the main questions for discussion were consistent across the three cities. To support consistency across the six meetings, each panel was facilitated by Professor Chris Leishman with the support of at least one additional member of the research team with professional familiarity with the city and its planning system context. Background research on the planning system in each jurisdiction and on planning policies and other programs to support diverse housing supply also helped to inform the research team. 
The Investigative Panel deliberations were guided by the following terms of reference:

1. The development of a concept of 'diverse' housing and its relationship to housing affordability and affordable housing.

2. The identification of gaps in Australia's current housing stock and new supply and the role different types and tenures of housing, offered at different pricepoints, could play in addressing these gaps.

3. The identification of emerging industry models for diverse housing and potential opportunities and barriers for their scaling in Australia.

4. The identification of current regulatory settings that inhibit the supply of diverse housing in different locations and housing market contexts.

5. The identification of barriers within industry — for instance, within the construction sector-which may inhibit innovation and diversity in new residential development.

6. The identification of existing and emerging policies, regulatory settings or financial incentives that support diverse housing supply in different contexts, the structure of those regulatory settings and financial incentives and potential opportunities and barriers for their scaling.

7. Potential for regulatory reforms and incentives at all government levels to support diverse housing supply.

These terms of reference were translated into a series of questions to prompt and guide discussion (see Appendix 3).

The project did not aim to capture all the details of specific diverse housing projects or the breadth of legal, financial, planning or other challenges specific projects or development models face. Rather, the aim was to identify high-level institutional factors that impact the supply of diverse housing and to recommend regulatory changes and government strategies that could better enable diverse housing supply across a range of housing types and development models.

While the panel deliberations focussed specifically on experiences in three Australian cities, the findings regarding the main barriers to diversity in housing sizes and designs, tenures and delivery models - and potential government strategies to support more diverse housing supply-have potential relevance for jurisdictions with comparable planning and housing systems, and contribute to the wider international literature on these themes.

The Investigative Panel proceedings were audio-recorded and the audiofiles were transcribed. For each panel meeting, analysis of the transcripts involved coding key ideas and passage of text against the series of questions outlined in the discussion paper. Responses to each question were then further analysed and grouped thematically to identify key ideas and themes in responses. Findings were then compared across the six panel meetings to identify commonalities and differences across the three cities and between professionals with different areas of expertise and experience. Examples of developments, programs and other government initiatives that were identified by panellists in the course of the proceedings as positive or successful examples of enabling diverse housing supply were noted-these projects and initiatives have been highlighted in text boxes in Chapter 5.

\section{Additional interviews}

Four additional interviews were arranged to capture the perspectives of experts who wished to contribute to the project but were unable to attend the panel meeting. In addition to these, short interviews were also conducted following the panel meetings to follow up with individuals about specific issues or examples that were raised in the course of the panel proceedings but were not discussed in depth. Interviews were recorded where consent was obtained to do so. For shorter telephone interviews, the researchers relied on note-taking. Interview recordings and researcher notes were analysed in the same ways as the Investigative Panel transcripts. 


\subsubsection{Other data collection and analysis}

In addition to the research evidence review, the research team examined select international practice in enabling new housing tenures and development models, as well as current policy settings and programs to support diverse housing supply in the three Australian cities that were the focus of the study. Specifically, this component of the research examined:

1. Recent policies, programs and regulatory reforms that have been enacted in parts of the UK and Canada to support alternative housing tenures and development models in the context of overarching concerns about housing affordability.

2. Key planning policies and other programs currently in place in Sydney, Melbourne and Perth that are designed to support more diverse housing supply_particularly forms of more affordable housing. This research provided important contextual and comparative information for the Investigative Panels.

3. Review of select international practice.

The review of international practice focussed on select jurisdictions in the UK and Canada that face significant housing affordability challenges, and where alternative housing tenures and development models are being enabled through regulatory reforms and government programs. The review was limited to England and Scotland in the UK, where national governments have responsibility for planning policy and housing programs, and the City of Vancouver in Canada which, under a special charter, has considerable autonomy in setting land-use policy. These jurisdictions were selected because of the parallels that could be drawn with Australian cities, as well as the high level of digitisation of policy and program documents. In researching these jurisdictions, the research team was also able to draw upon existing personal and professional knowledge.

Information on the design and operation of specific policies, reforms and programs to support specific diverse housing models was initially derived from a desk-based review of the content of key policy documents and government-issued explanatory material or program guidelines. Evidence of the outcomes of key policies and programs was derived from reviewing government monitoring reports, program evaluation reports and other secondary sources discussing outcomes. The findings of the desk-based review were supplemented with a small number of interviews (seven) that gathered additional information, where required.

Review of policies and programs to support diverse housing supply in Sydney, Melbourne and Perth

Applicable policies, initiatives and programs to support diverse housing supply in Sydney, Melbourne and Perth were initially identified through a web search, drawing on team members' knowledge of the planning and housing systems in their jurisdictions. Applicable legislation, policy documents and government-issued guidance material was reviewed to understand the design and aims of specific policies and programs. Where available, we reviewed evidence of program or policy outcomes. 


\section{Recent regulatory reforms and programs to support diverse housing models in Canada and the UK}

- In jurisdictions in Canada and the UK-which have comparable housing systems to Australia-changing housing needs, including declining purchase affordability for moderate-income households and limited government funding to support new affordable housing supply, have fostered industry and policymaker interest in new housing tenures and development models, including purpose-built rental, new affordable rental tenures and community-led housing models that can offer long-term affordability.

- Planning-based incentives, such as density bonuses and reforms to some development requirements, have been used in Vancouver to support the viability of purpose-built rental housing in particular, as well as cohousing and community land trust models.

- In the UK, governments have used special loans, tax incentives and income guarantees to support the development and scaling up of a purpose-built rental sector.

- In England, a special fund has been developed by government to support the scaling up of the community-led housing sector and the viability of community-led housing projects that would not otherwise be able to proceed.

- These interventions are supporting diversification in housing supply, particularly housing supply that is affordable to moderate-income groups.

- Deeper forms of subsidy such as grants and input of land are still required to deliver housing that meets the needs of lower income groups. 


\subsection{Background}

Interest in alternative housing models has arisen in both public and private sectors internationally, as it has in Australia. Development industry groups have recognised changing market conditions, while policy makers have sought to address increasingly complex housing needs - typically in the context of limited financial resources. The international experiences that are emerging in these contexts offer insight into how regulatory reforms and other strategies can support the emergence of new tenure and development models that address perceived gaps in housing supply.

In this section, we review recent experience in select parts of Canada and the UK. These cases provide an opportunity to examine how governments have used regulatory reforms and developed other incentives to support industry innovation and increase housing diversity. The purpose is to broadly explore how regulatory reforms and other government strategies can support the emergence and scaling up of housing types and development models that face financial viability constraints, but are desirable to urban policy makers because they address a gap in the housing market. We focus specifically on the City of Vancouver in Canada, and on Scotland and England in the UK. In discussing these cases, we draw on the findings of a desk-based review of strategies, programs, policies and their outcomes. We also draw on interviews with seven UK developers and built-environment practitioners who were able to provide additional information on policies and incentives to support the development of a purpose-built rental housing sector and its outcomes. Insights are also drawn from our Scotland-based international panellist.

In the jurisdictions examined, the private sector is the main supplier of new housing, but there is also a history of using the planning system to support the delivery of affordable housing for low-income and moderate-income groups. In Canada, the vast majority of new housing is delivered by private developers for sale in the market (Chisholm and Hulchanski 2019). As in Australia, this housing has typically been in the form of single, detached houses on the urban fringe, and high-rise apartments, delivered in city centres and around transport and service nodes, both of which are offered for sale. While significant volumes of purpose-built rental housing (both affordable and market-rate) were constructed in Canada in the post-war period, the sector declined from the 1980s and was overtaken by private condominium build-to-sell development following the withdrawal of federal tax incentives and programs to support the sector (CitySpaces Consulting 2019).

The City of Vancouver is the country's third largest city, but has the most expensive housing market, with price growth having been fuelled by foreign and domestic immigration and strong investment demand (Ley 2015, 2020; Saunders 2018). Vancouver has a long history of using inclusionary zoning and other inclusionary housing mechanisms to deliver affordable housing as part of urban renewal processes.

However, in the context of widening affordability problems that are now impacting moderate income households, and limited federal funding for new social housing development, the city is using planning-based incentives to support the re-emergence of a purpose-built rental sector providing market-rate and below-market-rate housing, and to incentivise housing development through community-led models that can offer improved long-term affordability. Other strategies have included regulatory reforms to allow temporary housing on vacant sites and the use of government land for affordable housing projects. While the latter strategies have not been able to address the full scale of housing need among low-income and moderate-income households, comparative research shows that, over the past decade, Vancouver has produced significantly more social and affordable housing than Melbourne, despite facing similar fiscal constraints and high urban land costs (Whitzman 2018). 
The majority of new housing supply In UK cities is also built for sale by the private housing industry. However, significant new housing developments typically include a diversity of housing types and tenures. Over several decades, private developers have been required to include a proportion of affordable housing in their developments, which is managed by an affordable housing provider and provided as social housing, shared ownership or other affordable rental tenures (Crook, Henneberry and Whitehead 2016). That housing policy (S106 in England and S75 in Scotland) has supported significant tenure diversity, particularly when compared to significant new developments in Australia. However, in the wake of the global financial crisis (GFC), with new barriers to home purchase-particularly for first-time buyers-and limited scope to expand social housing supply, governments have introduced a range of incentives to support the development of a purpose-built rental housing sector and to scale up other forms of non-speculative, community-led housing development which, until now, have only been a very small part of the housing system.

\subsection{Planning policies to support alternative housing tenures in Vancouver, Canada}

The City of Vancouver's 10-year housing strategy, adopted in 2018, aims to increase housing diversity in terms of tenure, dwelling size, built form and location and affordability to different income groups in the context of acute housing affordability pressures. The strategy includes a target to deliver:

- 12,000 social, support and non-profit cooperative housing units

- 20,000 purpose-built rental homes

- 10,000 townhouses or row houses

- 4,000 laneway houses (accessory dwellings accessed via laneways) (City of Vancouver 2018).

Regulatory reform is a key component of implementing the strategy. Actions under the strategy include:

- reviewing and simplifying regulation

- reconciling and aligning objectives with statutory policies and regulations

- allowing more development outright through as-of-right development rights.

The city is also identifying opportunities to expedite development approval processes in cases where there is an opportunity to provide temporary affordable housing on sites awaiting redevelopment, as well as faster permitting for prefab housing models and affordable housing developments (City of Vancouver 2018). These strategies build on a decade of policy learning regarding the use of the planning system to support diverse forms of market-rate and below-market-rate housing. As is discussed later, purpose-built rental housing is one model that the City has sought to revive and scale up through regulatory reforms and planning-based incentives that support project viability.

\subsubsection{Purpose-built rental housing}

Over the past decade, the City of Vancouver has used planning bonuses and concessions to enable and incentivise purpose-built rental housing (also referred to as 'secure rental housing'). In contrast to the majority of the city's new rental housing, which is provided by small-scale investors - and typically consists of apartments in condominiums built for sale-units in purpose-built rental buildings must remain as rental housing for 60 years, or for the life of the building. While the taxation and legal settings that favour building for sale remain unchanged, the city's planning-based incentives aim to support the financial viability of rental housing in a context where condominium projects typically outcompete rental housing projects for sites, finance and other development resources (City of Vancouver 2016: 4). 
A Short Term Incentives for Rental (STIR) Program was first approved by the City in 2009 to offered a range of incentives to support the creation of market-rate purpose-built rental housing. The program sought to 'test the city's ability to enable market rental housing without senior government assistance' (City of Vancouver 2012a: 2). Incentives included:

- waiving of development fees

- relaxation of parking requirements and minimum unit size standards

- density bonuses and faster development application processes for projects requiring rezoning.

A formal review of STIR by city staff found that STIR incentives had significantly increased rates of development of market-rate purpose-built rental housing from pre-program levels. Between 2009 and mid 2012, 1,648 new units had been created or were in application. Although affordability to target income groups was not a program requirement, the review found that apartments delivered under the STIR program were generally affordable to moderate-income households, and were significantly more affordable than comparable apartments for sale. For example, the cost to rent a two-bedroom apartment delivered under the STIR program was approximately 70 per cent lower than the cost of owning a two-bedroom unit in the same area (City of Vancouver 2012a). However, the program overall resulted in very few family-sized units, with over 85 per cent being studio or one-bedroom apartments (City of Vancouver 2012a).

A permanent policy to incentivise purpose-built rental housing was developed on the basis of learnings from the STIR program. It applies to residential or mixed-use developments where 100 per cent of the residential floor area is rental housing - that is, not strata titled. For projects that do not require rezoning - that is, they are permitted under a site's existing zoning-incentives include:

- parking reductions

- waiving of the development cost levy (DCL) for the residential floor space

- relaxation of the minimum unit size requirement to a minimum of 320 square feet (30 square metres) provided units comply with the liveability criteria specified in zoning and development by-laws.

The policy also applies to projects that require rezoning. In addition to the incentives outlined above, projects that require rezoning are eligible for:

- additional floor area-that is, a density bonus

- concurrent processing of the rezoning and development permitting applications to reduce the overall assessment time frame (City of Vancouver 2019b).

As outlined in the policy, proposals requiring rezoning will only be considered in areas with access to transport and employment (including commercial and light industrial zones) and in areas zoned for multi-unit development that do not currently include rental housing (City of Vancouver 2012; updated 2019). Applications are initially assessed by an interdepartmental group within the city council, consisting of staff from planning, development services, real estate, housing and engineering. A review of the program showed that by mid-2019, the incentives had resulted in about 540 new secure rental dwellings per annum. It found that while rental housing projects still face financial viability challenges due to competing land uses-particularly from build-to-sell projects-most rental projects would not have been able to proceed in the absence of incentives (City of Vancouver 2019e). 
Limiting rents and supporting family-sized units

Initially, market-rate rental units delivered under the policy were not subject to any rent controls beyond limitations on rental increases in tenancy law. Rather, it was assumed that units would offer greater affordability in the market owing to their tenure, location, small size, simplicity of design and limited on-site amenities, and that affordability over time would be secured 'as the buildings age' (City of Vancouver 2012b: 2). However, from 2013 - in a bid to improve affordability to moderate income households - maximum unit sizes and starting rental rates have been defined in the by-laws that prescribe conditions for DCL-waiving and in the Rental Incentives Guidelines (City of Vancouver 2015; 2012, updated 2019). Specifically, rental rates for units in proposed projects must now be equivalent to or below the average rents for units in newer rental buildings in the city, as published by the Canada Mortgage and Housing Corporation.

In July 2016, the council adopted the Family Room: Housing Mix Policy to increase the proportion of larger purpose-built rental housing units. This policy applies to secure market rental housing projects that require a rezoning. It requires a minimum of 35 per cent of units to be family housing-that is, with two or more bedrooms. The policy allows for some flexibility to account for project viability. The director of planning is enabled under the policy to relax the 35 per cent requirement where literal enforcement of the rule would deter development (City of Vancouver 2016).

\subsubsection{Below-market-rate housing and innovative models to support long-term affordability for moderate income groups}

A planning-based incentive in the form of a density bonus under the city's Affordable Housing Choices Interim Rezoning Policy aims to encourage alternative tenures of housing, and the scaling up of innovative development models that can deliver affordable housing for moderate income groups. It sits within the framework of the Housing and Homelessness Strategy and came out of the 2011-12 Mayor's Taskforce on Housing Affordability. Implemented in 2012, the policy allows for a density bonus for projects situated in transitional areas between major roads and low-density residential areas that meet one of the following criteria:

- All residential floor space is rental housing, and the tenure is secured for a term of 60 years or the life of the building through a legal agreement.

- Units are sold at a minimum of 20 per cent below-market value and include a mechanism to maintain that affordability overtime - such as a resale covenant or second mortgage.

- Use of an innovative housing model or tenure form, and can demonstrate greater affordability relative to conventional developments-such as cohousing.

- Uses a community land trust model to secure affordability over time (CitySpaces Consulting 2019: 28; City of Vancouver 2019a).

Proposals are considered in designated (mapped) areas of the city that have access to public transport and services (City of Vancouver 2019a). A 2019 review of the program showed that over 400 units had been delivered under the program, but that these have predominantly been market-rate rental housing, with affordable housing proving more difficult to deliver under the program (City of Vancouver 2019e).

In 2017, a Moderate Income Rental Housing Pilot Program was also introduced in an effort to increase the supply of rental housing for households on moderate incomes - that is, earning \$CAN 30,000 to 80,000. The pilot, which was limited to 20 proposals, provides additional incentives for the construction of new rental housing projects where at least 20 per cent of the residential floor area is permanently secured as rental housing offered at specified below-market rates (City of Vancouver 2019d). The additional incentives, which are beyond those offered under other rental incentive programs, include:

- additional height and density

- relaxation of parking requirements 
- minimum unit size and unit configuration requirements

- potential permissibility of rental apartments in a wider range of zones (City of Vancouver 2019c).

- By mid-2019, 20 projects had been selected under the scheme and invited to submit rezoning proposals.

\subsubsection{Affordable housing for higher need groups}

The regulatory reforms and planning-based incentives discussed earlier in this chapter have played an important role in supporting revived and new housing tenures and new development models that can offer more affordable forms of market housing, as well as supply of below-market-rate housing for households on moderate incomes. However, it also suggests that greater subsidies than can be offered through planning reforms and incentives alone are required to deliver housing for groups with higher needs. The main way the City is supporting delivery of affordable housing for low-income households is through:

- direct funding_capital grants for development

- provision of public sector land

- partnerships with not-for-profit housing providers.

In 2014 the city government approved the creation of the Vancouver Affordable Housing Agency (VAHA), which is a legally independent agent of the city. It has a mandate to deliver 2,500 new affordable homes on city-owned sites by 2021, using funding from the public and private sectors and community partners, and through the use of innovative building techniques (City of Vancouver 2018; Vancouver Affordable Housing Agency 2020a). To date VAHA has completed over 500 new dwellings across 11 projects. Many of them are units in temporary modular housing developments that are prioritised for people who are homeless or at risk of homelessness (Vancouver Affordable Housing Agency 2020b). The city has also directly partnered with not-for-profit organisations. That has included the not-for-profit Vancouver Community Land Trust (created in 2014), which is delivering 358 new affordable homes for low and moderate income households on city-owned sites (City of Vancouver 2018).

\subsection{Policies and programs to support alternative housing tenures and new housing models in the UK}

Compared to Australia, the UK has a history of diverse housing supply. Diversity of dwelling sizes and built form are now the norm in new housing estates. Since the 1990s, there have also been requirements to include social housing and other types of affordable housing managed by not-for-profit housing providers in all new developments of a significant scale-typically defined as 10 or more dwellings, with even lower thresholds in some areas (Crook, Henneberry and Whitehead 2016). While this approach to requiring affordable housing in otherwise market-rate schemes exists across the UK, policy details vary by devolved administration and in London.

In this section, we discuss the diversity of housing tenures that are now supported through public subsidies, as well as planning requirements for developers of significant projects to contribute affordable housing as a condition of planning consent.

We also review recent government efforts to address gaps in the housing market by supporting the scaling up of a purpose-built rental housing sector and the supply of housing delivered through non-speculative community-led housing projects. We focus specifically on England and Scotland. 


\subsubsection{Diversifying housing tenures}

Over time, governments have introduced new 'intermediate' housing tenures that sit in between social rental and unassisted homeownership (Monk and Whitehead 2010). These intermediate tenures have enabled working households in high housing cost areas to access housing they can afford. Requiring less subsidy than traditional social housing, these intermediate tenures have also help to stretch public subsidy in high cost areas and the amount of affordable housing that can viably be delivered through developer contributions (Crook and Whitehead 2010).

The definition of affordable housing in England's National Planning Policy Framework now encapsulates a variety of tenures, including:

- social housing

- affordable rental housing with rents set at intermediate levels between social and market rates

- discounted market sale-offered at a 20 per cent discount on market value

- housing offered for sale through a shared ownership or equity loan scheme that increases affordability for eligible buyers (Ministry of Housing, Communities and Local Government 2019b).

In Scotland, government recently introduced a mid-market rental tenure, with rents set between private and social levels. Under the scheme, a $£ 40,000$ government subsidy per dwelling is paid to a developer on the proviso that the rent is set at an affordable level. This is pegged to the housing benefit ceiling for the property type. The evidence shows that these developments are now out-competing the mainstream private rental sector and offer better quality dwellings than available elsewhere.

In both England and Scotland, government equity loans and shared ownership programs have been developed to assist eligible buyers to purchase new and established homes. Since 2013, government in England has offered Help to Buy equity loans to eligible households to purchase new-build properties valued at up to $£ 600,000$, in a scheme that is not restricted to first homebuyers. The government lends up to 20 per cent -40 per cent in London-with no interest for the first five years, and households can purchase with as low as a 5 per cent deposit (Help to Buy 2020a).

To mid-2019, equity loans had assisted in over 336,000 purchases, over 80 per cent of which were by first homebuyers (Ministry of Housing, Communities and Local Government 2019a). A Help to Buy shared ownership scheme also exists, in which eligible households can purchase a 25 per cent to 75 per cent share in a property and pay rent on the remaining share. The scheme is limited to new-build properties or existing shared ownership homes being offered through housing association resale programs, but is not limited to first homebuyers (Help to Buy 2020b).

The current Scottish variant has been in place since 2013 (James, Berry and Marks 2019) and uses an equity loan model that allows homebuyers to buy with a 5 per cent down payment, and the government then has a 15 per cent equity stake in the property. The scheme is limited to newly constructed dwellings, but applies to first or second time buyers, and there is a $£ 200,000$ price limit. By 2019, the scheme had supported about 12,800 purchases (James, Berry and Marks 2019). Another shared equity scheme in Scotland, which has been running since 2016, supports eligible purchasers to buy homes priced at or below defined, location-based thresholds on the open market (Scottish Government 2020). The scheme is open to first homebuyers and other priority groups, including people aged over 60, social housing tenants and disabled people.

\subsubsection{Purpose-built rental housing}

The Build to Rent (BTR) model is a relatively recent innovation in housing supply in the UK, and has generated significant interest in policy circles as well as in industry. The 2008 GFC played an important formative role in BTR, as it limited the scope for volume housing developers to sell off-plan to small-scale private investors. 
This resulted in a crisis in terms of sales rates and an overhang of finished units on one hand, and a desire by housing developers to seek alternative solutions involving on-sales to housing associations - the equivalent of the community housing sector-or arms-length companies directly engaged in private letting.

This crisis in sales was accompanied by growth in private renting, especially among younger households unable to purchase. Particularly in England, government interest in encouraging BTR in the wake of the GFC was about:

- addressing the housing needs of the growing cohort of long-term renters

- supporting overall housing supply (and construction industry jobs) in the context of weaker housing market conditions (Department for Communities and Local Government 2012).

More recently, BTR has been encouraged in other housing market areas, including in Scottish cities, where Scottish government has sought to actively encourage it as a means to improve the standards and quality of rental housing and to support labour market mobility (Scottish Government 2017).

The emergence of the BTR sector has been facilitated by supportive government policy. This has varied in form between UK regions. In UK regions except for Scotland, the Urban Land Institute (ULI; 2016) explains that the model underwent 'a period of extraordinary Government support'. After initially reforming the stamp duty charges on bulk purchases in an effort to support BTR, English Government undertook a review of barriers to institutional investment in private rental homes in 2012 (Department for Communities and Local Government 2012). The review found that BTR development had difficulty competing for land against build-to-sell projects, and that the viability of BTR was challenged by the modes of calculating development contributions used for build-to-sell projects. Among the recommendations were for:

- governments to support access to land for BTR projects

- local planning authorities to use the flexibility embedded in the planning system to support BTR proposals, particularly by exercising flexibility regarding developer contributions (Department for Communities and Local Government 2012).

Also in 2012, the government introduced a $£ 200$ million Built to Rent fund to support BTR projects in England. (In 2013, the fund was expanded £1 billion.)

The BTR fund, which has now been incorporated into the Home Building Fund, provided government loansfinanced on a commercial basis - of up to 50 per cent of eligible development costs, with government realising its return upon refinancing or sale of the project to an institutional investor (Homes and Communities Agency 2015). Long-term finance of up to 30 years is available to BTR operators through a government-guaranteed bond program under the Private Rented Sector (PRS) Guarantee Scheme (Future of London 2017; Ministry of Housing, Communities and Local Government 2018b).

Specific planning supports for BTR were also developed for London, where early interest in BTR was concentrated. The 2013 Mayor's Housing Covenant-'Making the private rental sector work for Londoners'-committed the mayor to using his planning powers to recognise the unique viability challenges of BTR in assessing development applications and to make clear that private rental housing development is welcome on land in Greater London Authority ownership (Future of London 2017).

The current London Plan requires that the planning system provide practical support for the private rental sector in addressing housing needs and increasing housing supply (Policy 3.8; Mayor of London 2016). The Mayor's Affordable Housing and Viability Supplementary Planning Guidance (2017):

- provides a definition of BTR

- clarifies the form affordable housing contributions can take in BTR schemes

- specifies that assessment authorities should allow for flexibility in unit size mixes and apply a different approach to assessing viability for BTR projects (Mayor of London 2017). 
Definitions of BTR are now also included in England's National Planning Policy Framework and government has issued planning practice guidance stating that planning authorities should include private rental in their housing needs assessment and, if applicable, policies to allow and support BTR (Ministry of Housing, Communities and Local Government 2018a; Ministry of Housing, Communities and Local Government 2019b).

In Scotland, the Scottish Government has issued Planning Delivery Advice which builds on Scottish Planning Policy. It provides a definition of BTR and encourages local planning authorities to take a flexible approach to assessing BTR projects. From 2016, Scottish policy also gives a tax advantage in the form of:

- a higher Land and Buildings Transaction Tax threshold

- relief for transactions involving six or more residential dwellings purchased in a single transaction.

In addition, a Rental Income Guarantee Scheme (RIGS) is available to boost investor confidence in BTR. However, to date the government has not had to pay out on this guarantee. The sector's growth and diversification is also encouraged through a $£ 30$ million loan fund to support the construction of family homes in the BTR sector (James, Berry and Marks 2019).

Despite its recent development, The British Property Federation (2020) reports that there are 40,181 completed BTR units in the UK, and over 109,000 under construction or in the planning phase. Around 50 per cent of BTR units are in London. Savills record that 479 BTR units have been built in Scotland to mid-May 2019, with a further 6,300 in the planning phases (Savills 2019). There is evidence that BTR developments offer some advantages in terms of development viability compared to traditional developments involving building for sale to owneroccupiers and small-scale private investors. For example, ULI (2016) note that absorption rates on BTR projects are faster than owner-occupied equivalents, which improves viability. While offering higher quality and more secure options within the private rental sector, particularly for young (25-to-34 year olds) working households-who are comfortable with the concept of renting longer term-BTR properties can be more expensive than other options within the private rental sector. Future of London (2017) has reported that BTR developments see rents typically up to and over the local upper quartile, making the products distinct from the mainstream private rented sector.

\subsubsection{Community-led housing development}

In 2018, English Government announced that $£ 163$ million would be made available through the Community Housing Fund to support community-led development across England. Community-led housing is broadly defined under the scheme, but specifically includes:

- community land trusts

- cohousing

- cooperative housing models.

The fund aims to support the overall supply of homes across England that are delivered through community-led housing models, as well as to build up the community-led housing sector (UK Government 2020). As outlined in the prospectus of Homes England, which manages the fund outside of London, this includes developing 'an effective and financially self-sustaining body of expertise within the house building industry in England' (Homes England 2018: 5). The scheme is open to:

- existing community-led housing organisations

- organisations looking to expand their community-based activities into housing

- small-scale developers, landowners and local authorities who want to partner with a community organisation to deliver a community-led housing project. 
Phase One funding is intended to support organisations with capacity building and pre-development costs, such as:

- forming a corporate body

- viability studies

- professional fees and training

- infrastructure to support community housing development such as access roads, site remediation and utilities.

Phase One funding also includes grants to local governments to support community groups-for example, through dedicated staff.

Phase Two funding is intended to support applicants with costs for acquiring land and building community-led housing schemes (Homes England 2018). Phase Two funding is open to:

- registered charities

- community benefit societies

- companies limited by guarantee

- other social enterprise organisations

- local authorities

- not-for-profit housing providers.

At the time of writing, the overall impacts of the Community Housing Fund in terms of building up the community -led housing sector were not clear, as bids had only recently closed. However, one of our Panel participants believed it was having a significant positive impact on the sector and on prospective housing delivery.

\subsection{Summary and policy development implications}

The cases outlined here suggest that, over time, regulatory reforms to planning and taxation settings-along with broader financial support through access to finance or more direct subsidies-can support and incentivise the introduction and scaling up of forms of new housing supply that are desirable to policy makers in terms of addressing housing need, and are also of interest to industry, but which face regulatory and financial viability challenges.

In Vancouver, planning-based incentives and concessions have played a key role in supporting the re-emergence of a purpose-built rental sector providing market-rate and below-market-rate rental housing. These incentives include density bonuses for projects requiring rezoning and concessions on carparking and development contributions and fees, and flexibility on minimum dwelling sizes. They have been explicitly designed to improve the financial viability and appeal of rental housing development relative to condominium development of apartments for sale. Density bonuses are also being offered to incentivise housing that offers greater long-term affordability compared to conventional products, including through cohousing and community land trust models.

In UK jurisdictions, tax concessions, access to special loans, an income guarantee and flexibility in the planning system regarding dwelling mixes and sizes and development contributions have worked to boost the viability of an emerging BTR sector. In England, grant funding to eligible organisations is also supporting the scaling up of the community-led housing sector.

In addition to supportive planning, tax settings and financial incentives, naming and legally defining new housing models has been an important step by governments, along with setting targets or expectations regarding the supply of different housing types and tenures within strategic planning documents. 
Detailed monitoring of outcomes is also important, in order to learn whether and how trial programs or policies should be refined, or whether permanent policies should be adjusted as they mature. As Vancouver's rental housing incentive programs have matured, and affordability problems worsened, the city has modified requirements and introduced parallel programs that seek to deliver improved affordability from purpose-built rental developments. This has included setting rental limits for purpose-built rental housing developments that utilise planning concessions, as well as a new pilot that provides additional planning-based incentives for schemes that provide 20 per cent of units at below-market rents. This suggests that there is potential scope over time to refine incentives and demand greater affordability as the delivery of new housing models becomes established.

It is important to note that housing supply and affordability remain key policy concerns in the jurisdictions discussed. New housing models, particularly purpose-built rental housing rented at market or below-market rates, are helping to address new housing needs stemming from increased barriers to home ownership. However, significant subsidy is still required to deliver new housing that addresses the needs of households at the lower end of the income spectrum. In Vancouver, government leadership in new construction techniques, use of government land and government and industry partnerships are helping to stretch limited public funds to support the provision of housing for those in highest need. In UK jurisdictions, requirements for developers to include affordable housing in their schemes and public subsidy to support affordable housing supply-including through assisted home ownership programs - play a significant role in addressing the need for housing that requires deeper levels of subsidy. 


\section{Current planning policies and programs to support diverse housing supply in Sydney, Melbourne and Perth}

- Each of the three states has a different approach to urban governance, planning regulation and housing assistance.

- Overall, a strong focus has been on supporting diverse housing supply through regulatory reforms to enable and incentivise diverse sizes and designs of market housing, and to clarify their permissibility under planning rules.

- Other strategies include planning policies to incentivise or require the private sector to contribute affordable housing as part of new development (typically on a small scale); projects by state development agencies or on government land demonstrating tenure and or structural diversity; and programs to assist eligible buyers into homeownership.

- Although there has been some evaluation of key programs, governments have not instituted systematic frameworks for monitoring the outcomes of regulatory reforms designed to enable more diverse housing supply.

- Existing evidence from NSW suggests that planning strategies to support the permissibility of diverse types of market-rate housing have supported increased supply, but not necessarily affordability, and delivery of dedicated affordable and low-cost housing units through inclusionary planning mechanisms has been low. 


\subsection{Background}

Governments in Australia have not introduced specific incentives or programs to support the extent of tenure diversity discussed in Chapter 2 or alternative development models, specifically. However, diversifying housing supply has been a focus of state strategic planning efforts since the 1990s. The so called 'urban consolidation' agenda sought to reuse well located, former industrial 'brownfield' sites for higher-density housing, thus:

- containing the spread of urban development

- capitalising on established infrastructure

- providing market choice through smaller apartments (Yates 2001, McLoughlin 1991).

Over time, the policy has been embedded in state-led planning strategies for major city regions, moving from excess industrial sites through to infill and redevelopment projects within inner and middle-ring residential suburbs, and medium-density forms even in new greenfield areas.

To facilitate such projects, the states-which govern land-use planning policy-have exerted changes to land-use zoning regimes and, in some cases, directly engaged in the master planning and development of significant sites. While an overarching focus has been on increasing the diversity of dwelling types particularly through higherdensity developments, some planning policies and programs have focussed on increasing tenure diversity with an overarching aim to improve affordability.

This chapter reviews how governments with jurisdiction over Sydney, Melbourne and Perth have sought to diversify housing supply generally, as well as the design and outcomes of specific planning policies and government programs designed to enable and encourage specific alternative types and tenures of housing. This information contextualises findings arising from the Investigative Panels, which are discussed in Chapter 4. Overall, it shows that many initiatives have been very recent, the outcomes are not yet known, and that longer standing programs - with some exceptions - have not resulted in large numbers of diverse homes.

\subsection{Sydney}

The Sydney metropolitan region comprises 35 local governments, with metropolitan-level planning overseen by the state government. It is the most expensive metropolitan housing market in Australia (ABS 2019b). While the housing stock includes a comparatively high proportion of apartments (28\%; ABS 2019e), these smaller dwellings have not improved housing affordability pressures.

In NSW, the government has sought to encourage more diverse and affordable housing supply through state policy directives articulated in metropolitan and regional planning strategies, as well as via state-led changes to zoning rules. The latter have been implemented through State Environmental Planning Policies (SEPPs), which take precedence over local planning policy settings. Overall, these changes have sought to overcome local barriers to diverse housing development in local plans and decision processes, increasing certainty for private and non-profit developers. A state policy also enables local governments with a need for affordable housing to adopt inclusionary zoning schemes. These policies are summarised in Table 2. 
Table 2: State planning policies relevant to housing diversity in NSW

\begin{tabular}{|c|c|}
\hline State policy & Overview \\
\hline $\begin{array}{l}\text { State Environmental Planning Policy (Sydney Region } \\
\text { Growth Centres) } 2006\end{array}$ & $\begin{array}{l}\text { - Defines minimum housing densities for specific locations within } \\
\text { the greenfield growth areas. }\end{array}$ \\
\hline $\begin{array}{l}\text { State Environmental Planning Policy (Exempt and } \\
\text { Complying Development Code) } 2008\end{array}$ & $\begin{array}{l}\text { Establishes as-of-right development rights for secondary } \\
\text { dwellings and some low-rise medium-density housing types } \\
\text { that meet the development standards defined in the code } \\
\text { (and design guidelines, where applicable) }\end{array}$ \\
\hline \multirow[t]{2}{*}{$\begin{array}{l}\text { State Environmental Planning Policy (Affordable Rental } \\
\text { Housing) } 2009\end{array}$} & $\begin{array}{l}\text { Defines permissibility and development standards and limits } \\
\text { scope for development refusal for boarding houses, residential } \\
\text { apartment buildings including affordable rental housing and } \\
\text { secondary dwellings }\end{array}$ \\
\hline & Density bonus for affordable rental housing developments. \\
\hline $\begin{array}{l}\text { State Environmental Planning Policy 70-Affordable } \\
\text { Housing (Revised Schemes) } 2019\end{array}$ & $\begin{array}{l}\text { - Allows local governments to impose mandatory requirements } \\
\text { for affordable rental housing contributions where there is an } \\
\text { identified affordable housing need and a contribution scheme } \\
\text { is in place. }\end{array}$ \\
\hline $\begin{array}{l}\text { State Environmental Planning Policy (Housing for Seniors } \\
\text { or People with a Disability) } 2004\end{array}$ & $\begin{array}{l}\text { - Sets a consistent framework and permits variations in planning } \\
\text { standards for developments accommodating the aged and } \\
\text { persons with a disability. }\end{array}$ \\
\hline $\begin{array}{l}\text { State Environmental Planning Policy_Design Quality of } \\
\text { Residential Apartment Development }\end{array}$ & $\begin{array}{l}\text { - Provides a set of design requirements to deliver consistent } \\
\text { standards of amenity and quality in apartments, addressing } \\
\text { criteria such as solar access, privacy and access to open space. }\end{array}$ \\
\hline
\end{tabular}

Source: Authors.

\subsubsection{Support for diverse housing supply in metropolitan strategic planning}

Housing supply targets for the metropolitan region-translated to district (sub-regional) and local area levels -based on projected population and household growth have long been articulated in metropolitan strategy. These housing targets are to be implemented within existing planned development areas or by amending the local land-use plan. These targets have historically been neutral in terms of dwelling types (built form) and tenure, only specifying the proportion of targeted housing supply that should be delivered in existing urban versus greenfield areas.

Although it is yet to be fully operationalised, the current metropolitan strategy indicates that targets for affordable rental housing are to be delivered through rezoning processes, and the NSW Government has issued guidelines for local councils opting to prepare an affordable housing contribution scheme (NSW Department of Planning 2019a). Also, local councils are now required to prepare their own housing strategies, identifying how they will accommodate supply targets, and addressing housing affordability goals (NSW Planning and Environment 2018).

\subsubsection{Planning-based incentives for lower cost market and affordable rental housing}

The NSW Government has long sought to overcome inconsistencies and barriers in local planning frameworks, which might otherwise prevent lower cost market accommodation such as boarding houses. Traditional boarding houses offer lower cost rental accommodation in rooms with shared facilities, while newer purpose-built facilities offer self-contained studios within a larger rental complex. The state government has also sought to incentiviserather than require-infill medium and higher-density developments that include an affordable rental component. State intervention was thought necessary to overcome potential for local communities to unnecessarily oppose boarding houses and residential apartment buildings - particularly developments incorporating affordable rental housing. 
The Affordable Rental Housing State Environmental Planning Policy 2009 (ARHSEPP) implements these objectives. Applying statewide, and overruling local development controls, it makes boarding houses permissible in residential and mixed-use zones on sites accessible to public transport. However, recognising ongoing community concern about the policy, since 2011 boarding-house proposals have to demonstrate compatibility with local character, which is determined by councils on a qualitative basis (NSW Department of Planning and Environment 2014).

Following amendments in 2019, the scale of new developments is limited to 12 rooms on a single site. On sites where residential apartment buildings are allowed, the policy also provides for a density bonus for projects including affordable housing. The policy limits scope for development refusal by defining development standards, including:

- height regulations

- minimum lot size requirements

- requirements for open space, landscaping and solar access

- parking requirements (differentiated for private developers and affordable housing providers).

If these standards are met, they cannot be a basis for councils to refuse applications (NSW Department of Planning and Environment 2019).

\subsubsection{Medium density in greenfield and infill contexts}

The State Environmental Planning Policy (Sydney Region Growth Centres) 2006 establishes land-use rules for Sydney's state-designated greenfield growth areas. As well as defining zones, minimum lot size requirements and height limits, more detailed place-based 'precinct' plans define different minimum housing densities for different areas. This approach encourages a range of dwelling types, including:

- detached homes on small lots

- terraces / townhouses

- manor homes (low-rise apartment blocks of up to four dwellings)

- apartments and secondary dwellings (in association with new detached homes).

The minimum lot sizes defined in precinct plans differ by dwelling type based on the minimum density designation for the site. Detached homes with zero side setbacks - so that the homes appear like terraces but can be Torrens-titled and separately financed via a standard construction loan-are also enabled in the growth centres. This has allowed the lower cost traditional greenfield development model that separates land subdivision and dwelling construction to continue to operate while delivering higher densities of housing (The Treadstone Company Pty Ltd 2012).

Diverse forms of infill housing development have also been encouraged by providing greater certainty of development rights for select housing types. In 2009, state policy introduced as-of-right development rights for new secondary dwellings meeting defined development standards. Further, 2018 reforms to NSW planning legislation extended that model to a range of medium-density housing types, including dual occupancies, manor homes and multi-dwelling houses and terraced housing.

1 Defined as housing that is managed by a community housing provider (CHP) and is rented to eligible low and moderate income households at rents not exceeding $80 \%$ of market rent for a minimum of 10 years. Boarding houses are not subject to rental limits or tenant eligibility criteria. 
The 2018 reforms were intended to enable 'missing middle' development (NSW Department of Planning 2019b). Under the policy, low-rise medium-density housing can be approved via a qualified private certifier independent of the local council in residential zones, provided the applicable housing type is permissible under the local planning scheme. This allows for an expedited and more certain approval process where the standards in the code are met and the proposal complies with the design criteria (NSW Department of Planning and Environment 2018; Ryan and Selmon 2019).

As of late 2019, the policy was in effect in 82 local government areas (LGAs) (NSW Department of Planning 2019b). Commencement in other council areas was deferred at the request of councils that were concerned about impacts on local character. Following the recommendations of a formal review undertaken by Ryan and Selmon (2019), the implementation of the code was deferred until 1 July 2020 for the remaining 40+ LGAs so they could review their own residential development controls in preparation for the code.

\subsubsection{Inclusionary planning mechanisms}

There are two planning policies in NSW that allow local planning authorities to require or negotiate affordable housing contributions as part of new development. Councils are able to impose mandatory requirements for affordable rental housing contributions as part of new development under State Environmental Planning Policy 70-Affordable Housing (Revised Schemes) 2019. The policy initially applied to only three Sydney LGAs but was extended to the whole state in 2019. In order to introduce affordable housing contribution requirements when land is rezoned, councils must:

- identify affordable housing need in their area

- develop an affordable rental housing contribution scheme (based on evidence of a viable contribution rate)

- amend their local environmental plan (LEP) to reference the affordable rental housing contribution scheme (NSW Department of Planning 2019c; 2019a).

In practice, this is a time-consuming process that ultimately requires ministerial approval of a LEP amendment.

Since 2005, the Environmental Planning and Assessment Act 1979 (EPA Act) has enabled councils and developers to negotiate voluntary planning agreements (VPAs) which, among other things, can be for affordable housing. This option is open to all councils provided they have a policy that outlines the circumstances in which a planning agreement for affordable housing may be negotiated (NSW Department of Planning 2019a).

\subsubsection{Evidence of outcomes of policies to support diverse housing supply}

There is no formal reporting by the NSW Government on dwelling approvals or completions under the ARHSEPP or other SEPPs, which presents a challenge for investigating outcomes (Troy, van den Nouwelant and Randolph 2018; Gurran, Gilbert, Gibb et al. 2018). Recent research has found that there have been significantly more applications for boarding houses (not subject to rental limits) under the ARHSEPP than for infill affordable rental housing developments (Troy, et al. 2018; Gurran, Gilbert, Gibb et al. 2018).

Although development application data shows that boarding-house applications face high rates of refusal-up to 75 per cent_-in some LGAs (Gurran, Gilbert, Gibb et al. 2018), research by Troy, van den Nouwelant et al. (2018) found that approximately 9,000 boarding-house rooms were approved in central and southern Sydney to early 2017. Two-thirds of these were in the City of Sydney and the majority were targeted at students. Research suggests that they are generally not serving low-income households that experience barriers accessing mainstream rental housing, and that they are not very affordable, with occupants experiencing high rates of rental stress (Troy, van den Nouwelant and Randolph 2019). 
Secondary dwelling development has increased significantly since 2009. Troy, van den Nouwelant et al. (2019) estimate that secondary dwellings have accounted for one in 12 building approvals in central and southern Sydney since 2006-but also that take-up has been more heavily concentrated in some LGAs, particularly in central western Sydney (Troy, van den Nouwelant et al. 2018).

While councils are entering into VPAs with developers, these agreements are predominantly being used for infrastructure contributions. Very few VPAs have been for affordable housing (Gurran, Gilbert, Gibb et al. 2018).

\subsection{Melbourne}

Melbourne, in the state of Victoria, is the second most expensive metropolitan region in Australia (ABS 2019b) and sits between Sydney and Perth in terms of the proportion of housing stock that is detached versus higher density (ABS 2019c). In Victoria, planning reform has also been a key strategy to support more diverse housing supply, particularly diverse forms of market housing.

In 2017, the Victorian Government published the Home for Victorians plan, which sets out a range of reforms and initiatives to address housing affordability. Initiatives arising out of the plan include:

- introduction and trialling of inclusionary zoning

- funding for the supply of new social housing units

- demand-side supports for first homebuyers (Victorian Government 2017).

\subsubsection{New planning objectives and strategies to support diverse housing supply}

The Victorian Planning Provisions (VPP) define the framework for decisions about land use and development in the state. In 2018, the State Planning Policy Framework was amended to include strategic directions for housing diversity (VPP 16.01-3S and VPP 16.01.3R) and affordable housing (VPP 16.01-4S). Under these provisions, planning authorities are required to:

- facilitate a mix of housing types

- encourage medium-density housing (compatible with local character)

- support households with a range of incomes to locate close to services

- $\quad$ ensure that growth areas provide for a diversity of housing types (VPP 16.01-3S).

The VPPs also include an objective to 'deliver more affordable housing close to jobs, transport and services' (VPP 16.01-4S). Planning authorities are expected to facilitate a mix of private and affordable housing (including social housing); and facilitate delivery of social housing through the redevelopment of surplus government land (VPP 16.01-4S). Many local councils in Victoria also embed objectives and strategies in their planning documents to support housing diversity. While these strategies differ across councils, they often emphasise achieving housing diversity on strategic opportunity sites or in areas undergoing substantial change.

\subsubsection{Diverse housing types in greenfield and infill contexts}

The Victorian state government introduced the Small Lot Housing Code in 2011. Like the NSW approach to complying development, the Victorian Code removed the requirement for planning permits to be obtained for construction on lots up to 300 square metres, provided that certain siting and design standards are met. The Code is designed to increase the supply of smaller-lot housing products in greenfield growth areas, in response to changing demographics, housing preferences and affordability issues. The Code is currently applied in most residential and mixed-use Precinct Structure Plans in the Urban Growth Zone in Melbourne's greenfield growth areas and in some regional locations. 
In the Victorian Planning Provisions, several diverse housing types do not require a planning permit in most residential zones, provided defined standards are met. This means that there are as-of-right land-use rights. However, a building permit is still required to undertake building works. Community care accommodation is allowed across all residential zones. Residential aged care facilities and rooming houses of up to nine rooms (and 12 occupants) are permitted in residential and mixed-use zones with the exception of the low-density residential zone. Rooming houses are defined as accommodation in which an occupant rents a private or shared room and has access to shared bathroom, kitchen and laundry facilities.

\subsubsection{Inclusionary planning mechanisms for affordable housing}

The objectives of Victoria's Planning and Environment Act 1987 were amended in June 2018, 'to facilitate the provision of affordable housing in Victoria'. To further this objective, the longstanding mechanism for planning agreements (under Section 173) was explicitly extended to the provision of affordable housing as part of a development. This framework - which is voluntary for developers to take part in-enables councils to work with developers and other partners to provide affordable housing as part of development assessment processes. In return for providing affordable housing, councils may offer developers various planning concessions. In an effort to assist councils in their negotiations, a total of $\$ 500,000$ of grant funding was also made available to councils in the $2018 / 2019$ financial year.

Under the Homes for Victorians plan, the Victorian Department of Environment, Land, Water and Planning is running a pilot inclusionary housing program across six government-owned sites. In 2018, bids were open for proposed redevelopment of six surplus sites to include at least 100 new social housing dwellings developed in partnership with an affordable housing provider (Victorian Department of Environment, Land, Water and Planning 2019).

\subsubsection{Affordable homeownership}

In early 2018, the Victorian Government opened the HomesVic shared equity scheme. The scheme is currently able to offer assistance to up to 400 first-homebuyer households with moderate incomes (up to $\$ 81,000$ for single-person households and $\$ 102,000$ for multi-person households). To be eligible, households must have a 5 per cent deposit, and be able to cover other costs associated with purchasing. The state's equity share under the scheme can be up to 25 per cent of the value of the property. Purchasers cover the remaining cost through a housing loan with a participating bank, and the state's equity share is paid back at the time of sale. Approved buyers are limited to purchasing in priority areas specified under the scheme and, in the Melbourne metropolitan region, the scheme is limited to apartments and townhouses in some suburbs. By early 2020, approximately 250 households had been assisted to purchase through the scheme (Victorian Government 2020).

\subsection{Perth}

House prices in Perth, Western Australia, rose steadily through the 2000s, but have remained flat and declined slightly since around 2014 (ABS 2019b). In contrast to Sydney and Melbourne, the vast majority of housing stock in the Perth metropolitan region is detached housing, which constituted about 80 per cent of stock at the time of the last census (ABS 2019d). In Western Australia, the approach to diverse and affordable housing has been underlined by a range of policy initiatives over the last decade. This includes the Affordable Housing Strategy 2010-20 (Housing WA 2010), initiated by the then Liberal National coalition government, updated in 2017 by the incoming Labor government with the establishment of the Affordable Housing Action Plan (Housing WA 2010). This policy work is now being updated by the WA State Housing Strategy 2020-2030 for completion by mid-2020 (Department of Communities 2020). These strategies have identified and supported a range of planning reforms necessary to deliver more diversity, particularly low-cost home ownership through Keystart (see below) and partnerships between the public and private sectors. 
Strategic planning documents Perth and Peel @ 3.5 Million and Directions 2031 have set out dwelling density targets, providing the framework for increased housing diversity through an emphasis on setting infill development targets. The latest round of planning reform (Action Plan for Planning Reform: Better Planning, Better Places 2019) has affordability and diversity at its centre through creation of a more streamlined planning system, making it quicker and easier for developers to deliver a range of dwelling types. The current state government has sought to facilitate development of affordable and diverse housing within its $\$ 8$ billion public transport investment program, Metronet. This project has made a commitment to identify opportunities to deliver social and affordable housing as part of station precinct redevelopments (Metrohubs). Additionally, a range of planning policies and reforms delivering guidance on residential development have tried to address a lack of diversity in the housing stock - for example, the residential design codes (R-Codes).

While the emphasis within each of these initiatives varies, all have sought to reform the planning approvals system to support communities by providing housing that is diverse, affordable, accessible and safe (Department of Communities 2020). This has focussed largely on setting in place processes of planning, design and regulatory reforms that aim to reduce development time and costs while delivering better quality housing outcomes.

\subsubsection{Support for diverse housing in strategic planning}

The metropolitan planning agenda for Perth is set out by the Western Australian Planning Commission's strategy Perth and Peel@ 3.5 Million and the associated sub-regional frameworks. These strategic planning frameworks present clear targets for infill and consequently housing diversity. In particular, the Central Sub-regional Planning Framework presents the case for increasing urban consolidation, focussed within activity centres, station precincts and corridors. Infill is thus a proxy for diversity and choice, given how the outer suburbs of Perth are dominated by detached housing products.

The overall target for infill housing development in Greater Perth is 47 per cent of all new dwellings-which equates to 380,000 new dwellings of the expected 800,000 dwellings by 2050 . A greater proportion of that target has been assigned to the central sub-region of Perth, where it is expected that approximately 56 per cent or 215,000 of those dwellings will occur.

The acknowledged policy intent of these infill targets, particularly in the central areas of Greater Perth, is that they offer good public transport accessibility and proximity to the CBD, which reduces transport and other living costs relative to living in outlying suburbs. The introduction of greater housing diversity to the existing urban environment will provide the opportunity for the provision of diverse housing in the form of smaller dwellings, including townhouses, apartments and ancillary dwellings (granny flats), which tend to be more affordable than larger homes, providing more housing options for lower income households (Department of Communities 2020).

The planning reform agenda outlined in Section 3.4.2 illustrates some of the mechanisms being used.

\subsubsection{Planning and other policy reform}

The planning reform process related to affordable and diverse housing has occurred in the context of a broader planning reform agenda. In late 2017, the government commissioned an independent review of the Western Australian planning system through the Minister for Planning. This resulted in a green paper and subsequent Action Plan for Planning Reform (Government of Western Australia 2019). While this agenda has been broad-based, it has been aligned where possible with the housing priorities outlined earlier, enhancing the consistency and efficiency of the planning systems between state and local governments-such as ensuring consistency of planning policies and schemes between local authorities - with the aim of reducing time frames and approval costs. 
Beyond the general reforms, these policy and planning processes have sought to enhance planning outcomes related to affordability and diversity through the following:

- Maintaining a Housing Advisory Unit within the Department of Planning, Lands and Heritage to inform major planning policies and decisions, and collaboratively pursue reforms that will lead to affordability and diversity.

- Implementing strata reforms, including new forms of tenure to facilitate mixed-use development, housing choice and infrastructure cost sharing (including Community Title).

- Delivering a toolkit to assist local governments to promote and incentivise affordable housing in their local areas.

- Using the Design WA Stage One and Stage Two development design guidance tools to help increase the supply, diversity and quality of 'missing middle' housing.

The apartment and medium-density design guidelines through Design WA are intended to make it easier for developers to deliver diverse product, and for local governments to more efficiently approve compliant developments. Design Stage Two focussed on the introduction of planning codes for medium-density development (Department of Planning Lands and Heritage 2019). There have also been efforts to introduce more flexible planning provisions in local government town-planning schemes to encourage tiny houses and granny flats.

A key element of recent planning reform was the introduction of Local Development Assessment Panels (LDAPs) and Joint Development Assessment Panels (JDAPs), which aim to increase the level of technical planning expertise in planning decisions (Department of Planning Lands and Heritage 2020a). The Panels are designed to deliver more independent decision-making on large-scale schemes, allowing developers to 'opt in' for Local Development Assessment Panel (LDAP) or Joint Development Assessment Panel (JDAP) assessment for projects of between $\$ 2$ million and $\$ 10$ million, and are mandatory for projects above $\$ 10$ million. The aim of the Panels is to introduce more consistency in decision-making by reducing the political components that often frame local government decisions.

\subsubsection{Joint ventures and government leadership}

For many years the Department of Communities has used its joint venture model, where the department enters into formal delivery models with the private sector to deliver land and housing developments in both greenfield and inner urban infill (Rowley, James et al. 2017). The model provides a mechanism for delivery of diverse housing type and tenure where the development agreements between the department and the private sector set the framework for delivering specific housing mixes - with the department usually retaining a proportion of dwellings for social housing provision and for shared ownership sales.

Another state government-led initiative is permitting small subdivisions in certain areas to allow 'micro lots'. These sub-100 square metre land and housing products have been championed through joint initiatives between the Department of Communities and developers, and have now evolved into a niche market (Terrace n.d.).

The other intervention and leadership role is through Development WA (and its predecessors LandCorp and Metropolitan Development Authority), which has championed housing diversity and affordability wherever possible within development projects (Development WA n.d.). 


\subsubsection{Affordable homeownership}

Since 1989, the WA Government has supported low-deposit home loans for eligible buyers through its lenderKeystart. The program was started to support access to home ownership for households that could not meet the deposit requirements for mainstream mortgages. The program reduces the cost of borrowing for households with low deposits, and has offered over 100,000 loans (Government of Western Australia Department of Communities and Housing 2019). The WA Government has also run a shared ownership initiative, in which the state government holds up to a 30 per cent equity share in a dwelling with the buyer purchasing the rest. Eligible properties are those procured by the Housing Authority, usually as part of a joint venture program with a private sector developer. The program is supported through Keystart shared ownership home loans (Government of Western Australia Department of Communities and Housing 2016).

\subsection{Summary and policy development implications}

In all three jurisdictions, concerns about the supply and affordability of housing and government pursuit of urban consolidation have driven a range of reforms to the planning system in recent years. Regulatory changes have predominantly focussed on enabling more diverse built form in both infill and greenfield contexts. However, there have also been efforts to improve the permissibility of a few specific housing types, particularly rooming and boarding houses and secondary dwellings, as well as to introduce or expand inclusionary housing policies to support affordable housing delivery, although these schemes remain small in scale. A longstanding approach in WA, and a new approach in Victoria, has been to assist eligible households into home ownership through shared equity schemes. Table 3 summarises the different approaches used in each jurisdiction.

Table 3: Comparison of reforms and policy efforts to encourage diverse housing supply

\begin{tabular}{|c|c|}
\hline State & Key reforms and strategies \\
\hline NSW & $\begin{array}{l}\text { - Codifying development rights and expedited approval (secondary dwellings, two-storey medium density) } \\
\text { - Limiting arbitrary refusal (boarding houses, apartments including affordable rental housing, secondary dwellings) } \\
\text { - Planning-based incentives for affordable rental housing inclusion } \\
\text { - Legal recognition of negotiated agreements for affordable housing inclusion } \\
\text { - Inclusionary zoning (geographically limited) } \\
\text { - Demonstration on government land. }\end{array}$ \\
\hline VIC & $\begin{array}{l}\text { - Requiring a building permit only for rooming houses and aged care in most residential zones } \\
\text { - Legal recognition of negotiated agreements for affordable housing inclusion } \\
\text { - Inclusionary zoning pilot / use of surplus government land to deliver affordable housing } \\
\text { - Government shared equity scheme for eligible buyers }\end{array}$ \\
\hline WA & $\begin{array}{l}\text { - Reform to statewide density controls and development standards (R-Codes) to enable smaller lots and higher } \\
\text { residential densities } \\
\text { - Amendments to strata law and new community title } \\
\text { - Development of a toolkit for local governments on enabling and incentivising affordable housing in their area } \\
\text { - Demonstration on government land } \\
\text { - Permitting and demonstration of small 'micro lots' } \\
\text { - Government shared equity / low-deposit loan scheme for eligible buyers }\end{array}$ \\
\hline
\end{tabular}

Source: Authors. 
While the timing and specific design of these regulatory reforms, policies and programs has differed, common initiatives include the following:

- Providing increased certainty around the permissibility of smaller lots, specific housing types or mediumdensity housing forms through statewide policy or codes that outline development rights and applicable development standards (NSW, Vic, WA).

- Legal frameworks for negotiating voluntary contributions of affordable housing in new developments (NSW, Vic).

- Very small-scale inclusionary zoning schemes (NSW, recently Vic).

- Using government land (developed by government agencies or private developers) to demonstrate diverse housing forms and to deliver small amounts of new social and affordable housing (NSW, Vic, WA).

- Assisting lower income households to enter home ownership through shared equity schemes (WA, recently Vic).

Although not specifically targeted at enabling diverse housing, the introduction of independent, regional-level development assessment bodies for projects with high capital investment value has sought to depoliticise development assessment decisions on large-scale (often infill) projects. In NSW, lower thresholds have been set for affordable housing projects to be determined by regional-level development assessment panels.

Evidence of the outcomes of these approaches is somewhat limited-particularly where they have been recently implemented. Low levels of government reporting mean that further systematic research is needed to determine the outcomes of these initiatives. Regulatory reforms in NSW to support the permissibility of diverse housing types and inclusionary planning mechanisms and planning-based incentives to support affordable rental housing supply have been in place for over a decade. Available data from Sydney suggests that regulatory reforms to support the permissibility of some diverse types of market housing-including boarding houses and secondary dwellings—have resulted in new supply.

However, in the absence of any affordability requirements, evidence suggests that these housing types are not delivering rental housing that is affordable to low-income groups. Very little affordable housing has been delivered through incentive-based mechanisms or the very small-scale inclusionary zoning schemes that are in place. Across the states, projects on government land and demonstration projects by state development agencies have delivered diverse housing sizes and designs and mixed tenures, but on a relatively small scale. In WA, long-term government support for low-cost lending and equity sharing has assisted over 100,000 lower income households to become homeowners over the past four decades.

In Chapter 4, we discuss industry and expert views on the opportunities and barriers for delivering diverse housing within these planning and housing systems. 


\section{Diversifying housing supply in Sydney, Melbourne and Perth: views from the Investigative Panels}

- The 50 built-environment and housing industry experts in Sydney, Melbourne and Perth who contributed to this research identified a need for: greater diversity in dwelling types, particularly in lowdensity suburbs; medium- and higher-density housing forms that meet a wider range of household needs and lifestyle preferences; rental housing that can offer long-term security of tenure; and rental and home ownership housing that is affordable to low- and moderate-income groups.

- Medium-density housing (townhouses, semi-detached homes and two-storey residential apartment buildings), deliberative and nonspeculative development models, community-led development models oriented to long-term affordability, different tenure models including shared ownership and increased supply of affordable and social rental housing could all play an important role in addressing those gaps.

- Planning-related challenges for delivering diverse dwelling types and housing tenures and implementing alternative development models that can support greater affordability include access to sites where medium and higher densities are permitted and where diverse housing developments are potentially feasible; lack of flexibility in development controls to allow design innovations; and uncertainty around the time frame and outcome of development assessment decisions. 
- While some of these challenges also impact traditional residential projects, tighter development margins can mean that diverse housing projects are less able to cope with higher development costs and unexpected time frames and, at the same time, may face community opposition, particularly when proposed in established residential areas with existing sensitive land uses.

- Other key challenges include high urban land costs; challenges obtaining development finance (particularly in flat or falling market conditions); and, a lack of skills and expertise in the housing industry.

- Challenges accessing land and development finance can be greater for housing projects that do not constitute highest value land use and that are initiated by start-up organisations and small developers without significant balance sheets or development track records.

- Projects geared towards long-term affordability and affordable housing projects by not-for-profit housing providers face additional viability challenges due to the higher gap between project costs and revenue, and the limited availability of subsidy to fill that gap. 


\subsection{Background}

This chapter is the first of two chapters that distil the outcomes of the Investigative Panels held in Sydney, Melbourne and Perth. It explores panellist perspectives on what constitutes diverse housing in the three cities and the barriers and challenges to delivering diverse housing. As outlined in Chapter 1, two 3-hour panel meetings were run consecutively in each city, with each session consisting of between eight and 13 panellists. The first session consisted of housing, development and finance professionals and researchers with expertise in diverse housing types and development models, while the second session captured the perspectives of planners, urban policy makers and financial regulators. The findings also include information derived from four separate interviews with housing and development experts.

\subsection{Dimensions of diversity and housing stock gaps}

This section discusses responses to the first two themes considered by the panels:

1. What is meant by 'diverse' housing and its relationship to housing affordability and affordable housing.

2. Gaps in Australia's current housing stock and new supply and the role that different types and tenures of housing, offered at different pricepoints, could play in addressing those gaps.

\subsubsection{Dimensions of diversity}

Panellists from across the three cities observed a tendency by governments to think about housing diversity in terms of built form, with diversity often being synonymous with medium- to high-density residential development. However, panellists argued that diversity should be thought about more widely, and identified key dimensions of diversity to be:

- price

- tenure and governance arrangements

- location

- dwelling size

- built form, delivery model and construction methods

- financing arrangements.

Panellists emphasised that households and their housing needs should be central to thinking about diverse housing:

'It's more than just the roof and the shape of the building. It's who lives in there, how they want to live in there, and the pricepoint they pay to live in there as well.' [Sydney panel participant]

'Diversity is actually providing housing for everybody [that] meets their needs through their lifecycle.' [Melbourne panel participant]

Panellists emphasised that a diverse housing stock should:

- include housing that is affordable to households on different incomes, in a variety of locations (including job-rich locations)

- meet the needs of people in different life stages, such as students, first-time buyers, households with children, households with ageing and elderly people, and people with disabilities

- accommodate different lifestyle and cultural preferences-for example, multi-generational families, or people wanting to have a smaller ecological footprint.

Framed in this way, panellists across the three cities argued that a broader range of housing types, designs and configurations (particularly for medium- and high-density developments), tenures and pricepoints is needed to better align housing supply with the full spectrum of housing need and demand. 


\subsubsection{What housing is missing and who is missing out?}

Panellists were asked to discuss the gaps they perceived in their city's housing stock-both existing and new supply - as well as the types of households whose needs they believed are currently not being met.

\section{Medium-density housing}

Across all three cities, panellists identified low-rise medium-density housing-often referred to as 'missing middle' housing - as a type of housing with strong demand that is not being delivered at a significant scale in the market, with new supply dominated by detached houses and high-rise apartments (usually confined to specific locations).

'They're building single dwellings and high density, but not a lot in between.' [Sydney panel participant]

Medium-density housing was seen to offer a desirable alternative for smaller families, first homebuyers and downsizers. In Perth, in particular — which has the largest housing stock in terms of number of bedrooms-this 'missing middle' housing was seen as a necessary alternative to larger ('four by two') family homes, and a more suitable option for first-time buyers and smaller households.

In Sydney, where housing affordability problems are the most acute, panellists saw a need for smaller homes in suburban areas in order to provide more affordable market entry points for first homebuyers. In all three cities, increasing the supply of lower maintenance, medium-density homes in established suburbs was seen to be important for enabling older households to downsize within their existing areas.

More diverse higher-density housing designs and configurations

In Sydney and Melbourne, which have both had significant new supply of apartments in recent years, panellists highlighted the problem of the lack of diversity within new apartment stock. In particular, panellists remarked on the lack of apartments suitable for families:

'I think the market hasn't really demonstrated steps towards good quality family apartment living, or denser family living.' [Melbourne panel participant]

While families might traditionally prefer living in a larger detached dwelling, affordability constraints - and an increasing preference for dual-income households to live within a central location to access employment-means that families are often living in apartments while older couples and even single-person home owners remain in larger detached housing stock. The panel explained that three-bedroom apartments are often penthouses, which are not affordable for many families.

The lack of diversity in apartments was seen to extend beyond apartment sizes. As one panellist pointed out, new apartments have not tended to cater to different lifestyle preferences, for example, by providing more environmentally sustainable features, fewer car spaces, or offering varying extents of communal outdoor space and tenant facilities (and, by extension, varying levels of strata fees).

Secure, long-term rental housing

Across all three cities, panellists pointed out that demand for rental housing is increasing, stemming both from growing financial barriers to home ownership, particularly acute in Sydney and Melbourne, and, to a lesser extent, changing household preferences - particularly among younger households. As one Perth panellist explained, there are many households 'looking for long-term security of tenure but [who] can't afford to buy it'. [Perth panel participant-morning] In this context, high quality rental housing with greater security of tenure and opportunity to establish a stable community was seen as a significant gap in each city's housing market.

'I think that element of secure rental is very important. We have very poor regulations in terms of what tenants can expect.' [Melbourne panel participant] 
Panellists saw a need for an expanded rental sector able to offer high quality, long-term rental accommodation suited to a broad range of households. As one panellist remarked:

'That goes for everyone, from single people looking for proximity to work or services through to families, through to very large families.' [Melbourne panel participant].

\section{Bridging the gaps between social housing and private rental and home ownership}

In Sydney and Melbourne, where housing affordability problems are most acute, panellists discussed the significant gap (identified by one panellist as another form of 'missing middle') between social housing and private rental and ownership housing. In particular, they regarded the significant gap in cost and tenure security between social and private renting as a major disincentive to leaving social housing for the few households who are able to attain it. Panellists also pointed out that there is a growing cohort of people who will not qualify for social housing, but who are still unable to affordable market-rate housing in areas where they need to live. This cohort includes many young professionals and essential workers.

Across the three cities, panellists discussed the need to significantly increase the supply of housing that is affordable to households on a range of low-to moderate incomes. This included:

- rental housing offered at a discounted market rent-but significantly above typical social housing rents

- ownership housing offered at a market discount-for example, through a deliberative development model, or a community-led scheme designed to secure long-term affordability

- housing made affordable through a shared equity program.

At the other end of the affordable housing continuum, they also saw a need for increased supply of crisis and transitional accommodation, as well as specialist accommodation to house people with high support needsincluding young people, who account for a quarter of people on social housing waiting lists.

\subsubsection{Features of a more diverse housing system}

Panellists were asked to share their perspectives on what a housing system characterised by more diverse housing stock would look like. Across the three panels, there was consensus that more diverse housing stock could support greater mobility within the housing system, enabling households to relocate to housing best suited to their needs. By contrast, the current system was seen to disincentivising moves-and thus more efficient use of housing stock - due to the lack of suitable housing options, but also because of taxation settings.

Specific transitions that panellists suggested could be enabled through more diverse housing stock included:

households entering the ownership market (and leaving the private rental sector)

- households downsizing

- households moving out of social housing.

Regarding the transition point of moving out of social housing, one panellist remarked:

'Until you can provide equity in the private market, security and tenure-why would they move? ... Unless you're providing mixed [community] developments where they can say stay in their community with their support member and even potentially stay in their home which then becomes their affordable rental unit, and then eventually becomes the unit that they buy. Until we have that kind of flexible building typology and mixed income and mixed tenant developments, why would somebody leave social housing if they've been lucky enough to get into social housing?' [Sydney panel participant] 


\subsection{Barriers and challenges for delivering diverse housing supply}

This section discusses panellist responses to themes around regulatory and other barriers to diverse housing supply. This included:

1. Emerging industry models for diverse housing and potential opportunities and barriers for their scaling in Australia.

2. Regulatory settings that inhibit the supply of diverse housing in different locations and housing market contexts.

3. Barriers within industry-for instance within the construction sector-which may inhibit innovation and diversity in new residential development

The discussion begins with barriers and challenges directly related to the planning system, including zoning and other development control policies and development assessment processes. The focus then turns to factors beyond the planning system, including:

- role of the housing market

- requirements for development finance

- factors internal to the development industry.

\subsubsection{Zoning, development control policies and developer contributions}

Across the three cities, land-use zoning is the primary means of development control. Zones specify maximum residential densities as well as land uses that are potentially permissible with development consent. Therefore, land-use zoning was seen to be a significant driver of land-use and built-form outcomes. However, the specific issues raised differed because of differences in each state's planning system.

Prevalence of land where medium densities are not permitted

In all three cities, expert panellists from the development and housing industry regarded extensive low-density residential zoning as a barrier to diverse built form, as well as having implications for diversity of tenure.

Panellists in all three cities pointed to the extensive use of low-density residential zoning by local governments and the comparatively limited geographic locations where medium- and higher-density development is permitted. The geographic extent of low-density zoning actually reflects the large amount of land required to support single detached houses, as opposed to high-density uses. Limited zoning for higher-density land uses also reflects the sensitivity of existing land uses in established residential areas.

Lack of sites zoned for medium- and higher-densities beyond central city areas were seen to have implications for diversity of housing tenure, as well as built form. As panellists explained, medium-density housing and small-scale residential apartment buildings are often the preferred built form for:

- deliberative development projects

- cohousing

- affordable housing developed by Community Housing Organisations.

As one panellist in Melbourne explained, developments of 25 to 35 units are the ideal size for affordable housing providers. However, there are very few sites of the right size and right zoning across the city to deliver that built form. 
Financial viability of medium-density relative to higher-density land uses

Panellists explained that medium-density housing is typically not viable where high-density residential development is permitted, as is usually the case in areas adjacent to transport and services. This applies particularly in Sydney and Melbourne. Panellists explained that land vendor expectations typically reflect the highest and best economic use value. This means that only proposals for market-rate housing that maximise density allowances will be able to compete for land and be financially viable. This is because projects that maximise the allowable density, and deliver homes for sale, will generally have higher revenue and higher residual value. So, where medium-density built form is permitted alongside higher densities such as residential apartment buildings, medium-density housing forms tend to be 'crowded out' as they are less economically viable.

'In [zones intended for medium density] you're closing the door on lesser density or less diverse outcomes because you can do a lot of residential flat [apartment] building.' [Sydney panel participant]

Panellists explained that in the Sydney greenfield growth areas, planning policies specifying minimum density bands - that is, the number of dwellings per hectare-rather than maximum controls, have enabled developers to 'skip forward' from the terrace style development envisioned to seek development approval for apartments.

'The market seems to have missed them altogether, and that is even in a new release area where you'd think, if anywhere, terraces were going to be feasible.' [Sydney panel participant]

As panellists pointed out, zoning to allow for higher densities ahead of market viability can also have a counterintuitive effect-which leads to sites remaining undeveloped until the highest and best-use value is viable. Referring again to greenfield development areas of Sydney, panellists expressed doubt over whether approved apartments would actually be developed prior to greenfield areas becoming more established with the amenities to support apartment demand.

\section{Permissibility of diverse dwelling types within residential zones}

Panellists also pointed out that there can be a disconnect between the objectives of residential land-use zones - which typically aim to deliver diverse housing in response to community needs - and actual permitted land uses. As one Melbourne-based panellist explained, although Victorian planning policy includes objectives for housing diversity, there is little clarity around how an objective for housing diversity might be addressed:

'One of the objectives of the zone is to create diversity of housing ... but then the definition, dwelling, doesn't put any onus on the applicant ... to actually deliver diverse housing.' [Melbourne panel participant]

Panellists explained that state planning policies that clarify the permissibility and development standards for diverse housing forms (such as the R-Codes in WA) and select diverse housing types, such as boarding and rooming houses (NSW, Vic.), seniors' accommodation and secondary dwellings (NSW) have helped to address this problem. However, they only include select diverse housing types, meaning that the potential permissibility of other residential development types is not clear. Moreover, statewide policies permitting particular development types and development standards have been criticised for being insensitive to local contexts and having the unintended effect of fuelling community opposition to infill development. As a development industry expert in Sydney pointed out:

'Some of the [State Environmental Planning Policies] do override the local provisions to actually unpack what you can do in R2 [low-density residential zone] and often, because of the tension, they do end up in court.' [Sydney panel participant]

As the panellist explained, this can lead to long development application processes and unpredictable outcomes (which are discussed in more detail later). This is in contrast to the aim of state level policies in NSW, which are designed to overcome local regulatory barriers to diverse housing types and tenures. 
Heritage preservation

Across the three cities, panellists pointed out that heritage designations, particularly in inner and middle-ring suburbs, can act as a barrier to redevelopment of lots at higher densities. In Perth, one panellist from the development industry also pointed out that requirements for particular building materials in some LGAs-in order for infill development to be sensitive to building heritage-can limit scope for innovation in construction techniques and materials. These legitimate council and community concerns around built and natural heritage, and the existing character of established neighbourhoods, highlight some of the challenges surrounding attempts to diversify housing types within existing residential settings.

\section{Car parking requirements}

Panellists explained that communities and councils typically want significant volumes of off-street parking in new developments, even where proposed developments have good access to public transport and anticipated low rates of car ownership among occupants. Consistent with research that has found inflexible car parking requirements to be an important viability constraint for infill and greyfield development (Rowley and Phibbs 2012; Murray, Bertram et al. 2015), panellists highlighted the significant impact provision of car parking can have on development costs, with particular implications for the viability of projects with tight development margins - particularly those delivering housing at below-market rates. Flexible car parking requirements, including allowing no additional off-street car parking, was seen as a potential way to support the viability of:

- medium-density infill housing

- affordable housing projects

- deliberative and community-led housing projects where there is evidence occupants will not own cars.

\section{Development contribution requirements}

While development contribution requirements-for community facilities and infrastructure to support growth - contribute to overall development costs and can therefore have an impact on project viability, they were not a strong focus of the discussion of regulatory barriers to diverse housing. The exception was in Sydney where, at the time of the panels, changes to the method of calculating Special Infrastructure Contribution requirements in the greenfield growth areas was scheduled to come into effect. Panellists were concerned that the new approach of calculating contribution requirements on a per dwelling rather than an area basis could disincentivise mediumand higher-density housing development. However, at the time of writing the outcomes of this change were not yet known.

Consistent with car parking requirements, some panellists suggested that waiving or reducing development contribution requirements for community-led and affordable housing projects because of their social and community benefits could help to support their viability. One panellist gave the example of a Melbourne local government area (LGA) that now exempts cohousing projects from developer contributions.

\subsubsection{Development assessment processes}

Zoning and development control policies (discussed earlier) define the type and scale of development that can potentially occur on a site, and what must be included or contributed as part of a new development. However, development rights for most projects are conferred when planning approval is granted by the applicable assessment authority. While the majority of development applications in Australia are determined by professional planners in local government, applications that attract significant community opposition are subject to different approval processes, including determination by a vote of local councillors.

However, in NSW all such projects are now determined by expert state, regional or local panels (with regional and local panels including local representation), and there is an increasing trend for expert panels to oversee development assessment decisions for larger projects in other states as well (Williams 2014). In this context, we asked expert panellists about their experience of the development assessment process, and how it impacts the permissibility and viability of diverse housing projects. 


\section{Community opposition}

International research has found local political opposition to be an important factor in development permitting and rezoning decisions, and a particular barrier to permitting of higher-density projects (Gabbe 2018b; Whittemore and BenDor 2019; Bramley and Watkins 2014). Across the three cities, community opposition to development generally, and higher-density and affordable housing in particular, was seen by many panellists to be a significant challenge for more diverse housing. In particular, it was seen to add to uncertainty around whether a project would be approved and the time and cost required to attain approval-particularly if a local government refusal has to be appealed.

Panellists from the development industry suggested that most of the opposition to diverse housing projects was coming from local homeowners who were concerned about the impact of higher-density infill projects and affordable housing on the value of their own properties and the amenity of their local area. They explained that community opposition tends to be most concentrated in lower-density suburbs characterised by high levels of home ownership and with increased potential for sensitive adjacent land-use conflicts such as overlooking and overshadowing. Nevertheless, even small-scale projects for rental or affordable housing can attract community opposition in these residential areas. One developer gave the example of an application for a single-storey boarding house in a suburban area of Sydney that attracted 800 community objections, in contrast to a 100-room boarding house in central Sydney that attracted no objections.

Panellists also remarked that community anxiety and opposition to infill development can arise from the element of discretion in planning decisions-which creates uncertainty about what will be permitted-and the perceived poor quality of some infill developments.

'You get a whole lot of fairly dodgy development and once people see dodgy development then noone wants to see that development near them.' [Perth panel participant]

The panellists also pointed out that planning strategies and zoning schemes that aim to concentrate redevelopment in centres, along transport routes and in 'growth zones' (Melbourne) have fostered an expectation in the community of limited or no change outside of those locations.

As noted earlier, and in Chapter 3, governments have sought to address this issue through special assessment pathways and use of expert development assessment panels to determine larger projects and or development applications in specific areas. In NSW, the threshold for panel assessment is lower for projects that include affordable housing. While some panellists regarded this approach as significant in reducing scope for political opposition to influence development assessment outcomes, some development industry panellists still perceived challenges for getting affordable housing projects, in particular, approved.

Third-party appeal rights and development risk

In NSW and WA, third parties are generally not able to appeal a planning decision, unless there has been an administrative error in the decision process. So although neighbours and local residents are able to make formal objections to most types of residential development applications, they are not able to appeal the outcome. However, this is not the case in Victoria, where third-party appeal rights for objectors of residential development persist.

In Melbourne, these third-party appeal rights were seen to be a significant risk for higher-density and affordable housing projects. Panellists explained that while objections tend to be 'dressed up', and focus on planning issues such as built form and car parking, they believe that housing tenure is a significant driver of community opposition and appeals. One panellist remarked that they had never been involved in an affordable housing project that had not been appealed. They explained that even if the application is eventually approved, appeals are a significant cost to developers and housing organisations. 
This can be particularly problematic for deliberative development, community-led housing developments and affordable housing projects, as they have tighter margins. They are also often delivered by smaller, start-up organisations that have less resources than larger companies to manage long development application processes and appeals. Panellists pointed out that the financial viability of these projects is typically more sensitive to the cost of time than conventional projects and, at the same time, because of third-party appeal rights, these projects face less certainty about whether they will ultimately be approved. In that context, some panellists suggested that certain types of diverse housing projects that deliver a community benefit, or projects by not-for-profit organisations, should either be exempt from or have limited third-party appeal rights.

\subsubsection{Development financing and taxation settings}

Panellists were asked whether lending requirements and taxation settings present a barrier to diverse housing development, particularly by constraining access to development finance, but also access to mortgage finance for purchasers of diverse housing products.

\section{Conservative valuation and lending practices}

Across the three cities, panellists explained that lending practices are generally very conservative, which can be a challenge for early implementers of diverse housing products and projects. The Royal Commission into Misconduct in the Banking, Superannuation and Financial Services Industry (Australian Government 2019) was seen by one panellist to have generated furthering risk aversion in an already conservative industry, hindering discussions about financing, in this case, community-led housing models. In Perth, one panellist explained that they had been unable to obtain finance for a project including a rental housing component.

Panellists discussed the difficulty of accurately valuing unique housing products:

'Valuation is a traditionally very conservative sector ... any change is a problem in that space because they operate on a look-back model.' [Perth panel participant]

As one Sydney panellist explained, the lack of comparables can make accurate valuation difficult-and can lead to significant undervaluation. He claimed that it can take five to 10 years from the introduction of a new type of housing product for the banking sector to get enough comparables for an accurate valuation.

They also explained that financing costs can be higher for projects with different development models, and that terms of lending are insufficient for projects with a long-term affordability aim. Referring to their non-speculative development model, one panellist explained that while their model eliminates settlement risk as buyers are known and committed from the outset, their cost of borrowing is actually higher:

'They don't lend us as much as they would otherwise because they see that it is a little bit different and it is a struggle but that's not just this model. I mean every developing model I think is struggling with funding so it's not unique to us.' [Melbourne panel participant]

Another panellist pointed out that development models that are non-speculative and have an affordability aim-such as cohousing and other community-led housing models, for example, community land trusts - typically need a 30-40year loan term to lower repayments to a viable level. However, banks will typically only lend for a 20-year term.

\section{Developer track record}

The size and experience of developers and organisations seeking to do innovative housing projects was also discussed as an important factor in accessing finance. Panellists pointed out that organisations seeking to do innovative housing projects are often small-scale start-ups without a development track record. They explained that smaller organisations do not have the significant balance sheets, cash reserves, institutional backing or option to provide a personal director guarantee that larger-scale mainstream housing developers have. These factors can decrease lender confidence and, as a result, restrict access to development finance. 
One panellist gave the example of a start-up organisation that approached 33 different lenders before getting financing for their deliberative development. The lender considered the project to be too risky to lend prior to the development application being approved. As a result, the organisation needed to purchase a site and fund the costs of a development application upfront, before being able to access any development finance. In this case the organisation was able to fund those costs through private sources, but the panellist noted that that may not be possible for every organisation and community group trying to implement non-speculative and community-led housing projects.

\section{Mortgage finance for purchasers}

As a panellist with a finance background explained, non-speculative housing projects typically have an affordability aim. Therefore, they often target households who may be less able to get a retail mortgage because of low or unstable incomes. Low deposit requirements (e.g. 5\%) are one way that some projects aim to improve access to home ownership. However, if buyers have to get conventional mortgages, mortgage insurance can add to the cost for purchasers and there are risks for the developer or development organisation that potential participants will not have their mortgage application approved.

\section{Not-for-profit housing providers and finance}

Panellists with experience in the not-for-profit housing sector explained that community housing providers (CHPs) often have difficulty accessing finance, with revenue alone being insufficient to service debt-which results in a funding gap. For lending to support new development, panellists explained that CHPs require a sufficient asset base. This is a problem for CHPs with a small number of units, or which are predominantly engaged in management. One panellist explained that when their organisation started taking a portfolio rather than a site-based approach, they were more successful at getting construction finance. However, that strategy is only possible where an organisation has a portfolio of properties.

Panellists also pointed out that CHPs continue to face significant refinancing risk, with banks only offering very short (3-year) terms). While the NHFIC provides longer term refinancing, one panellist noted that it is still significantly less than the 30-year terms that are available in other countries, which give stability of funding certainty. They explained that the debt CHPs are able to raise can only cover a proportion of construction costs for social and affordable housing, owing to limited cashflow to service the debt.

'A dwelling is a dwelling is a dwelling, regardless of who's going to live in it; it's going to cost what it costs so the subsidy does need to be in the finance not in any of the delivery costs. It's really been tricky to articulate that in finance ...' [Sydney panel participant]

Panellist argued that while a range of different subsidies are needed for affordable housing projects to be financially feasible, longer term debt financing needs to be part of the package.

\section{Diverse housing projects and investment funding}

Within the broader discussion of development financing and lending, panellists discussed barriers to attracting institutional investment to rental and affordable housing projects-particularly superannuation fund investment. While panellists pointed out that there is growing interest in corporate social investment, there are a number of barriers to institutional investment in housing. One of the issues panellists raised is the scale required to attract superannuation funds:

'You need to be able to show them that you want a serious partnership with them and how you can get them to billions invested in a platform over time.' [Melbourne panel participant] 
Another panellist pointed out that attracting institutional investment requires significant resources from a housing or development organisation:

'We've had to forward-fund a whole bunch of resources within our business to be able to track the institutional capital ... it's extremely difficult to attract institutional investment.' [Melbourne panel participant]

Panellists also expressed a view that superannuation funds, like lenders, are relatively conservative, and want clear proof of concept and demonstrated returns before they will invest.

Consistent with recent research findings, panellists also pointed out how aspects of the current tax system act as a barrier to institutional investment in rental housing in Australia (Pawson, Martin et al. 2019). As one panellist explained, the returns on rental housing investment are currently below the levels expected by superannuation funds. Unlike individual investors who accept a lower return but can claim capital gains, that incentive is not available to institutions.

As one panellist pointed out, Australian superannuation funds are investing in affordable housing and BTR overseas, where they can get tax concessions. Discussing the impact of the tax system on the viability of build to rent generally, one panellist explained that in order to bring BTR 'closer to a level playing field' with build-to-sell, governments would need to look at significant reform to the tax system, as well as offer planning-based incentives to support viability [Sydney panel participant].

\subsubsection{Land costs and acquisition}

Panellist were also asked how access to sites and the cost of land impact the diversity of housing supply. In Sydney and Melbourne, in particular, the very high cost of land was seen as a significant challenge for delivering medium-density housing forms:

'Where underlying land prices are so high, it's just not feasible to do anything, but starting at about six or seven storeys sometimes and going upwards from there.' [Sydney panel participant]

In Melbourne, panellists questioned whether it would be possible to scale land values back to a level that would make medium- and mid-rise apartment developments feasible in desirable areas:

'We've almost overcapitalised on our land. I don't know how we can get back down to [less than] the eight storeys.' [Melbourne panel participant]

The lack of height limits in some areas of the city were seen to have exacerbated landowner price expectations.

High land costs were seen as a particular challenge for projects and models oriented to long-term affordability. One panellist regarded access to land as the primary barrier to implementing community land trusts and other community-led housing models. Panellists also pointed out that CHPs face considerable challenges competing for sites on the open market. Unable to generate the same returns as market-rate developments, they have to rely either on access to government-owned land, benevolent landowners or develop where there is less competition for sites and where land values are lower. 


\section{Lack of large sites}

Panellists explained that the diverse dwelling sizes and designs and mixed housing tenures that have been demonstrated in some public-sector-led projects are difficult for the private sector to replicate, particularly because they do not have access to large sites.

'People like Development WA' $\ldots$ can deliver innovation but they're the ones who get all the school sites or they get all the decent parcels of land in that middle ring and they can deliver it.' [Perth panel participant]

In Perth, panellists argued that there is little incentive-such as additional density allowance-to work to amalgamate sites.

In Sydney, panellists from the development industry pointed out that the best projects in recent years that have demonstrated housing diversity, have benefited from a single masterplan—for example, Thornton Park. As one panellist argued: 'We don't have huge landholdings available to us like we once had ... Everything we've got to do is now an aggregation process.' [Sydney panel participant]. Panellists explained that in Sydney's greenfield growth areas, small landholdings, high landowner price expectations and limited pressure to sell creates significant challenge for amalgamating sites. Moreover, the cost of amalgamating fragmented landholdings puts pressure on financial viability and can mean there is limited appetite from developers to experiment with diverse housing types or tenures.

\subsubsection{The housing development industry and housing market factors}

A final discussion point was how factors internal to the development industry and broader housing market conditions impact the diversity of housing supply.

\section{Structure of the development industry}

Across the three cities, panellists generally regarded the large developers who dominate the residential development industry as conservative in their development models. This conservatism was also seen to stem from financing requirements, established supply chains, and the need to generate a return for shareholders:

'Industry are about what has sold in the past and therefore can attract funding to be built in the future, so that's always, by nature, conservative and backward-looking.' [Melbourne panel participant]

'We've got a small number of large builders ... they've got the materials all the way through the supply chain. They're highly efficient and they can just deliver products very efficiently ... there's no incentive to try and change.' [Perth panel participant]

Small-sized developments were seen by some panellists to be 'more agile' [Perth panel participant] than large developers in terms of the products they can produce. Across the three cities, panellists noted that the majority of medium-density infill development was coming from small-scale developers. However, as one panellist in Melbourne pointed out, the small-scale of these developers and the tendency to redevelop single lots on an ad hoc basis limits the quantity of supply they can bring to the market. In Perth, the prevalence of 'mum and dad' developers in the medium-density space was seen to be producing poorer quality products which, in turn, was seen to be impacting demand for medium-density housing, as well as creating community opposition to infill development.

2 Development WA was created in 2019 from a merger between the state's development agency Landcorp and the Metropolitan Redevelopment Authority. 
Skills and availability of tradespeople a challenge

Across all three cities, the skills and availability of building tradespeople was seen at times to be a barrier to residential supply generally, and also to innovation in building design and construction methods. In Perth, panellists expressed concern over the loss of tradespeople following the housing market downturn. They argued that the lack of a consistent construction workforce meant there has been limited opportunity to invest in skilling up the building industry in new technologies and housing products, with implications for the diversity of new supply.

\section{Housing market conditions}

The housing market was seen as an important factor in driving interest from the mainstream housing development industry in innovation, but in complex and often context-specific ways. Panellists explained that, by necessity, the development industry may be more willing to innovate in weaker housing market conditions when there are fewer purchasers for conventional build-to-sell products. However, panellists in Perth also pointed out that developers may be more willing to try diverse housing products in strong and rising housing markets in order to differentiate their development or to get a faster approval-especially in locations where the council desires specific diverse dwelling types.

In Sydney, declining affordability_particularly for first homebuyers — was seen to be a significant driver of interest in:

- delivering smaller homes that can be offered at a lower pricepoint-particularly in greenfield areas

- housing tenures beyond conventional ownership.

Some panellists in Perth believed that weaker housing market conditions in Perth had made home purchasers more conservative, reinforcing demand for conventional detached housing products. They also pointed out that in the relatively affordable Perth housing market, buyers are less willing to enter into more complex ownership arrangements when they can buy outright in another suburb. Those issues were less relevant in Sydney and Melbourne where, despite the recent decline in average house prices, affordability is still a significant challenge for many households - particularly first homebuyers.

\subsection{Summary and policy development implications}

The Investigative Panel findings presented in this chapter suggest that there are a number of significant gaps in the housing stock of Australia's major cities, as well as potential for alternative types and tenures of housing and development models to help to address those gaps. These include a need for the following:

- More diverse built form, particularly in lower-density suburban areas, which could be addressed through more medium-density housing.

- Medium- and high-density housing forms that better accommodate resident design and lifestyle preferences-such as housing delivered through a deliberative, non-speculative development model.

- Rental housing that can offer longer term security of tenure.

- More housing across tenures that is affordable to very low to moderate income households, including:

- housing delivered through community-led development models oriented to long-term affordability

- shared ownership housing

- affordable and social rental housing.

The findings reveal that the challenges for implementing and scaling up diverse housing types, tenures and development models consist of a mix of barriers and factors that might better be conceptualised as challenges or disincentives. 
Factors that can be considered real barriers to housing diversity include:

- zoning rules that do not permit diverse built forms

- the high cost of urban land, particularly in accessible locations suitable for infill development

- access to development finance, particularly for smaller start-up organisations and for projects delivering unique housing products or demonstrating alternative development models

- lack of consistent subsidies to support projects that deliver affordable housing

- lack of appropriate skills in the development and construction industry.

Factors that add to the cost of development, with potential negative implications for financial viability and the financial risk of developing diverse housing projects, include:

- development approval times and uncertainty as to whether an application will be approved-factors that can relate both to the assessment authority and the characteristics of the application itself

- the scale of development contribution requirements

- inflexible car parking controls.

Overall, panellists across the three cities agreed that statutory planning controls and development standards are essential for achieving a minimum level of amenity and liveability in residential developments. However, they emphasised that those settings should allow for variety in housing and include some scope for flexibility, particularly for projects that address a recognised unmet housing need. Panellists also emphasised that, in practice, the factors that impact on the viability of individual projects will:

- differ on a case-by-case basis

- differ depending on the housing model.

The delivery of diverse housing supply also depends on the willingness of developers to try new housing products, tenures and development models. While regulatory settings are an important factor in whether innovative projects can go forward, market conditions and skills and knowledge within industry itself are also important. With these considerations in mind, Table 4 summarises the key barriers and challenges for delivering diverse housing supply, as identified by expert panellists and interviewees.

Chapter 5 examines how all levels of government can potentially support more diverse housing supply through initiatives, regulatory reforms and programs that could help to address these barriers. 
Table 4: Overview of key barriers and challenges for delivering diverse housing supply

\begin{tabular}{|c|c|c|}
\hline Development stage & Main barrier or challenge & Dimensions / examples \\
\hline Pre-development & Information & $\begin{array}{l}\text { - Market for diverse housing products and alternative development } \\
\text { models not clear }\end{array}$ \\
\hline \multirow[t]{3}{*}{ Site acquisition } & Land cost & - High price of land / vendor expectations a challenge for: \\
\hline & & $\begin{array}{l}\text { - site amalgamation to supported master-planned redevelopment } \\
\text { that can incorporate different dwelling sizes, designs and tenures }\end{array}$ \\
\hline & & $\begin{array}{l}\text { the financial viability of non-speculative and affordable housing } \\
\text { developments }\end{array}$ \\
\hline \multirow[t]{8}{*}{ Development finance } & Access to finance & $\begin{array}{l}\text { - Lenders' willingness to lend for projects including unique housing } \\
\text { products or a different development model (i.e. higher perception } \\
\text { of risk) }\end{array}$ \\
\hline & & - Lender's willingness to lend to small, start-up organisations \\
\hline & & - Undervaluation of new housing products due to lack of comparables \\
\hline & & $\begin{array}{l}\text { - Access to mortgages and repayment costs for buyers of unique } \\
\text { housing products or housing delivered through different development } \\
\text { models }\end{array}$ \\
\hline & Upfront capital costs & $\begin{array}{l}\text { Requirement for developers of projects demonstrating new } \\
\text { development models to fund site acquisition and planning } \\
\text { application before getting finance }\end{array}$ \\
\hline & Cost of finance / loan terms & - Finance costs higher where lenders perceive higher risk \\
\hline & & $\begin{array}{l}\text { - Loan terms not long enough to lower repayments to viable levels } \\
\text { for community-led and affordable housing projects }\end{array}$ \\
\hline & $\begin{array}{l}\text { Subsidy gap for affordable } \\
\text { housing projects }\end{array}$ & $\begin{array}{l}\text { - Projects delivering affordable housing for low and moderate income } \\
\text { groups need additional subsidy to be feasible }\end{array}$ \\
\hline \multirow[t]{8}{*}{ Planning } & Zoning (built form) & - Limited sites zoned for medium and higher residential densities \\
\hline & & $\begin{array}{l}\text { - In medium- and high-density zones, developments that do not } \\
\text { constitute the highest and best land use permitted (e.g. market- } \\
\text { rate dwellings in residential apartment building) are unlikely to } \\
\text { be financially viable }\end{array}$ \\
\hline & Potential permissibility & $\begin{array}{l}\text { - Diverse housing types not named as potentially permissible uses } \\
\text { in planning schemes, meaning that their permissibility is unclear }\end{array}$ \\
\hline & Car parking requirements & - Add to development costs and can impact viability \\
\hline & & $\begin{array}{l}\text { - Depending on project objectives and location of development } \\
\text { site, occupants may not own cars }\end{array}$ \\
\hline & $\begin{array}{l}\text { Development contribution } \\
\text { requirements }\end{array}$ & - Add to development costs and can impact viability \\
\hline & $\begin{array}{l}\text { Development assessment } \\
\text { time frame and outcome }\end{array}$ & $\begin{array}{l}\text { - Can increase landholding costs and overall development costs } \\
\text { and impact viability }\end{array}$ \\
\hline & & - Additional costs if decisions need to be appealed \\
\hline Construction & $\begin{array}{l}\text { Industry skills and } \\
\text { knowledge }\end{array}$ & $\begin{array}{l}\text { - Lack of experience and skills in diverse dwellings forms, dwelling } \\
\text { configurations, construction methods and materials }\end{array}$ \\
\hline
\end{tabular}

Source: Authors. 


\section{Potential levers for government to support more diverse housing supply: views from the Investigative Panels}

- While interest in housing innovation needs to come from industry, all levels of government can potentially play a role in de-risking diverse housing projects and supporting their viability through subsidies in the form of land, grants and access to special mortgage products for purchasers of diverse housing products, as well as through access to development finance and special development assessment pathways.

- State and local governments can ensure that zoning and the permissibility of different residential types within zones allows for or requires a range of housing types and tenures in different locations. Where appropriate, flexibility or concessions on development requirements and fees and charges could also help to support the viability of diverse housing projects, particularly those that deliver below-market-rate housing.

- While regulatory reform and planning-based concessions can play an important role in supporting the viability of projects that do not constitute the highest and best land use, they are insufficient on their own to enable projects that deliver housing that is affordable to low and moderate income groups. 
- All levels of government can take a leadership role in communicating the need for diverse housing supply. State governments can establish targets and strategic directions for diverse housing supply, and support innovation by demonstrating diverse housing projects that are replicable by industry. Local governments can work with communities to build support for housing designed to meet the full spectrum of local needs; they can also help affordable housing developers and community organisations and developers undertaking new development models to navigate the planning system.

- Commonwealth and state governments can also collect and make available detailed data on housing needs, preferences and supply to provide an evidence base for housing innovation and to evaluate the outcomes of regulatory reforms, programs and other initiatives intended to encourage more diverse types and tenures of housing and increase affordable housing supply. 
This chapter continues to distil the findings of the Investigative Panels and four interviews. It focusses on panellists' perspectives on the role that all levels of government could play in supporting more diverse housing supply. The results are drawn from panellists' responses to questions posed in the last component of each panel meeting, These related to:

1. The identification of existing and emerging policies, regulatory settings and or financial incentives that support diverse housing supply in different contexts, the structure of those regulatory settings and financial incentives and potential opportunities and barriers for their scaling.

2. Potential for regulatory reforms and incentives at all government levels to support diverse housing supply

\subsection{Land}

Across the three cities, panellists saw government land as a significant lever to support diverse housing supply - particularly projects delivering affordable housing for a broad range of income groups:

'Something that state governments can do-and the biggest thing [in] my perspective for delivering diversity of housing from a developer's perspective-is access to sites.' [Perth panel participant]

One panellist remarked that the benefit of using government land to support diverse housing supply is that it gives government additional scope, beyond the planning system, to require particular outcomes in the public interest - such as diversity of dwelling types, environmental sustainability and other community outcomes; see, for example, Boxes 1 and 2. While panellists recognised the political constraints around gifting or selling land at reduced rates to facilitate diverse housing projects, panellists argued that achieving public benefits, particularly in terms of addressing unmet housing need, should be an obligation for governments in disposing of land:

'There is, I believe, an obligation to use local, state and federal land to actually [support] this supply.' [Sydney panel participant]

Panellists discussed different means through which governments could support diverse housing projects using public land, apart from discounted sale. These options are discussed below.

Leasing

Panellists from different sectors pointed out that land could be made available for housing projects meeting defined criteria through 99-year leases, or even shorter term leases. Panellists pointed out that governments have land that is being held for future purposes but may not be required for a significant period of time:

'They've got prime land around rail corridors and things that maybe they might need in 50 years' time, so why not find a good use [in the] meantime?' [Sydney panel participant]

It was also suggested that sites awaiting redevelopment could be used for temporary housing-for example, to house the homeless. This is a model that has been demonstrated in cities internationally.

Panellists argued that long-term leases might be favourable to governments as an alternative to permanently disposing of a public asset. Long-term leasing-as opposed to sale-was also seen to have benefits for some developers and CHPs because it would not require upfront capital outlay for land purchase. This was seen to offer greater scope for delivering affordable housing:

'You cut out the land cost and put it on a long-term lease arrangement, you've got more chance of getting affordable housing on that government land than selling the land and then having to equate that into the cost of the product.' [Melbourne panel participant]

However, panellists also questioned whether organisations would have issues accessing construction finance where they do not own the site. 


\section{Joint venturing}

One panellist from the development industry saw joint venture models-where government puts in the landas having significant potential to deliver structurally diverse, mixed-tenure projects. As the panellist explained, drawing on the experience in WA, not having to purchase land and fund holding costs frees up a lot of capital, which can support delivery of lower cost housing forms. Another panellist from WA pointed out that when government puts in the land, they have power to impose restrictions regarding the type of product that can be delivered and ensure diverse housing outcomes.

\section{Extended settlement}

One panellist pointed out that even where land is sold, an extended settlement period can support development viability and reduce financial risk - offering similar benefits to joint venturing. A panellist pointed out that in Germany, sites earmarked for innovative projects are sold to developers at market rates, with the price known in advance so it can be factored into viability assessment. An extended settlement period then gives the developer time to get development approval and find purchasers or investors without having to pay holding costs.

Maximising opportunities from public housing estate redevelopment

In discussing the potential role of government land in supporting more diverse housing supply, one panellist pointed out that governments could better maximise opportunities to deliver affordable housing as part of the redevelopment of lower-density public housing estates. The practice of delivering a 70/30 per cent mix of private and social housing, the panellist argued, was potentially missing opportunities to deliver more affordable housing:

'I think there's a value in ... doing proper financial feasibility studies, as you would if you were, let's say, a private developer. Saying, 'How do you optimise these sites rather than just this 30 per cent social housing?' You need to look at what's the value of the land and the development overall and then it's not 30 per cent, it might be 50 per cent [affordable housing]; or maybe it's 20 per cent, but it needs to be done like you would do any other development and look at ... what's the actual output back for affordable housing.' [Sydney panel participant] 
Box 1: Master planned redevelopment on underutilised government land (Montario Quarter)

\section{Montario Quarter (Shenton Park, WA)}

Montario Quarter is an infill development on a 15 ha former hospital site in Perth, Western Australia. It is adjacent to Shenton Park train station and close to Perth CBD. A minimum of 1,100 dwellings will be developed at the site when it is complete.

The site has been masterplanned by the government land developer, Development WA, and will be delivered by Fini Group and Iris Residential/Primewest.

The redevelopment will deliver a range of housing types, including detached houses on small lots (most under 350 square metres), townhouses and apartments ranging from one to three bedrooms. The precinct will also include commercial spaces, parklands and improved pedestrian and bicycle paths. An overarching aim of the masterplan is to support intergenerational living.

The State Department of Planning is the determining authority for development applications pertaining to the site. Development WA has developed detailed design guidelines for small lot detached homes.

Montario Quarter is also demonstrating sustainable development, with a 6-star rating for the Green Star Communities accreditation.

Keys to success:

- Large, underutilised government-owned site.

- Masterplanning and leadership by Development WA.

- Extensive community consultation and working with state, local government and local community groups.

- Design guidelines for small lot homes.

Further information:

- Montario Quarter

http://www.landcorp.com.au/Residential/Shenton-Park/

Source: Authors (information derived from Development WA 2020b).

Box 2: Master-planned development on underutilised government land (Edmonson Park and Ed.Square)

\section{Ed.Square (Edmonson Park)}

Ed.Square at Edmonson Park in western Sydney is a project in partnership with Fraser Property Australia and disability housing provider Summer Housing.

The Ed.Square project is located within a 24 ha site framed around the Edmondson Park train station, within the Edmonson Park development in Sydney's South West Priority Growth Area. Edmonson Park has been masterplanned by government developer Landcom on a former Department of Defence site. The residential component of Ed.Square will comprise 892 terraces and townhouses and 992 apartments, including a 19-storey residential tower.

Fraser Property Australia has partnered with Summer Housing, a not-for-profit disability housing provider, to design 10 apartments in Ed.Square specifically for young people with disabilities, meeting the High Physical Support housing benchmarks under the National Disability Insurance Scheme. An additional apartment will be allocated to an on-site support worker.

Keys to success:

- Masterplanned site on underutilised government land.

- Partnerships between developer and not-for-profit housing provider.

- Financing incentives from government disability support agency.

Further information:

- https://www.frasersproperty.com.au/nsw/ed-square

Source: Authors (information derived from South West Voice 2019; Frasers Property 2020). 


\subsection{Leadership, demonstration and education}

Panellists across the three cities called for government leadership in:

- elevating the importance of diverse housing supply in urban policy

- educating communities about the need for diverse types and tenures of housing

- demonstrating these diverse housing types.

Requirement to plan for diverse housing

Across the cities, panellists pointed to the need for governments-particularly state governments, but also the federal government-to identify housing affordability and diverse housing supply as policy priorities:

'It's about leadership, you know ... if it's on the premier's priority list ... it will happen. So, you need strong leadership.' [Sydney panel participant]

Panellists in all three cities saw strategic planning targets as a potentially important government tool for articulating diverse housing need and situating diverse housing as a policy priority.

In Sydney and Perth, metropolitan strategies include targets for infill housing development and housing supply overall. Panellists argued that these supply targets should be more detailed or differentiated-for example, by articulating desired housing outcomes for particular precincts, or setting targets for different housing forms and tenures. Housing affordability targets were also suggested.

In Melbourne, panellists also pointed to the need for the Victorian Government to set differentiated targets—or to define expected outcomes - particularly for major renewal areas based on existing and anticipated housing needs, particularly in terms of dwelling sizes and configurations and affordability levels.

\section{Education and communicating need}

Panellists also saw a role for all levels of government in communicating the need for diverse housing supply, and making councils and communities aware of (and familiar with) diverse housing types:

'I think government has a really important education role about what diverse typologies are.'

[Sydney panel participant]

Panellists explained that one aspect of this communication should be clarifying terminology and definitions. Particularly in Sydney, panellists remarked that terminology needs to more accurately reflect the nature of diverse housing products. For example, they pointed out that use of the term 'boarding house' to describe contemporary single-room occupancy accommodation has negative connotations for many community members. Likewise, panellists pointed to the need for greater differentiation of products in the discussion of medium-density housing, with many members of the public associating medium density with mid-rise apartment buildings, fuelling concerns about infill development in established suburbs.

Panellists suggested that government strategies for communicating the benefits of diverse housing supply to communities and government agencies should focus on the following:

- Opportunity for non-speculative and affordable housing development to smooth ups and downs in supply cycles and construction activity.

- The economic or productivity case for increasing affordable housing supply and housing options in a range of locations-which was seen as particularly important for gaining treasury support.

- Personalising the discussion around the need for more diverse housing by focussing on real community members and their housing challenges. 
In terms of the last point, panellists in Melbourne highlighted a piece of work by Moreland Council (described in the Box 3 as a good example of messaging housing need through personal stories. At the community level, panellists saw a crucial role for local governments in building support for a broader range of infill housing types and tenures to address the full spectrum of local housing needs.

Box 3: Communicating housing need (Moreland Council)

\section{A Home in Moreland: the housing we need now and in the future}

This research piece prepared for Moreland Council provides a detailed overview of housing needs in the community, how housing is adjusting to those needs, and the housing needs of the future to 2036. The document incorporates six ethnographic pieces focussing on different people's housing stories and needs, intended to reflect the diversity of the Moreland community, and the housing challenges and decisions community members face or have recently faced.

Further information:

- https://www.moreland.vic.gov.au/globalassets/areas/social-policy/final-report-a-home-in-moreland.pdf

Source: Authors (information derived from id [the population experts] 2018).

\section{Demonstration}

Panellists also saw a role for governments, particularly at the state level, in demonstrating diverse housing models and structurally diverse, mixed-tenure projects:

'I think it does come down to demonstration, good demonstration around the place more than anything.' [Sydney panel participant]

In all three cities, panellists gave examples of how governments-primarily through government development agencies - are already working to demonstrate diverse housing sizes and designs, mixed tenures and environmental sustainable developments-see the example of White Gum Valley in WA in Box 4. In Sydney, there was discussion of how the government developer Landcom has purchased a site specifically to demonstrate different tenure models. The purpose is to demonstrate the value of affordability and how different tenures can deliver positive social outcomes.

Building on practical experience, panellists suggested that demonstration projects by government development agencies could play an important role in demonstrating:

- the value of delivering more affordable new housing supply

- the viability of different tenure models and new construction methods.

However, panellists emphasised that to be effective in driving change, demonstration projects need to be replicable. As one panellist explained, demonstration projects should not be 'too detached from the norm' and should also 'assist in breaking down policy barriers ... for those that follow behind'. [Perth panel participant]. This suggests that demonstration projects provide an important opportunity to generate detailed understanding of regulatory and other barriers to diverse housing supply, and provide opportunities for broader scale reform.

In addition to large-scale, state-led demonstration projects, panellists also pointed to the need for governments to support demonstration of diverse housing models from the bottom up. In particular, they saw an important role for local government in supporting community-led housing initiatives. As one panellist pointed out, there is currently no onus on local governments or resourcing for them to work with stakeholders to develop their own solutions for housing. They stated that state governments could support bottom-up innovation by making funds available to local government and directly to community groups to support community-led housing initiatives. Local governments could help to support affordable housing developers and community-led housing projects by helping organisations, particularly recent start-ups, to navigate the planning system. 


\section{Box 4: Government demonstration (White Gum Valley)}

\section{White Gum Valley residential development (White Gum Valley)}

The White Gum Valley development is being built on a 2-hectare site that was previously home to the former Kim Beazley School, in Fremantle, Western Australia.

The precinct is masterplanned by Development WA, and incorporates different types of infill housing with the aim of being flexible to different residents' needs, and includes a community housing project, outdoor amenities, and alternatives to car-based travel.

The precinct has a number of social, economic and environmentally positive outcomes. The design was intended to maintain existing neighbourhood characteristics and trees and to demonstrate energy efficient design with the aim of reducing grid energy consumption by 60 per cent.

To encourage social diversity and support the creative industry, LandCorp, Access Housing and Sustainable Housing for Artists and Creatives (SHAC; a Fremantle-based cooperative) developed part of the precinct as a community housing development for local artists and their families.

Further information:

- White Gum Valley's Initiatives for an Innovative and Sustainable Community https://developmentwa.com.au/projects/residential/white-gum-valley/overview

Source: Authors (information derived from Development WA 2020c).

Government leadership needed for shared equity

Panellists pointed out that, regarding leadership and demonstration, shared equity schemes only work on a mass scale and are difficult to implement at the level of individual projects. Therefore, state government leadership was seen as essential to enabling shared equity as an alternative ownership tenure. As discussed in Chapter 3, the WA Government has a longstanding shared ownership home loan program for eligible moderate income households. Also, the Victorian Government recently introduced a small-scale scheme, initially open to up to 400 moderateincome households. At the time of the panels, no such program had been introduced in NSW.

\subsection{Reform to zoning and statutory planning rules}

Zoning for diversity

Panellists argued that rezoning of land to allow for medium and even higher densities of development in a broader range of locations could help to support the supply of structurally diverse housing and, by extension, scope for greater tenure diversity.

However, they also warned that 'over zoning' land - that is, allowing higher densities ahead of market demandcould also be counterproductive to generating new supply. In this context, zoning specifically to allow development up to medium densities was seen as an effective way to support more diverse infill housing supply in established lower-density areas.

Panellists also suggested that zoning rules could be reformed to allow specific types of diverse housing in locations where they would not typically be permitted. This includes allowing:

- small-scale medium-density developments in low-density residential zones-for example, four-unit manor homes and small-scale townhouse developments

- residential development in non-residential zones where land-use conflicts can be managed, such as light industrial and commercial zones-but only for purpose-built rental or affordable housing projects. 
Allowing residential development in non-residential zones was seen as a way to support access to sites for rental housing projects by limiting competition from build-to-sell residential developers. This approach was also seen to have the added benefit of providing affordable live-work opportunities. However, panellists pointed to the need to investigate whether requirements for additional soundproofing of residential units, for example, would impact viability.

Other ideas for reforms to zoning and development control policies to support diverse housing supply in jurisdictions where these approaches are not currently permitted, included:

- no longer allowing one-for-one replacement of single dwellings in well serviced areas or on corner lots-that is, requiring a minimum of a dual occupancy

- enabling subdivision of large houses into multiple units - currently, the main issue was seen to be fire-safety ratings

- allowing unused land or sites awaiting redevelopment to be used for housing - particularly to house people who are homeless or at risk of homelessness-without requiring rezoning to residential status

- making it easier for empty buildings to be used temporarily for affordable housing or accommodation of people who are homeless.

Panellists recognised that further consideration and research would be needed on how to operationalise these ideas.

\section{Broaden use of inclusionary zoning}

A potential reform to the planning system raised consistently across the three panels was the need for increased use of inclusionary zoning-a requirement that developers contribute to affordable housing supply as part of new development. This was particularly seen to be the case where public infrastructure projects and other public actions are likely to increase property values.

Panellists saw inclusionary zoning as having a number of positive attributes, compared to policies to incentivise the private sector to deliver affordable housing. One of these attributes was the extent of policy certainty that an inclusionary zoning scheme can offer, in comparison to negotiated, voluntary contributions. This was particularly emphasised in Melbourne, where provisions for voluntary negotiation of affordable housing contributions had recently been introduced into the planning system:

'I actually think the development industry would appreciate some guidance, because we now are undertaking voluntary agreements...for every site. It takes time ... [There] is ongoing negotiation because there's no set minimum or anything. So, if the government came out with [an inclusionary zoning policy], even if it was scaled and even if it was grandfathered, at least they would have more certainty.' [Melbourne panel participant]

Panellists also pointed out that inclusionary zoning requirements-as opposed to incentives like density bonuses - may be less likely to undermine the legitimacy of the height and density limits prescribed in local land use plans. This is because inclusionary zoning requirements apply to all development and maintain existing height and density controls, unlike voluntary incentives which 'trade off' density controls for affordable housing. It was implied that this approach might be more acceptable to communities, as density is a significant issue in community opposition to infill development.

Panellists argued that unless required to do so through the planning system, private housing suppliers will not deliver housing that is affordable to lower income groups, particularly in areas where it is needed, such as close to jobs and transport:

'I think inclusionary zoning-actually making it a requirement that in the areas where you need diversity that it's a requirement of the development sites-is going to need to happen. Because if you leave it to the market, highest and best use will prevail-and that's not around diversity of housing.' [Perth panel participant] 
However, panellists did argue that inclusionary zoning should be implemented incrementally over time, in order to give industry lead time.

Panellists in different cities pointed to South Australia as a positive example, as it has a statewide inclusionary zoning scheme (SA Department of Human Services 2020). An overview of the SA approach is given in Box 5. A key attribute of the SA policy was seen to be flexibility in how the inclusionary zoning requirement is addressed. Panellists pointed out that where CHPs are funded to purchase dwellings, the requirement can be addressed through social housing inclusion. However, the requirement can also be met through the sale of properties at a discounted market rate. This flexibility was seen to have the benefit of allowing the policy to work in the context of different funding opportunities, while also resulting in housing at different points on the housing continuum.

While generally positive about inclusionary zoning as a mechanism to support diverse housing supply, panellists pointed out that the approach is unlikely to result in sufficient levels of affordable housing supply relative to need. They argued that the approach should be in addition to direct government support for new affordable housing supply, rather than in place of it.

Box 5: South Australia's statewide inclusionary zoning scheme

\section{Inclusionary zoning in South Australia}

This policy, introduced in 2005, requires developers of all 'significant developments' in areas designated an affordable housing zone to provide 15 per cent affordable housing.

To meet the 15 per cent requirement, developers are encouraged to partner with or sell to a CHP or Defence Housing, or to sell units to eligible buyers at or below a defined affordable pricepoint.

Further information:

- https://www.sa.gov.au/topics/planning-and-property/land-and-property-development/planning-professionals/ developer-responsibilities-for-affordable-housing

Source: Authors (information derived from SA Department of Human Services, 2020; see also Gurran, Gilbert, Gibb et al. 2018).

Concessions and exemptions to reduce development costs

Panellists also pointed out the potential for concessions on development contributions, development fees and inclusions such as car parking to support the viability of diverse housing projects-particularly those delivering below-market-rate housing. GST exemptions and waiving of council rates were also discussed as possible concessions.

However, one panellist argued that planning and other financial concessions need to be project-specific, as the appropriateness of concession and their effects on a project's financial viability will be different in different cases. This suggests that while concessions could be enabled under state planning policy, they should be designed and offered at the local government level, taking account of different housing market and development contexts.

\section{Update local plans to better align with strategic goals}

Beyond specific policy reforms, panellists emphasised the need to update local planning schemes and development control policies to better align with planning goals and strategies for diverse housing. Panellists argued that this would help address misalignment between the aims and objectives of metropolitan and local planning strategies and the statutory planning controls that are actually in place. However, panellists noted that updating plans is time consuming and resource intensive, and that councils need to be adequately resourced to undertake local plan updates-particularly when new metropolitan strategies are introduced. 


\subsection{Reform to development assessment processes}

Panellists also discussed ways that reform to development assessment processes could better enable diverse housing supply. Panellists suggested that depoliticising development assessment decisions for diverse housing projects meeting specified criteria could support more timely assessment and approval. Panellists also argued for special development assessment pathways or expedited approval processes for development applications by CHPs or developers that include affordable housing in their schemes.

Planning application decisions for innovative and affordable projects

Panellists discussed a number of ways to minimise the perceived influence of community opposition in local planning decisions regarding higher-density and affordable housing projects. One of these was through existing pathways for ministerial determination of particular classes of development, or development in particular locations. Panellists pointed out that ministerial call-in powers are politically controversial and, in some jurisdictions, have been used minimally. However, they were also seen to be effective in enabling development that might not otherwise have been approved under local government planning policies and assessment processes.

In Sydney, panellists discussed how the Thornton development (see Box 6 for project overview), which was highlighted by panellists as an excellent example of house type and tenure diversity, was approved by the Minister for Planning under a former assessment pathway for major projects. That provided flexibility to set development controls based on the master plan, including having no minimum lot sizes. Particularly in Melbourne, panellists saw ministerial determination as a way to exempt diverse housing projects from third-party appeals. Another suggestion was to have specific types of diverse housing projects, for example, those delivering affordable housing or addressing a defined unmet housing need to be assessed by regional-level development assessment panels comprised of local political representatives as well as professional experts.

\section{Box 6: Structural and tenure diversity through a state-led masterplan (Thornton)}

\section{Thornton (Penrith, NSW)}

Thornton at North Penrith in western Sydney includes terraces, different designs of semi-detached homes, zero-lot-line detached houses, apartments and affordable rental and social housing.

The project is located on a 41-hectare former defence site adjacent to Penrith rail station. It was purchased by Landcom in 2011 and masterplanned by UrbanGrowth NSW to demonstrate the 21st Century Living Program. It aimed to achieve transit-oriented development with a diversity of housing types and pricepoints.

The planning controls defined basic standards for solar access and site setbacks, but allowed for flexibility in other areas. Architectural styles, landscaping and other aspects of design were defined in design guidelines, supported by a design kit developed by UrbanGrowth NSW (UrbanGrowth NSW 2014). The subdivision included four standard lot sizes for terraces, designed to minimise land area while maximising usable dwelling space.

The scheme includes the mixed-tenure Harts Landing development. Developed by PAYCE in conjunction with Evolve Housing, it includes 268 apartments, of which 128 are affordable rental housing (discounted market rent under the former NRAS program) and 10 units of social housing (Evolve Housing 2018).

Keys to success:

- Planning controls defined following development of a vision and agreement of key principles for the development.

- Government leadership in undertaking market research and demonstrating design innovation.

- Partnerships - for example, between developer and affordable housing provider.

Further information:

- Thornton: North Penrith-21st Century Living https://www.landcom.com.au/assets/Downloads/Research-and-Learning/ce7521938a/Thornton-21st-Century-Living.pdf

- Harts Landing development https://evolvehousing.com.au/100m-evolve-housing-development-delivers-268-properties/ 
Priority development assessment for innovative and affordable housing projects

Across the cities, panellists also argued that priority development assessment for proposals by CHPs and not-forprofit organisations could help to enable non-speculative and affordable housing projects, by reducing the time and costs associated with development approval. Others argued that this could be extended to include private developers that include a proportion of affordable housing in their development.

'The fact that they've got X per cent of affordable housing should mean they're at the top of the pile ... in the local government's big pile ... And you would imagine the private sector could say, "Well, I want to be at the top of that pile."' [Sydney panel participant]

\subsection{Funding affordable housing and supporting the not-for-profit housing sector}

Panellists emphasised that delivering housing for low-income groups requires subsidy, as project costs cannot be covered by revenue alone. They pointed out that regulatory reform alone and design-based approaches to producing lower cost housing are not enough to enable affordable housing projects for low-income groups at any scale, as there are limits to what the market will deliver:

'The obsession in saying the market will deliver and we should get out of the way: that's where these problems keep coming up.' [Sydney panel participant]

Panellists also argued that a single incentive or policy alone is unlikely to facilitate new affordable housing supply. Rather, a package of incentives is required:

'When you deliver affordable housing, you need dispensations along the way because there are so many barriers and challenges to deliver ordinary housing, to have something that's sub-marketsomething that's less than the highest return that you can get for that particular outcome-you need many incentives and dispensations to do it.' [Sydney panel participant]

Direct funding for affordable housing

Across the cities, panellists argued that governments should have a stronger focus on supply-side measures to address the housing needs of lower income groups:

'If we can start to see housing as essential infrastructure, and then it forms part of the infrastructure expenditure that all levels of government spend money on, then we might get somewhere.' [Melbourne panel participant]

In this context, several panellists expressed concern about the sustainability and inefficiency of demand-side affordability measures aimed at supporting low-income households in the private rental market:

'I'm concerned that [the demand-side] subsidy model is seen as potentially the solution into the future, as against actually investing in supply and releasing capital for supply, because it's incredibly inefficient.' [Melbourne panel participant]

The same panellist went on to point out that Commonwealth Rent Assistance payments to eligible low-income renters involves very large sums of money and that there needs to be consideration of how some of that money might actually be turned into equity or capital to provide housing.

They explained that while the NHFIC, which provides finance for community housing providers, is a very helpful recent development, it is unlikely to result in significant new supply of affordable housing:

'NHFIC is putting out some cheaper money, and that's - it's helpful, but it's just ... [not enough].'

[Melbourne panel participant] 
Ideas for how consistent funding for affordable housing could be established included:

- Government bonds to publicly fund social housing development.

- Allocating a small proportion of stamp duty revenue-for example 1 per cent-to fund social housing development.

- A program similar to the former National Rental Affordability Scheme (NRAS), and the US Low Income Housing Tax Credit (LIHTC) program (which NRAS was modelled on) to support development of affordable rental housing supply.

Box 7: Mixed-tenure housing project delivered by a CHP (Macarthur Gardens)

\section{Macarthur Gardens (Campbelltown)}

Macarthur Gardens is a mixed-tenure development including affordable rental housing in Campbelltown, western Sydney. The development is adjacent to the Macarthur train station and Western Sydney University Campbelltown campus.

The Gardens were developed by the community housing provider, BlueCHP. The project includes 101 apartments across three towers. Of those, 45 apartments were sold on the private market and 56 are let as affordable rental housing. BlueCHP has retained 44 of the affordable units (under its vesting commitment), and the remaining 12 were sold to private investors. The scheme received funding under the former National Rental Affordability Scheme (NRAS).

The development is the largest residential timber building in Australia, made of sustainable Cross Laminated Timber (CLT). This construction method allowed for a faster and less costly build.

Keys to success:

- Mixed private market and community housing financing model.

- Supported by the former NRAS program.

- Cost-saving construction technique.

Further information:

- https://bluechp.com.au/projects/macarthur-gardens/

Source: Authors (information derived from BlueCHP Ltd. 2016).

Lending for diverse housing

Panellists also pointed to the need for government to play a role in supporting access to finance for projects that struggle to obtain finance or to obtain finance on terms that support project viability - particularly projects demonstrating new housing products and development models.

In Perth, panellists pointed out that there are already models in place that could be extended and replicated, such as the national level Clean Energy Finance Corporation and Keystart, in WA. One panellist suggested that a program based on Keystart could be developed to provide loans to developers wanting to develop diverse housing - particularly purpose-built rental models, which currently struggle with access to finance.

Panellists also highlighted international examples to potentially emulate and draw lessons from. One panellist pointed out that in the US, the federal loan guarantee program (Freddie Mae and Fanny Mac) has been important in enabling non-speculative housing projects and the Low Income Housing Tax Credit (LIHTC) program. Referring to Germany, another panellist explained that KfW Bank, a government bank, only lends to environmentally sustainable projects. The panellist explained that availability of finance through that bank has been a major driver of the expansion of the Baugruppen movement (whereby future residents take shared responsibility for the design and develop of their housing, in contrast to the speculative, developer-led model). 


\subsection{Data collection, reporting and monitoring}

Panellists also identified a need for Commonwealth and state governments to engage in more detailed data collection and reporting in relation to housing needs and supply. More comprehensive data and analysis was seen as essential to help:

- small housing developers understand niche demand, and to innovate to meet unaddressed housing needs

- CHPs to minimise research and consultancy costs

- local governments accurately assess housing needs and understand the existing housing stock, particularly to inform their local housing strategies and planning policies

- communities better understand community housing needs, and the need for more diverse housing supply in their area

- government to better understand where there is need for specific housing products versus housing subsidy

- governments be able to monitor the outcomes of policies and programs designed to enable more diverse housing supply.

In relation to government monitoring of policy outcomes, panellists pointed out that high-level indicators of dwelling approvals and completions is not fine-grained enough. More detailed data is needed in order to:

- understand how planning policies and the wider planning system are performing in relation to housing supply diversity

- provide the evidence needed to adjust policies if necessary.

\subsection{Summary and policy development implications}

Drawing on their own experience and expertise and Australian and international examples, panellists pointed to a range of ways that all levels of government could help to support more diverse housing supply in Australian cities - particularly projects that deliver affordable housing or address an unmet housing need. One important way governments can support the viability of such projects is through subsidy, in forms such as:

- land

- capital grants

- access to special mortgage products for purchasers of housing delivered through innovative models.

Other ways that governments can address challenges within the development process include the following:

- Supporting access to development finance or grants, particularly for start-up organisations and for projects that deliver more affordable housing products.

- Ensuring zoning and development control policies allow for or require diverse types and tenures of housing.

- Allowing exceptions to land-use criteria for specific types of projects such as rental housing and affordable housing projects.

- Granting concessions, where appropriate, on development fees, contributions and development standards such as car parking to support the feasibility of projects that deliver affordable housing or address a defined unmet housing need.

- Streamlining development assessment for projects that include affordable housing or address a defined unmet housing need. 
5. Potential levers for government to support more diverse housing supply: views from the Investigative Panels

Panellists emphasised that government leadership is essential, particularly in communicating the need for diverse housing to communities and across government. They also saw an important role for state and local government in working with the development industry to demonstrate and build knowledge of diverse housing products and models, including supporting bottom-up and community-based innovation and demonstration. Participants further emphasised the need for more detailed data collection and reporting by Commonwealth and state governments on aspects of housing affordability, housing needs and demand and housing supply.

Overall, panellists saw an important role for government in supporting industry innovation and in fostering the institutional change required to better enable diverse housing supply. However, as the vast majority of new housing supply in Australian cities is delivered by the private development sector, they pointed out that the drive for innovation and the necessary skills to support it also has to come from within industry itself. The concluding section, which follows, outlines the policy implications of these findings. 


\section{Policy development options}

- According to the $\mathbf{5 0}$ built-environment and housing industry experts who shared their views, a more diverse housing stock in Australian cities would enable households to better meet, first and foremost, their housing needs and then their housing aspirations. It would support greater mobility in the housing system, improved affordability and more efficient use of the existing housing stock.

- Gaps in current provision include medium-density housing forms, particularly in existing suburbs; medium- and higher-density housing forms that are designed for a broader range of households and lifestyle preferences; rental housing that can offer long-term security of tenure, including rental housing that is affordable to low- and moderate-income households; lower cost and assisted home ownership options suited to different household types; and supply of social housing.

- Main barriers to delivering diverse types and tenure of housing and development models can include: difficulty accessing appropriately zoned sites; high land costs; challenges obtaining development finance for non-traditional housing products and development models; lack of flexibility in development controls; uncertainty regarding the permissibility of unique housing or development types, long and uncertain development assessment processes; lack of subsidies to support the viability of below-market-rate housing; and a lack of skill and expertise regarding diverse housing types and models in the housing industry. 
- The drive for innovation in new housing supply has to come from the development industry, which delivers almost all new housing in Australia. However, all levels of government can play a role in enabling diverse housing supply through planning policies that clarify and support the permissibility of diverse housing types and tenures; accelerated approval processes for applicable projects; and support for delivery of below-market-rate housing through direct subsidies and access to land and finance.

- All levels of government can play a leadership role in supporting more diverse housing supply, including by communicating the need for diverse housing supply; establishing detailed targets for different housing types, tenures and affordability levels, either metropolitanwide or for major renewal areas; and working with industry and community organisations to demonstrate diverse housing projects and work through viability issues. 


\subsection{Why is more diverse housing supply needed and what are the opportunities to diversify housing in Australian cities?}

The findings of this study point to the need to look beyond higher-density built form in conceptualising diverse housing in Australia. Price and affordability, tenure, governance arrangements and financing arrangementsas well as construction techniques and materials - are all important elements of housing diversity. Further, household needs and preferences should be central in assessing the demand for different types of residential accommodation. That requires more detailed understanding of housing needs and preferences across age cohorts, income groups, household types and lifestyle aspirations.

According to the 50 built-environment and housing industry experts who shared their views as part of the six Investigative Panels, a more diverse housing stock in Australian cities would enable households to better meet, first and foremost, their housing needs, and then their housing aspirations. It would support greater mobility in the housing system and more efficient use of the existing housing stock.

Expert panellists and interviewees identified a number of gaps or shortfalls in current housing supply across the three cities. They spoke of a need for the following:

- More diverse built form in lower-density suburban areas-particularly medium-density housing forms.

- Medium- and high-density housing forms that can better accommodate resident design and lifestyle preferences, such as housing delivered through community-led and deliberative development models.

- Rental housing that can offer increased security of tenure compared to the current private rental sector.

- More housing across tenures that is affordable to very low- to moderate-income households, including housing offered through assisted ownership models and through development models oriented to long-term affordability, and social and affordable rental housing.

\subsection{What are the major barriers for increasing the diversity of new housing supply?}

The Investigative Panels and additional interviews revealed a range of challenges-or, as one expert put it, 'missed opportunities'-for delivering diverse housing supply, including the implementation and scaling up of emerging diverse housing types and development models.

Major factors include the following:

- The high cost of land in Australia's major cities.

- Difficulty accessing appropriately zoned sites in locations where diverse housing types and development models are feasible.

- Challenges obtaining development finance for non-traditional housing products and delivery models.

- Access to finance for small, start-up organisations interested in delivering innovative housing developments.

- Lack of flexibility in development controls to allow for design innovation or to support the feasibility of projects with affordability objectives.

- Uncertainty regarding the potential permissibility of types of housing or development.

- Uncertainty around the time frame and outcome of development assessment decisions.

- Lack of subsidies to support the viability of projects delivering below-market-rate housing.

- Lack of appropriate skills, experience and expertise in the development and construction industry. 
In a context where lending practices support build-to-sell development and small-scale housing investment, and where land is generally sold for the highest and best-use value, projects delivering other housing tenures and below-market-rate housing products face significant challenges in competing for land and development finance.

Developers and organisations looking to deliver diverse housing types and implement diverse housing development models are often small scale-and in some cases, start-up_organisations that do not have a development track record or significant balance sheets, which exacerbates difficulties in securing finance. Projects delivering housing for low-income households need additional subsidy to be economically feasible, but sources of subsidy are limited, and inconsistent.

Diverse housing projects also face challenges as they progress through the planning system. There may be limited sites where medium- and higher-density built form is permitted and where diverse housing types and development models and affordable housing projects are potentially feasible. The permissibility of diverse housing projects can be unclear, as many diverse housing types are not named in planning strategies or in statutory planning documents.

Moreover, diverse housing projects can face increased community opposition, stemming from their built form, design, limited car parking and tenure, which can increase the risk of prolonged development application processes and an uncertain outcome-particularly where there is opportunity for third-party appeal of planning decisions. With tighter development margins, non-speculative and affordable housing projects are less able to cope with the costs associated with prolonged application processes than more mainstream projects.

While these external factors are important, barriers to innovation exist within the housing development industry itself. Larger developers with shareholders and established supply chains can be averse to economic risk and slow to change their housing products and methods of delivery. Innovation can also be limited by a lack of necessary skills and experience within the housing development industry. This can include lack of knowledge of (or experience with) different housing models, building forms and dwelling configurations, as well as lack of knowledge about building materials and construction methods.

\subsection{How can governments better enable diverse housing supply?}

The findings of the Investigative Panels and interviews suggest that there are significant opportunities for governments to both enable and demonstrate housing projects delivering diverse and more affordable housing supply. Reform to planning regulation has been a key strategy by governments over the past two decades to address lack of diversity in the housing stock of Australian cities and declining housing affordability.

Although important, the findings of this research suggest that regulatory reform alone is unlikely to 'unlock' innovation or support the scaling up of diverse types and tenures of housing and alternative delivery models. This is because there are important barriers and challenges for delivering diverse housing supply beyond the planning system.

More wholistic approaches are needed, which include:

- government leadership in articulating the need for diverse housing supply

- increased guidance and support for diverse housing suppliers and community organisations looking to deliver housing in response to local needs

- proactive measures to subsidise and help to de-risk diverse and affordable housing projects

- demonstration to industry. 


\section{Reforms to planning}

State and local governments could support more diverse housing supply by taking the following steps:

- Ensuring land-use zoning allows for medium- and higher-density land uses in a range of locations. This could extend to permitting rental housing or affordable housing tenures in appropriate non-residential zones where land-use conflicts can be managed-for example, light industrial zones can provide opportunities for affordable 'live-work' precincts.

- Naming diverse housing types and models in state planning strategies and policies and local planning schemes, so that their potential permissibility is clear.

- Requiring a mix of housing sizes, built forms and tenures as part of significant new residential development.

- Expediting or prioritising development assessment processes for projects that can demonstrate an affordability outcome, or that address a defined unmet housing need. This reform would have the benefit of reducing time-related costs, but does not require any form of subsidy.

- Allowing concessions such as waived development application fees, council taxes, development contribution requirements or car parking requirements for projects that can demonstrate an affordability outcome, or that address an identified unmet housing need. However, the appropriateness of these-and the extent to which they impact viability - will vary on a project-by-project basis. These concessions might be considered as part of an incentive package.

\section{Scaled subsidy}

Projects that deliver housing at below-market rates are likely to require additional subsidy to be financially viable. Governments at all levels could support the viability of projects that deliver affordable housing and address recognised community housing needs through:

- provision of government land-made available through discounted sale, long-term lease or joint venturing

- access to finance for developers, organisations and purchasers of alternative housing products or housing delivered through non-speculative development models-for example, special low-rate loans

- capital grants to support the development of new sectors within the housing industry and for specific projects, including community-led pilot or demonstration projects

- long-term sources of funding in addition to NHFIC to support the not-for-profit housing sector to deliver new affordable housing supply.

\section{Government leadership}

Apart from regulatory reform and subsidies, governments have an important leadership role to play in developing a strategic framework in which to situate policies and programs to enable diverse housing supply, and in working with industry to demonstrate innovation. Specifically, governments can:

- communicate the need for diverse housing supply across the housing continuum to communities, other government agencies and to the housing development industry

- gather and publish detailed data, and commission research on housing needs, preferences, affordability and housing supply

- establish detailed metropolitan housing supply targets that go beyond overall housing numbers to distinguish required housing tenures, dwelling types and affordability levels

- help affordable housing developers and community organisations interested in developing housing to navigate the planning system

- support bottom-up, community-led innovation in addressing diverse local housing needs

- demonstrate projects that show industry potential demand for diverse housing products - and their profitability - and work through delivery challenges.

It is important that government projects demonstrating diverse housing types and tenures be potentially replicable by the development industry, including the subsidies required, and are at a sufficient scale to make a difference. 


\section{Industry innovation}

The drive for housing innovation also needs to come from industry. In particular, there is a need for the following:

- Non-traditional approaches by lenders and developers, including assessment of risk, coupled with an increased understanding of alternative development models and what the real financial risks are.

- Willingness of developers to deliver mixed housing types and tenure products, incorporating both owneroccupied, market and affordable rental options.

- Skill development in alternative building types and dwelling configurations, construction methods and materials.

\subsection{Conclusion}

This research set out to examine how urban regulation and other factors in the development process impact the diversity of new housing supply in three Australian cities, with a particular focus on the emergence and scaling of housing which, in terms of, size, design, tenure and development model, differs to the majority of housing delivered in Australia's major cities.

Urban planning has frequently been positioned as a barrier to market responses to changing demand-implying that relieving regulatory constraint will lead to better matching of supply with demand across the market. However, research also shows that the planning system is just one factor influencing the decisions of housing suppliers (Adams, Leishman et al. 2009; Rowley and Phibbs 2012), with specific regulatory settings and processes conceptualised as offering incentives and disincentives - sometimes unintentionally-for particularly types of development in particular locations (Monk and Whitehead 1999).

The findings also reveal that the planning system is just one factor that influences the viability of diverse housing projects. Other important factors are:

- lending practices and access to development finance

- the appetite for risk and innovation within the development industry itself

- industry skills and capacity to implement new models

- the availability of subsidies to support the viability of projects that deliver below-market-rate housing.

These findings suggest that regulatory reform to planning to permit more diverse housing types and to allow for greater flexibility in scheme design alone is unlikely to 'unlock' delivery of this type of housing by the development industry. In addition, there is a need for government leadership and financial supports and incentives to encourage the delivery of housing that meets contemporary housing needs and preferences, and is affordable to households across the income spectrum. Without interventions across the housing system, housing projects that deliver more affordable housing tenures and desirable, but less profitable, designs and configurations are unlikely to be delivered at a significant scale.

In terms of implementing changes to the institutional settings impacting housing development, this points to a need to move beyond regulatory interventions, despite their importance in supporting more diverse housing through the planning system. Rather, there is opportunity for governments to take more proactive measures to subsidise and de-risk diverse housing projects-particularly those that can deliver affordable housing for low and moderate income groups. In the context of uncertain economic conditions and persistent unmet housing needs, there is an opportunity for governments to take a strong leadership role in supporting industry innovation and housing delivery, while at the same time addressing important gaps in Australia's housing stock. 


\section{References}

ABS see Australian Bureau of Statistics

Adams, D., Leishman, C. and Moore, C. (2009) 'Why not build faster? Explaining the speed at which British housebuilders develop new homes for owner-occupation', Town Planning Review, vol. 80, no. 3: 291-314.

Australian Bureau of Statistics (2019a) Residential Property Price Indexes: Eight Capital Cities, cat. no. 6416.0, Table 1: Residential Property Price Indexes, Index Numbers and Percentage Changes, ABS, Canberra.

Australian Bureau of Statistics (2019b) Residential Property Price Indexes: Eight Capital Cities, cat. no. 6416.0, Tables 4 and 5: Median Price (unstratified) and Number of Transfers (Capital City and Rest of State), ABS, Canberra.

Australian Bureau of Statistics (2019c) Melbourne (GCCSA), 2016 Census Quickstats, ABS, Canberra.

Australian Bureau of Statistics (2019d) Perth (GCCSA), 2016 Census Quickstats, ABS, Canberra.

Australian Bureau of Statistics (2019e) Sydney (GCCSA), 2016 Census Quickstats, ABS, Canberra.

Australian Government (2019) Royal Commission into misconduct in the banking, superannuation and financial services industry: final report, Commonwealth of Australia, Canberra, accessed 12 March 2020, https://treasury.gov.au/ publication/p2019-fsrc-final-report

Been, V., Gould Ellen, I. and O'Regan, K. (2019) 'Supply skepticism: housing supply and affordability', Housing Policy Debate, vol. 29, no. 1: 25-40.

Bramley, G. and Watkins, D. (2014) '"Measure twice, cut once"-revisiting the strength and impact of local planning regulation of housing development in England', Environment and Planning B: Planning and Design, no. 41: 863-884.

British Property Federation (2020) ‘BPF Build to Rent Map of the UK', accessed 27 March 2020, https://www.bpf.org.uk/ what-we-do/bpf-build-rent-map-uk

Calavita, N. and Mallach, A. (eds) (2010) Inclusionary Housing in International Perspective: Affordable Housing, Social Inclusion, and Land Value Recapture, Lincoln Institute, Washington.

Chakraborty, A. and McMillan, A. (2018) 'Is housing diversity good for community stability? Evidence from the housing crisis', Journal of Planning Education and Research:1-12, doi: 10.1177/0739456X18810787

Chisholm, S. and Hulchanski, D. (2019) 'Canada's housing story', in D. Maclennan, H. Pawson, K. Gibb, S. Chisholm and D. Hulchanski (eds), Shaping futures: changing the housing story-final report, Policy Scotland, Glasgow, accessed 17 February 2020, https://cityfutures.be.unsw.edu.au/research/projects/shaping-futures-changing-housing-story/

City of Vancouver (2012a) Policy report: social development, May 8 2012, City of Vancouver, Vancouver, 5 November 2019 , https://silo.tips/download/supports-item-no-2-cfs-committee-agenda-may-15-2012

City of Vancouver (2012b) Secured market rental housing policy, City of Vancouver, Vancouver, accessed 5 November 2019, https://www2.gov.bc.ca/assets/gov/housing-and-tenancy/tools-for-government/uploads/van_secure_market_ rental_policy.pdf

City of Vancouver (2012; updated 2019), Rental incentives guidelines, City of Vancouver, Vancouver, accessed 20 September 2019, https://vancouver.ca/files/cov/rental-incentive-guidelines.pdf 
City of Vancouver (2015) Administrative report-enhancing housing for families: amendments to the Vancouver Development Cost Levy By-law and the Area Specific Development Costs Levy By-Law regarding for-profit affordable rental housing, City of Vancouver, Vancouver, accessed 20 September 2019, https://council.vancouver. ca/20150526/documents/rr1b.pdf

City of Vancouver (2016) Family room: housing mix policy for rezoning projects, City of Vancouver, Vancouver, accessed 20 September 2019, https://vancouver.ca/files/cov/family-room-housing-mix-policy-for-rezoningprojects-2016-07-13.pdf

City of Vancouver (2018) Housing Vancouver strategy, City of Vancouver, Vancouver, accessed 5 November 2019, https://council.vancouver.ca/20171128/documents/rrlappendixa.pdf

City of Vancouver (2019a) Affordable housing choices interim rezoning policy, City of Vancouver, accessed 29 August 2019, https://vancouver.ca/people-programs/affordable-housing-interim-rezoning-bylaw.aspx

City of Vancouver (2019b) Creating and protecting market rental housing, City of Vancouver, accessed 29 August 2019, https://vancouver.ca/people-programs/creating-new-market-rental-housing.aspx

City of Vancouver (2019c) Moderate income rental housing pilot program: frequently asked questions-December 2019, Vancouver City Council, Vancouver, accessed 17 February 2020, https://vancouver.ca/files/cov/mirhpprequirements-and-process-fags.pdf

City of Vancouver (2019d) Rental incentives review phase ii report back, City of Vancouver, Vancouver, accessed 17 February 2020, https://council.vancouver.ca/20191126/documents/p1.pdf

City of Vancouver (2019e) Review of Vancouver's rental inventives programs, City of Vancouver, Vancouver, accessed 17 February 2020, https://goodmanreport.com/app/uploads/2019/07/Review-of-Vancouver's-RentalIncentive_2019-07-24.pdf

CitySpaces Consulting (2019) City of Vancouver Rental Incentives Program review, Vancouver: CitySpaces Consulting, accessed 17 FAebruary 2020, https://vancouver.ca/files/cov/rental-incentive-program-review-cityspaces-reportjuly.pdf

Crabtree, L. (2018) 'Self-organised housing in Australia: housing diversity in an age of market heat', International Journal of Housing Policy, vol. 18, no. 1: 15-34.

Crook, T., Henneberry, J. and Whitehead, C. (2016) Planning Gain: Providing Infrastructure and Affordable Housing, Wiley and Sons, Oxford.

Crook, T. and Whitehead, C. (2010) 'Intermediate housing and the planning system', in S. Monk and C. Whitehead (eds), Making Housing More Affordable: the Role of Intermediate Tenures, Wiley-Blackwell, Oxford, pp.101-119.

Crosby, N., McAllister, P. and Wyatt, P. (2013) 'Fit for planning? An evaluation of the application of development viability appraisal models in the UK planning system', Environment and Planning B: Planning and Design, no. 40: 3-22.

Department for Communities and Local Government (2012), Review of the barriers to institutional investment in private rented homes, DCLG, London, accessed 8 July 2020, https://assets.publishing.service.gov.uk/government/ uploads/system/uploads/attachment_data/file/15547/montague_review.pdf

Department of Communities (2020) WA Housing Strategy, Government of Western Australia, Perth, accessed 29 March 2020, https://www.communities.wa.gov.au/wa-have-your-say/wa-housing-strategy-2020-2030/

Department of Housing and Western Australian Housing Commission (2013) The housing we'd choose: a study of Perth and Peel, WA State Government, Perth, accessed 12 November 2019, https://www.dplh.wa.gov.au/ getmedia/445a07de-bc30-446d-a4e8-17e39431b2a2/FUT_the-housing-we-d-choose-report

Department of Planning Lands and Heritage (2019) Design WA Stage 2-precinct design, Department of Planning, Lands and Heritage, Perth, accessed 29 March 2020, https://www.dplh.wa.gov.au/designwa-precinct-design

Department of Planning Lands and Heritage (2020a) Development assessment panels, Department of Planning, Lands and Heritage, Perth, accessed 29 March 2020, https://www.dplh.wa.gov.au/daps

Department of Planning Lands and Heritage (2020b) Perth and Peel @ 3.5 million frameworks, Department of Planning, Lands and Heritage, Perth, accessed 29 March 2020, https://www.dplh.wa.gov.au/perth-and-peel-@-3-5-millionframeworks

Development WA (2020a) Innovation through demonstration, Development WA, accessed 1 April 2020, https://www. landcorp.com.au/Our-Work/Innovation-Through-Demonstration/ 
Development WA (2020b) Montario Quarter, Development WA, Perth, accessed 1 April 2020, https://www.landcorp.com. au/Residential/Shenton-Park/

Development WA (2020c) WGV, Development WA, accessed 15 October 2020, https://developmentwa.com.au/projects/ residential/white-gum-valley/overview

Development WA. n.d. Residential, Development WA, Perth, accessed 29 March 2020, https://developmentwa.com.au/ projects/residential

Evolve Housing (2018) \$100m Evolve Housing development delivers 268 properties, Evolve Housing, Sydney, accessed 10 July 2020, https://evolvehousing.com.au/100m-evolve-housing-development-delivers-268-properties/

Fischel, W.A. (2004) 'An economic history of zoning and a cure for its exclusionary effects', Urban Studies, vol. 41, no. 2: 317-340.

Fisher, L. and Marantz, N. (2014) 'Can state law combat exclusionary zoning? Evidence from Massachusetts', Urban Studies, vol. 52, no. 6:1071-1089.

Frasers Property (2020), Ed.Square, accessed 10 July 2020, from https://www.frasersproperty.com.au/nsw/ed-square

Freeman, L. and Schuetz, J. (2017) ‘Producing affordable housing in rising markets: what works?' Cityscape, vol. 19, no. 1: 217-236. doi: 10.2307/26328307

Future of London (2017) Making the Most of Build to Rent, Future of London, London, accessed 10 July 2020, https:// www.futureoflondon.org.uk/wp-content/uploads/delightful-downloads/2017/10/Making-the-Most-of-Build-to-RentWEB.pdf

Gabbe, C.J. (2018a) 'How do developers respond to land use regulations? An analysis of new housing in Los Angeles', Housing Policy Debate, vol. 28, no. 3: 411-427. doi: 10.1080/10511482.2017.1368031

Gabbe, C.J. (2018b) 'Why are regulations changed? A parcel analysis of upzoning in Los Angeles', Journal of Planning Education and Research, vol. 38, no. 3: 289-300.

Gilbert, C. and Gurran, N. (2018) 'Planning for diverse and affordable housing supply? A survey of 200 Australian planning schemes', Journal of Planning Education and Research, doi:10.1177/0739456X18818278.

Glaeser, E.L., Gyourko, J. and Saks, R. (2005) 'Why is Manhattan so expensive? Regulation and the rise in housing prices', Journal of Law and Economics, vol. 48, no. 2: 331-369.

Glaeser, E.L. and Ward, B.A. (2009) 'The causes and consequences of land use regulation: evidence from Greater Boston', Journal of Urban Economics, vol. 65, no. 3: 265-278. doi: 10.1016/j.jue.2008.06.003

Government of Western Australia (2019) Action plan for planning reform: better planning, better places, Department of Planning, Lands and Heritage, Perth, accessed 19 February 2020, https://www.dplh.wa.gov.au/getmedia/075dc761ad2a-4f43-99e2-91a246bb4114/PRJ-PR-Action-Plan

Government of Western Australia Department of Communities and Housing (2016) Shared home ownership, WA Government, Perth, accessed 23 March 2020, http://www.housing.wa.gov.au/sharedstart/Pages/default.aspx

Government of Western Australia Department of Communities and Housing (2019) Keystart home loans, WA Government, Perth, accessed 23 March 2020, http://www.housing.wa.gov.au/housingoptions/ homeownershipoptions/KeyStart/Pages/default.aspx

Greater Sydney Commission (2018) Greater Sydney Region Plan: a metropolis of three cities-connecting people, NSW Government, Sydney, accessed 6 November 2020, https://gsc-public-1.s3-ap-southeast-2.amazonaws.com/s3fspublic/greater-sydney-region-plan-0618_0.pdf?SsIsd8gyH4.nrDDg3eZ3PIOBWzWnC3CV

Gurran, N., Gilbert, C., Gibb, K., van den Nouwelant, R., James, A. and Phibbs, P. (2018) Supporting affordable housing supply: inclusionary planning in new and renewing communities, AHURI Final Report No. 297, Australian Housing and Urban Research Institute Limited, Melbourne, http://www.ahuri.edu.au/research/final-reports/297, doi: 10.18408/ahuri-7313201.

Gurran, N., Gilbert, C., Zhang, Y. and Phibbs, P. (2018) Key worker housing affordability in Sydney, Report prepared for Teachers Mutual Bank, Firefighters Mutual Bank, Police Bank and My Credit Union, The University of Sydney, Sydney, accessed 1 August 2018, https://www.tmbank.com.au/ /media/community/news/pdf/2018/tmb-keyworker-housing-affordability-report-part-1.ashx 
Gurran, N., Phibbs, P., Yates, J., Gilbert, C., Whitehead, C., Norris, M., McClure, K., Berry, M., Maginn, P., Goodman, R. and Rowley, S. (2015) Housing markets, economic productivity, and risk: international evidence and policy implications for Australia-Volume 1: Outcomes of an Investigative Panel, AHURI Final Report No. 254, Australian Housing and Urban Research Institute, Melbourne, https://www.ahuri.edu.au/research/final-reports/254

Gurran, N., Rowley, S., Milligan, V., Randolph, B., Phibbs, P., Gilbert, C., James, A., Troy, L. and van den Nouwelant, R. (2018) Inquiry into increasing affordable housing supply: evidence-based principles and strategies for Australian policy and practice, AHURI Final Report No. 300, Australian Housing and Urban Research Institute, Melbourne, http://www.ahuri.edu.au/research/final-reports/300, doi: 10.18408/ahuri-7313001

Help to Buy (2020a), Equity loan: how does it work?, HM Government, accessed 26 July 2020, https://www. helptobuy.gov. uk/equity-loan/equity-loans/

Help to Buy (2020b) Shared ownership, HM Government, accessed 26 July 2020, https://www.helptobuy.gov.uk/sharedownership/

Homes and Communities Agency (2015) Built to Rent Fund-continuous market engagement prospectus, Homes and Communities Agency, London, accessed 10 July 2020, https://assets.publishing.service.gov.uk/government/ uploads/system/uploads/attachment_data/file/558164/Build_to_Rent_continuous_market_engagement_ completion_instructions_-_archived.pdf

Homes England (2018) Community Housing Fund: Prospectus, Homes England, England, accessed 13 January 2020, https://assets.publishing.service.gov.uk/government/uploads/system/uploads/attachment_data/file/772919/CHF_ prospectus___FINAL_updated_16.1.19.pdf

Housing WA (2010) Affordable Housing Strategy 2010-2020; opening doors to affordable housing: An affordable housing system that provides real opportunity for people on low-to-moderate incomes, Government of Western Australia, Perth, accessed 23 March 2020, http://www.housing.wa.gov.au/HousingDocuments/AHS_Report_final.pdf

Hulse, K., Parkinson, S. and Martin, C. (2018) Inquiry into the future of the private rental sector, AHURI Final Report No. 303, Australian Housing and Urban Research Institute, Melbourne, http://www.ahuri.edu.au/research/finalreports/303, doi: 10.18408/ahuri- 5112001.

id (the population experts) (2018) A Home In Moreland: the housing we need now and in the future, City of Moreland. Moreland, Melbourne, accessed 20 March 2020, https://www.moreland.vic.gov.au/globalassets/areas/social-policy/ final-report-a-home-in-moreland.pdf

James, A., Rowley, S. and Stone, W. (2020) Effective downsizing options for older Australians, AHURI Final Report No. 325, Australian Housing and Urban Research Institute, Melbourne, http://www.ahuri.edu.au/research/finalreports/325, doi:10.18408/ahuri- 8118801 .

James, A., Rowley, S., Stone, W. Parkinson, S., Spinney, A. and Reynolds, M. (2018) Older Australians and the housing aspiration gap, AHURI Final Report No. 317, Australian Housing and Urban Research Institute, Melbourne, http:// www.ahuri.edu.au/research/final-reports/317, doi: 10.18408/ahuri-8117301

James, G., Berry, K. and Marks, A. (2019) Alternative housing tenures, Scottish Government, Edinburgh, accessed 6 November 2018, https://sp-bpr-en-prod-cdnep.azureedge.net/published/2019/11/4/Alternative-Housing-Tenures/ SB\%2019-51.pdf

Kelly, J-F, Weidmann, B. and Walsh, M. (2011) The housing we'd choose, Grattan Institute, Melbourne, 1 August 2018, https://grattan.edu.au/wp-content/uploads/2014/04/090_cities_report_housing_market.pdf

Les, M. and Maher, C. 1998 'Measuring diversity: choice in local housing markets', Geographical Analysis, vol. 30, no. 8: 172-190.

Ley, D. (2015) 'Global China and the making of Vancouver's residential property market', International Journal of Housing Policy, vol. 17, no. 1: 15-34, doi: doi.org/10.1080/14616718.2015.1119776

Ley, D. (2020) 'A regional growth ecology, a great wall of capital and a metropolitan housing market', Urban Studies, doi: $10.1177 / 0042098019895226$

Marantz, N.J. and Zheng, H. (2020) 'State affordable housing appeals system and access to opportunity: evidence from the northeastern United States', Housing Policy Debate vol. 30, no. 3: 370-395.

Mayer, C. and Somerville, C. (2000) 'Land use regulation and new construction', Regional Science and Urban Economics, vol. 30, no. 6: 639-662. 
Mayor of London (2016) The London Plan: the spatial development strategy for London (Consolidated with alterations since 2011), Greater London Authority, London, accessed 10 July 2020, https://www.london.gov.uk/what-we-do/ planning/london-plan/current-Iondon-plan/london-plan-2016-pdf

Mayor of London (2017) Homes for Londoners: affordable housing and viability supplementary planning guidance 2017, Greater London Authority, London, accessed 10 July 2020, https://www.london.gov.uk/sites/default/files/ ah_viability_spg_20170816.pdf

McLoughlin, B. 1991 'Urban consolidation and urban sprawl: a question of density', Urban Policy and Research, vol. 9, no. 3: 148-156.

Milligan, V., Gurran, N., Lawson, J., Phibbs, P. and Phillips, R. (2009) Innovation in affordable housing in Australia: Bringing policy and practice for not-for-profit housing organisations together, AHURI Final Report No. 134, Australian Housing and Urban Research Institute, Melbourne, https://www.ahuri.edu.au/research/final-reports/134.

Ministry of Housing, Communities and Local Government (2018a) Planning practice guidance: Build to Rent, Ministry of Housing, Communities and Local Government, London, accessed 10 July 2020, https://www.gov.uk/guidance/buildto-rent

Ministry of Housing, Communities and Local Government (2018b) Private Rented Sector Housing Guarantee Scheme, Ministry of Housing, Communities and Local Government, London, accessed 10 July 2020, https://assets. publishing.service.gov.uk/government/uploads/system/uploads/attachment_data/file/686404/PRSGS_rules.pdf

Ministry of Housing, Communities and Local Government (2019a) Help to Buy (equity loan scheme) Data to 30 June 2019, England, Ministry of Housing, Communities and Local Government, London, accessed 10 July 2020, https://assets. publishing.service.gov.uk/government/uploads/system/uploads/attachment_data/file/848947/HTB_Equity_Loan_ statistical_release_Q2_2019.pdf

Ministry of Housing, Communities and Local Government (2019b) National planning policy framework, Ministry of Housing, Communities and Local Government, London, accessed 10 July 2020, https://assets.publishing.service. gov.uk/government/uploads/system/uploads/attachment_data/file/810197/NPPF_Feb_2019_revised.pdf

Monk, S. and Whitehead, C. (2010) 'Introduction', in S. Monk and C. Whitehead (eds), Making Housing More Affordable: The Role of Intermediate Tenures, Wiley-Blackwell, Oxford: 1-14

Monk, S. and Whitehead, C.M.E. (1999) 'Evaluating the economic impact of planning controls in the United Kingdom: Some implications for housing', Land Economics, vol. 75, no. 1: 74-93.

Morley, S. (2002) 'The financial appraisal of development projects', in S. Guy and J. Henneberry (eds), Development and Developers: Perspectives on Property, Blackwell Science, Oxford: 73-95.

Morrison, N. and Burgess, G. (2014) 'Inclusionary housing policy in England: the impact of the downturn on the delivery of affordable housing through Section 106', Journal of Housing and the Built Environment, vol. 29, no. 3: 423-438, doi: 10.1007/s10901-013-9360-7

Murray, S., Bertram, N., Khor, L., Rowe, D., Meyer, B., Murphy, C., Newton, P., Glackin, S., Alves, T. and McGauran, R. (2015) Processes for developing affordable and sustainable medium-density housing models for greyfield precincts, AHURI Final Report No. 236, Australian Housing and Urban Research Institute, Melbourne, http://www.ahuri.edu. au/publications/projects/52012.

Newton, C., Gilzean, I., Pert, A., Alves, T. and Backhouse, S. (2015) Housing expos and the transformation of industry and public attitudes-a background report for transforming housing: affordable housing for all, Melbourne School of Design, University of Melbourne, Melbourne, accessed 21 January 2020, https://msd.unimelb.edu.au/_data/assets/ pdf_file/0007/2603698/Housing-expos-paper.pdf

NSW Department of Planning and Environment (2014) Supporting infill affordable rental housing, NSW Government, Sydney, accessed 19 November 2020, https://www.planning.nsw.gov.au/policy-and-legislation/housing/ / media/180BF5EA62894296B4F7FD96782344B5.ashx

NSW Department of Planning and Environment (2018) Low rise medium density: design guide for development applications, NSW Government, Sydney, accessed 20 January 2020, https://www.planning.nsw.gov.au/-/media/ Files/DPE/Manuals-and-guides/Policy-and-legislation/Housing/Medium-density-design-guide-for-developmentapplications-2017-07-05.pdf?la=en 
NSW Department of Planning and Environment (2019) State Environmental Planning Policy (affordable rental housing) 2009 Fact sheet, NSW Government, Sydney, accessed 19 November 2019, https://www.planning.nsw.gov.au/-/ media/Files/DPE/Factsheets-and-fags/fact-sheet-sepp-affordable-rental-housing-boarding-houses-2019-02-28. pdf

NSW Department of Planning, Industry and Environment (2019a). Guideline for Developing an Affordable Housing Contribution Scheme. Sydney: NSW Government, accessed 7 April 2020, https://www.planning.nsw.gov.au/-/media/ Files/DPE/Guidelines/guideline-sepp70-developing-affordable-housing-contribution-scheme-2019-02-28.pdf

NSW Department of Planning, Industry and Environment. (2019b). 'The Low Rise Medium Density Housing Code.' NSW Government, accessed 20 January 2020. https://www.planning.nsw.gov.au/Policy-and-Legislation/Housing/ Medium-Density-Housing/The-Low-Rise-Medium-Density-Housing-Code

NSW Department of Planning, Industry and Environment (2019c). 'SEPP 70 Affordable Housing Revised Schemes.' NSW Government, accessed 20 January 2020, https://www.planning.nsw.gov.au/Policy-and-Legislation/Housing/ Diverse-and-affordable-housing/SEPP-70-Affordable-Housing-Revised-Schemes

NSW Planning and Environment (2018) Local housing strategy guideline, NSW Government, Sydney, accessed 12 March 2020, https://www.planning.nsw.gov.au/-/media/Files/DPE/Guidelines/Local-Housing-Strategy-Guideline-andTemplate.pdf

Ong, R., Dalton, T., Gurran, N., Phelps, C., Rowley, S. and Wood, G.A. (2017) Housing supply responsiveness in Australia: distribution, drivers and institutional settings, AHURI Final Report No. 281, Australian Housing and Urban Research Institute Limited, Melbourne, http://www.ahuri.edu.au/research/final-reports/281, doi:10.18408/ahuri-8107301

Parkinson, S., James, A. and Liu, E. (2018) Navigating a changing private rental sector: opportunities and challenges for low-income renters, AHURI Final Report No. 302, Australian Housing and Urban Research Institute, Melbourne, https://www.ahuri.edu.au/research/final-reports/302, doi:10.18408/ahuri-5112301

Parkinson, S., Rowley, S., Stone, W., James, A., Spinney, A. and Reynolds, M. (2019) Young Australians and the housing aspiration gap, AHURI Final Report No. 318, Australian Housing and Urban Research Institute, Melbourne, https://www.ahuri.edu.au/research/final-reports/318, doi:10.18408/ahuri-5117101

Paulsen, K. (2012) 'The evolution of suburban relative housing-unit diversity', Housing Policy Debate, vol. 22, no. 3: 407-433, doi: 10.1080/10511482.2012.680480

Pawson, H., Martin, C., van den Nouwelant, R. and Milligan, V. (2019) Build-to-Rent in Australia: product feasibility and potential affordable housing contribution, Landcom, Sydney.

Randolph, B., L. Troy, V. Milligan, and R. van den Nouwelant. (2018) Paying for affordable housing in different market contexts, AHURI Final Report No. 293, Australian Housing and Urban Research Institute, Melbourne, https://www. ahuri.edu.au/research/final-reports/293, doi:10.18408/ahuri-7113301

Raynor, K. (2018) 'Social representations of children in higher density housing: enviable, inevitable or evil?', Housing Studies, Vol. 33, no. 8: 1207-1226.

Raynor, K. (2019) 'Assembling an innovative social housing project in Melbourne: mapping the potential for social innovation', Housing Studies, vol. 34, no. 8: 1263-1285.

Rowley, S., Costello, G., Higgins, D. and Phibbs, P. (2014) The financing of residential development in Australia, AHURI Final Report No. 219, Australian Housing and Urban Research Institute, Melbourne, http://www.ahuri.edu.au/ publications/projects/p81009

Rowley, S., Gilbert, C., Gurran, N., Leishman, C. and Phelps, C. (2020), The uneven distribution of housing supply 20062016, AHURI Final Report No. 334, Australian Housing and Urban Research Institute, Melbourne, https://www.ahuri. edu.au/research/final-reports/334, doi:10.18408/ahuri-8118701

Rowley, S. and James, A.C. (2017) 'Housing demand, diversity and affordability', in S. Rowley, R. Ong and A. James (eds), Perth's Infill Housing Future: Delivering innovative and sustainable housing, Bankwest Curtin Economics Centre, Perth: 27-52.

Rowley, S., James, A., Phibbs, P., van den Nouwelant R. and Troy, L. (2017) Government led innovations in affordable housing delivery, AHURI Final Report No. 289, Australian Housing and Urban Research Institute, Melbourne, http://www.ahuri.edu.au/research/final-reports/289, doi: 10.18408/ahuri-8113101 
Rowley, S., Ong, R. and James, A. (2017) ‘Perth's infill housing future', in S. Rowley, R. Ong and A. James (eds), Perth's infill housing future: delivering innovative and sustainable housing, Bankwest Curtin Economics Centre, Perth, accessed 20 January 2020, http://bcec.edu.au/assets/BCEC-Perths-Infill-Housing-Future-web-2.pdf

Rowley, S. and Phibbs, P. (2012) Delivering diverse and affordable housing on infill development sites, AHURI Final Report No.193, Australian Housing and Urban Research Institute, Melbourne, https://www.ahuri.edu.au/_data/ assets/pdf_file/0014/2066/AHURI_Final_Report_No193_Delivering_diverse_and_affordable_housing_on_infill_ development_sites.pdf

Ryan, R. and Selmon, N. (2019) Low rise medium density housing code: independent review report, NSW Department of Planning, Industry and Environment, Sydney, accessed 19 November 2020, https://www.planning.nsw.gov.au/-/ media/Files/DPE/Reports/Policy-and-legislation/independent-review-report-low-rise-medium-density-housingcode-2019-09-18.pdf?la=en

SA Department of Human Services (2020) Developer responsibilities for affordable housing, Government of South Australia, accessed 15 March 2020, https://www.sa.gov.au/topics/planning-and-property/land-and-propertydevelopment/planning-professionals/developer-responsibilities-for-affordable-housing

Saunders, D. (2018) Report on the demographic situation in Canada-internal migration: overview, 2015/2016, Statistics Canada, Ottawa, accessed 6 March 2020, https://www150.statcan.gc.ca/n1/pub/91-209-x/2018001/article/54958eng.htm

Savills (2019) Build to Rent developments are on the rise in Scotland, Savills, accessed 27 March 2020, https://www. savills.co.uk/blog/article/282300/residential-property/build-to-rent-developments-are-on-the-rise-in-scotland. aspx

Scally, C.P., Gold, A. and DuBois, N. (2018) The low income housing tax credit: how it works and who it serves [research report], Urban Institute, Washington, accessed 20 January 2020, https://www.urban.org/sites/default/files/ publication/98758/lithc_how_it_works_and_who_it_serves_final_2.pdf

Scottish Government (2017) Planning delivery advice: build to rent, Scottish Government, Edinburgh, accessed 1 April 2020, https://www.gov.scot/publications/planning-delivery-advice-build-to-rent/

Scottish Government (2020) Open market shared equity scheme, Scottish Government, accessed 30 March 2020, https://www.mygov.scot/open-market-shared-equity-scheme/overview/

Sharam, A. (2020) '"Deliberative development": Australia's Baugruppen movement and the challenge of greater social inclusion', Housing Studies, vol. 35, no. 1: 707-122, doi: 10.1080/02673037.2019.1594712

South West Voice (30 September 2019). Ed.Square: 10 homes for young people with disabilities, accessed 10 July 2020, https://southwestvoice.com.au/ed-square/

State Government of Victoria (2017) Metropolitan Planning Strategy: Plan Melbourne 2017-2050, State Government of Victoria, Melbourne.

Talen, E. (2006) 'Design that enables diversity: the complications of a planning ideal', Journal of Planning Literature, vol. 20, no. 3: 233-249, doi: 10.1177/0885412205283104

Tan, S. (2018, 28 June) ‘Establishing build-to-rent in Australia is a chicken-and-egg game', The Financial Review, https://www.afr.com/real-estate/establishing-buildtorent-in-australia-is-a-chickenandegg-game-20180628-h11z6x

Terrace (n.d.) 'Micro Lots Perth-The 80 Series', Terrace Homes, accessed 29 March 2020, https://www.terracewa.com. au/micro-lots-perth/

The Treadstone Company Pty Ltd (2012) The delivery of medium density housing in new release areas, The Treadstone Company, Sydney.

Thompson, S., Macdonald, A. and Moullakis, J. (2017, 31 August) 'Mirvac to pioneer build to rent sector', The Financial Review, https://www.afr.com/street-talk/mirvac-to-pioneer-build-to-rent-sector-20170829-gy6vgb

Troy, L., van den Nouwelant, R. and Randolph, B. (2018) State Environmental Planning Policy (Affordable Rental Housing) 2009 and affordable housing in Central and Southern Sydney: a research report commissioned by the Southern Sydney Regional Organisation of Councils (SSROC), City Futures Research Centre, UNSW Built Environment, UNSW, Sydney, accessed 20 January 2020, https://cityfutures.be.unsw.edu.au/research/projects/affordablehousing-sepp-and-southern-sydney/ 
Troy, L., van den Nouwelant, R. and Randolph, B. (2019) Occupant survey of recent boarding-house developments in Central and Southern Sydney: a research report commissioned by the Southern Sydney Regional Organisation of Councils (SSROC), City Futures Research Centre, UNSW Built Environment, UNSW, Sydney, accessed 16 March 2020, https://ssroc.nsw.gov.au/occupant-survey-of-recent-boarding-house-developments-in-central-and-southernsydney/

Tucker, C.A. and Ryland, D. (2014). 'Affordable smaller size housing development in Palmerston North: incentives and barriers.' New Zealand Sociology, vol. 29, no. 1: 58-78.

UK Government. (2020) Community Housing Fund, UK Government, accessed 29 March 2020, https://www.gov.uk/ government/collections/community-housing-fund

Urban Land Institute [ULI] (2016) Build to rent: a best practice guide, Urban Land Institute, London, accessed 29 March 2020, https://ulidigitalmarketing.blob.core.windows.net/ulidenc/2016/03/B2R-Edition-2-1-22.pdf

UrbanGrowth NSW (2014) Thornton: North Penrith-21st Century Living, UrbanGrowth NSW, Sydney, accessed 20 January 2020, https://centraltoeveleigh.nsw.gov.au/assets/Publications/UGNSW-21stCenturyLiving2.pdf

van den Nouwelant, R., Crommelin, L., Herath, S. and Randolph, B. (2016) Housing affordability, central city economic productivity and the lower income labour market, AHURI Final Report No. 261, Australian Housing and Urban Research Institute, Melbourne, http://www.ahuri.edu.au/research/final-reports/261.

van den Nouwelant, R., Davison, G., Gurran, N., Pinnegar, S. and Randolph, B. (2015) 'Delivering affordable housing through the planning system in urban renewal contexts: converging government roles in Queensland, South Australia and New South Wales', Australian Planner, vol. 52, no. 2: 77-89.

Vancouver Affordable Housing Agency (2020a) About VAHA, VAHA, Vancouver, accessed 12 January 2020, https://vaha. ca/about/

Vancouver Affordable Housing Agency (2020b) Projects, VAHA, Vancouver, accessed 12 January 2020, https://vaha.ca/ projects/

Victorian Department of Environment, Land, Water and Planning (2019) Inclusionary Housing Pilot, Victorian Government, Melbourne, accessed 18 March 2020, https://www.planning.vic.gov.au/policy-and-strategy/housingstrategy/inclusionary-housing-pilot

Victorian Government (2017) Homes for Victorians: affordability, access and choice, Victorian Government, Melbourne, accessed 20 January 2020, https://www.vic.gov.au/sites/default/files/2019-08/Homes-for-Victorians.pdf

Victorian Government (2020) HomesVic shared equity initiative, Victorian Government, Melbourne, accessed 18 March 2020, https://www.vic.gov.au/homesvic-shared-equity-initiative

Whittemore, A.H. and BenDor, T.K. (2019) 'Opposition to housing development in a suburban US county: characteristics, origins and consequences', Land Use Policy, 88: 1-9

Whitzman, C. (2018) Tap turners and game changers: lessons for Melbourne, Victoria and Australia from affordable housing systems in Vancouver, Portland and Toronto, Melbourne School of Design, University of Melbourne, Melbourne, accessed 20 January 2020, https://msd.unimelb.edu.au/_data/assets/pdf_file/0007/2882491/TapTurners-and-Game-Changers.pdf

Williams, P. (2014) 'The 'panelization' of planning decision-making in Australia', Planning, Practice and Research, vol. 29, no. 4: 426-447, doi: 10.1080/02697459.2014.893677

Yates, J. (2001) 'The rhetoric and reality of housing choice: The role of urban consolidation', Urban Policy and Research, Vol. 19, no. 4: 491-527, doi: 10.1080/08111140108727895

Zabel, J. and Dalton, M. (2011) 'The impact of minimum lot size regulations on house prices in Eastern Massachusetts', Regional Science and Urban Economics 41, vol. 6: 571-583, doi: 10.1016/j.regsciurbeco.2011.06.002 


\section{Appendix 1: Built-environment and housing industry experts}

\section{Sydney (Morning)}

- Richard Benedict (Richard Benedict Consulting)

- Nick Chandler (Rawson Homes)

- Carrie Hamilton (Housing Action Network)

- Leo Patterson Ross (Tenants Union NSW)

- Sam Stone (UDIA)

- Nicole Woodrow (Landcom)

- Anonymous panellist

\section{Sydney (Afternoon)}

- Janet Chappell (Landcom)

- Mark Nutting (Southern Sydney Regional Organisation of Councils)

- Richard Pearson (Pearson Planning Solutions)

- Roberta Ryan (UTS)

- Lynne Sheridan (formerly Department of Planning, Industry and Environment)

- Anonymous panellists (2)

\section{Melbourne (Morning)}

- Kris Daff (Make Ventures)

- Hanna Ebeling (Social Enterprise Financing Australia)

- Peter Hart (Barnett Foundation)

- Myfan Jordan (Per Capita)

- Rob McGauran (MGS Architects)

- Julie Miao (University of Melbourne)

- Elena Pereyra (Cohousing Australia)

- Tim Rylie (The Property Collectives)

- Caroline Speed (UDIA)

- Katherine Sundermann (MGS Architects)

- Anonymous panellist

\section{Melbourne (Afternoon)}

- Mike Collins (City of Moreland)

- Teresa Dominik (Cohousing Australia Planning and Policy Group)

- Roz Hansen (Hansen Consulting)

- Sunny Haynes (Darebin City Council)

- Christina McRae (Urbis)

- Tess Pickering (Victorian Planning Authority)

\section{Perth (Morning)}

- Chris Green - (UDIA)

- Ray Haeren - (Urbis)

- Jane Bennet - (CLE)

- Mark Atkinson - (Atkinson Legal)

- Tao Burton - (Yolk Properties)

- Anonymous panellists (2)

\section{Perth (Afternoon)}

- Grant Shepherd - (Stockland)

- James Yuen - (Office of Land Supply)

- Chris Smith - (Foundation Housing)

- Fraser Henderson - (Stirling Council)

- Anonymous panellists (3) 


\section{Appendix 2: Housing market trends and housing stock in Sydney, Melbourne and Perth}

While median house prices have risen in all three cities since the early 2000s, patterns have varied. Data from the ABS shows that prices rose rapidly in Perth from the mid-2000s, while they remained relatively flat in Sydney and rose only moderately in Melbourne. All three cities experienced a small dip in the wake of the 2007-08 GFC, but prices quickly climbed again to pre-GFC levels. Since around 2014 the trajectories have again been different, with house prices in Perth remaining level and declining slightly and prices in Sydney and Melbourne rising rapidly before declining from around 2017/18, but with median prices, particularly for detached dwellings, remaining significantly higher than before the mid-2010s price boom. In Sydney, more so than in Melbourne, the median price for attached dwellings also remains significantly higher than pre-boom levels (ABS 2019a; 2019b).

Figure A1: Residential property price index: Sydney, Melbourne and Perth

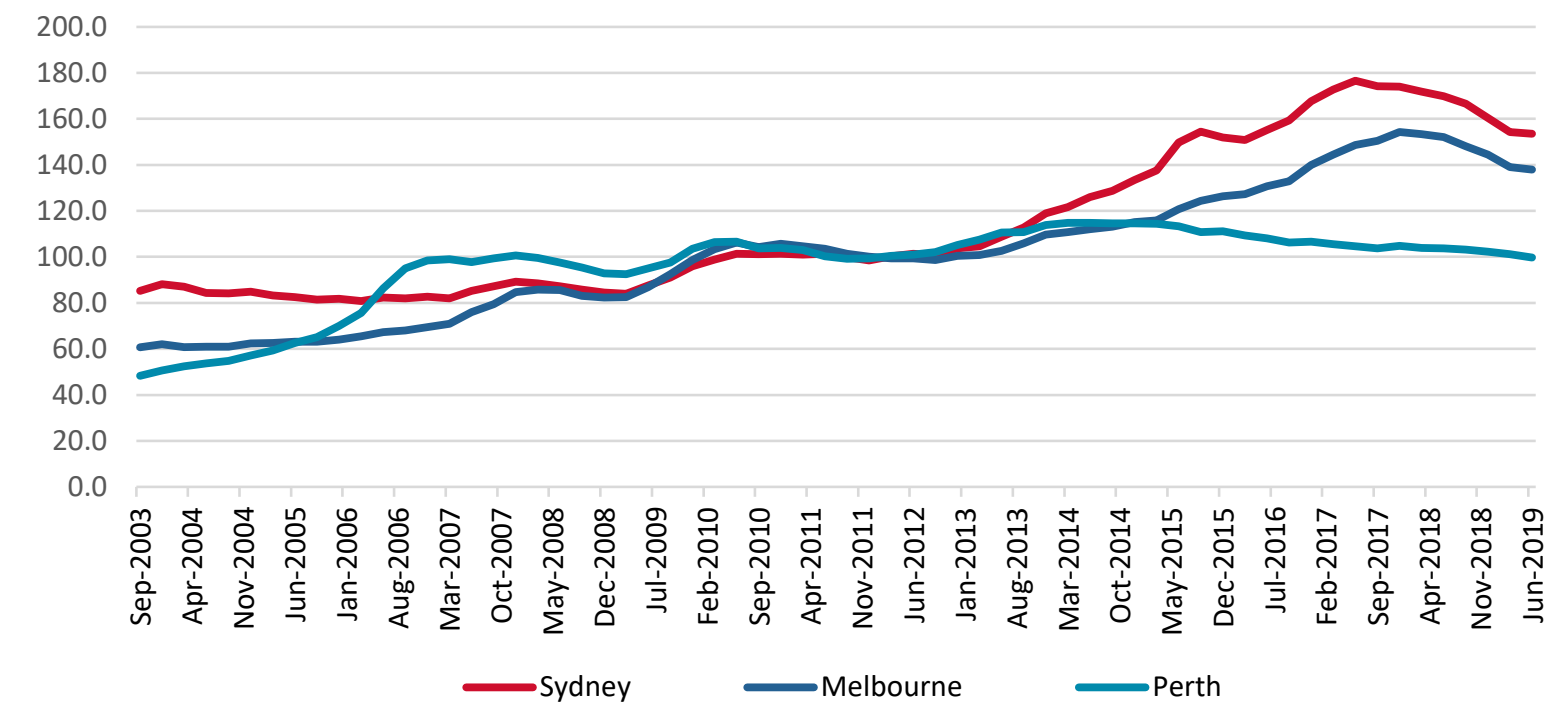

Source: Authors (data derived from ABS 2019a). 
Figure A2: Median price at transfer (unstratified) of detached dwellings

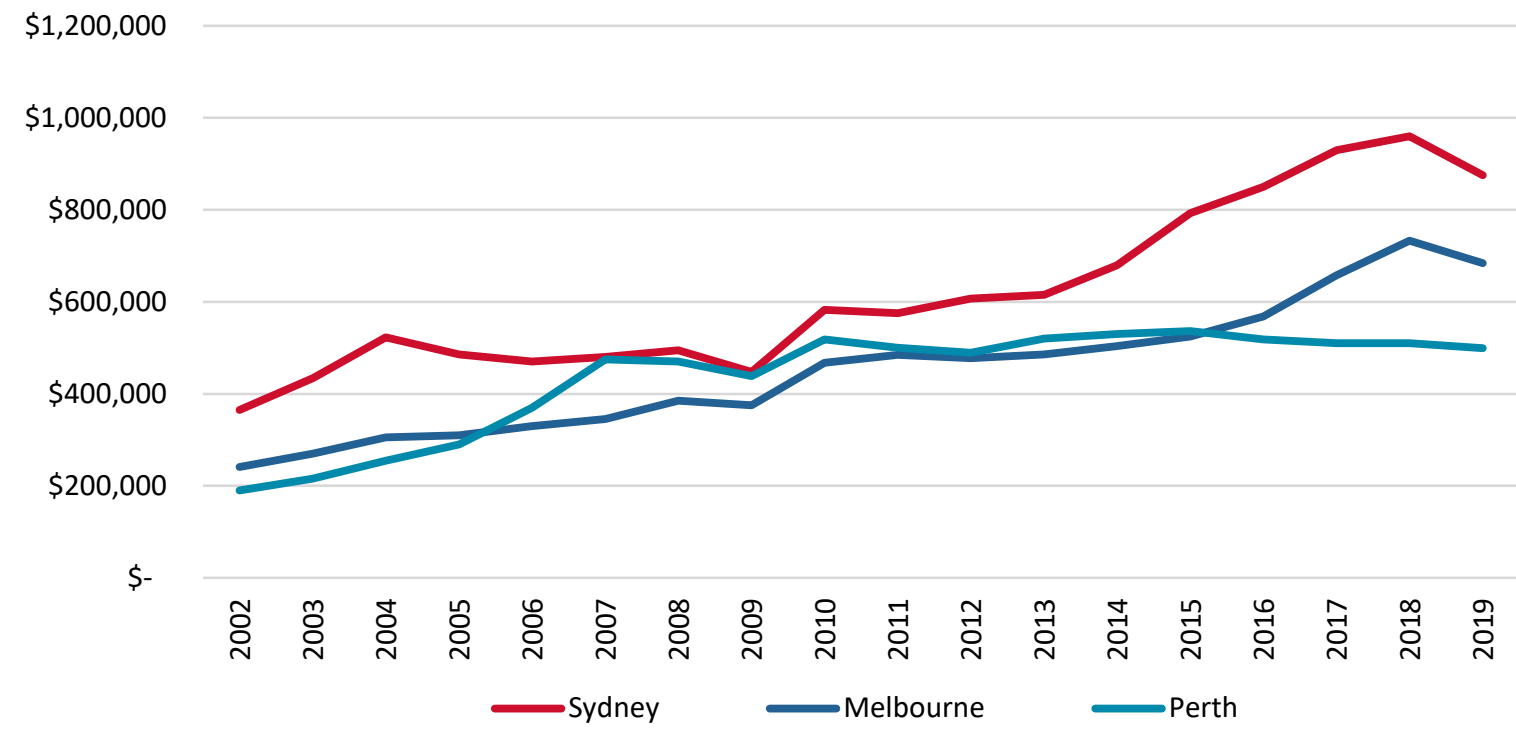

Source: Authors (data derived from ABS 2019b).

Figure A3: Median price at transfer (unstratified) of attached dwellings

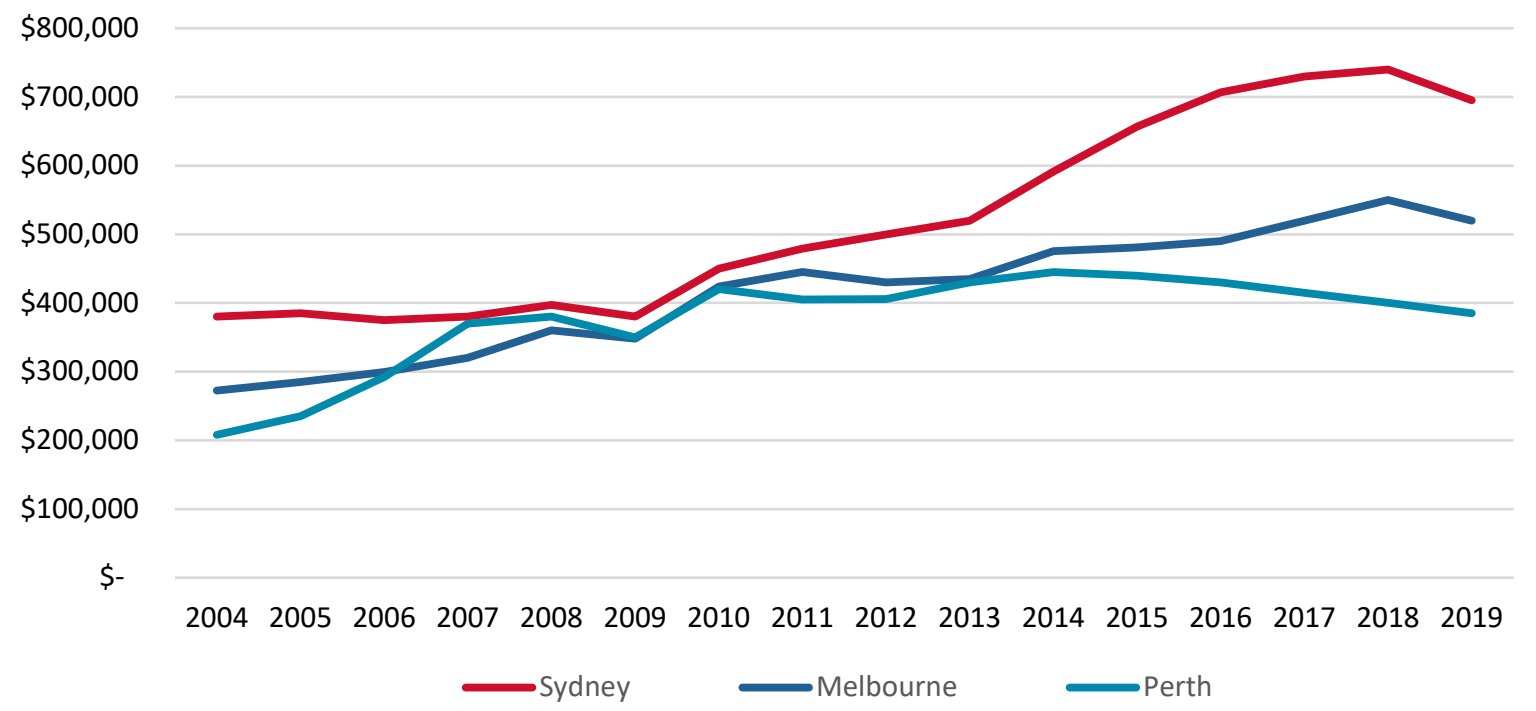

Source: Authors (data derived from ABS 2019b).

Data from the 2016 Census (outlined in Tables A1-A3) shows key differences in the housing stock across the three cities (GCCSA). The most significant contrast is between Sydney, where 57 per cent of housing stock is detached housing and 28 per cent is apartments, and Perth, where detached housing makes up almost 80 per cent of the housing stock, and apartments constitute just less than 7 per cent. Melbourne sits between these two extremes, and has the largest proportion (albeit by a very small difference) in medium-density housing. Despite having similar average household sizes, Perth has a greater proportion of large (4+ bedroom homes) and a lower proportion of one- and two-bedroom dwellings compared to Sydney and Melbourne (ABS 2019c; 2019d; 2019e). 
Table A1: Comparison of housing stock: dwelling types (2016)

\begin{tabular}{lccr}
\hline Dwelling type (structure) & Greater Sydney & Greater Melbourne & Greater Perth \\
\hline Occupied private dwellings & & & \\
Separate house & $56.9 \%$ & $67.8 \%$ & $79.2 \%$ \\
\hline Semi-detached, row or terrace house, townhouse etc & $14.0 \%$ & $16.8 \%$ & $16 \%$ \\
\hline Flat or apartment & $28.1 \%$ & $14.7 \%$ & $6.6 \%$ \\
\hline Other dwellings & $0.6 \%$ & $0.4 \%$ & $0.3 \%$ \\
\hline
\end{tabular}

Source: Authors (data derived from ABS 2019c; 2019d; 2019e).

Table A2: Comparison of housing stock: number of bedrooms and average household size (2016)

\begin{tabular}{lcrr}
\hline Number of bedrooms & Greater Sydney & Greater Melbourne & Greater Perth \\
\hline Occupied private dwellings & & & \\
\hline None (includes bedsitters) & $0.8 \%$ & $0.4 \%$ & $0.2 \%$ \\
\hline 1 bedroom & $7.3 \%$ & $5.7 \%$ & $3.4 \%$ \\
\hline 2 bedrooms & $24.8 \%$ & $20.3 \%$ & $12.2 \%$ \\
\hline 3 bedrooms & $33.8 \%$ & $42.1 \%$ & $37.0 \%$ \\
\hline 4 or more bedrooms & $30.9 \%$ & $29.2 \%$ & $45.2 \%$ \\
\hline Average number of people / household & 2.8 & 2.7 & 2.6 \\
\hline
\end{tabular}

Source: Authors (data derived from ABS 2019c; 2019d; 2019e).

As the most expensive of the three housing markets, it is unsurprising that Sydney has the highest proportion of renters and the highest proportion of households paying unaffordable rents (defined as paying 30\% or more of their income on rent). Sydney also has the lowest number of single-person households, while Sydney and Melbourne have a slightly larger proportion of group households.

Table A3: Comparison of housing tenure and select household characteristics (2016)

\begin{tabular}{lcrr}
\hline Tenure and household characteristics & Greater Sydney & Greater Melbourne & Greater Perth \\
\hline Occupied private dwellings & & & \\
Owned outright & $29.1 \%$ & $30.4 \%$ & $28.1 \%$ \\
\hline Owned with a mortgage & $33.2 \%$ & $36 \%$ & $41.9 \%$ \\
\hline Rented & $34.1 \%$ & $30 \%$ & $26.7 \%$ \\
\hline $\begin{array}{l}\text { Households where rent payments are greater than } \\
\text { or equal to 30\% of household income }\end{array}$ & $14.2 \%$ & $11 \%$ & $9.9 \%$ \\
\hline Single-person households & $21.6 \%$ & $23.2 \%$ & $23.0 \%$ \\
\hline Group households & $4.7 \%$ & $5.0 \%$ & $4.0 \%$ \\
\hline
\end{tabular}

Source: Authors (data derived from ABS 2019c; 2019d; 2019e). 


\section{Appendix 3: Investigative Panel question prompts and key terms and definitions}

\section{Diversity of existing housing stock and opportunities}

- How would the panel define 'diverse' housing in the Australian context?

- What are the current gaps in the housing market in Sydney? How do these differ by location? Are particular household types more or less served in current housing models?

- To what extent do housing market gaps reflect longstanding unmet housing need versus emerging demand arising from current market conditions, new lifestyle preferences, etc?

- To what extent could alternative structures and tenures of housing address housing market gaps, and increase housing opportunities for low- and moderate-income households?

\section{Barriers to diverse housing}

- Are local planning policies (development controls and approval processes) a barrier to delivering diverse housing forms? If so, which ones, and how?

- Are local political influences a barrier to delivering diverse housing?

- Do infrastructure funding arrangements, particularly development contribution requirements, disincentivise diverse housing development (e.g. smaller dwellings, medium-density housing)?

- To what extent do housing market conditions impact upon the diversity of housing produced?

- How do requirements for development financing impact the structure and tenure of housing being produced?

- How do tax settings impact the structure and tenure of housing being produced?

- Are there barriers within the industry-for instance within the construction sector-which inhibit innovation and diversity in new residential development?

- What do you see as the most significant challenges for delivering housing that achieves:

- structural diversity, particularly medium-density housing forms?

- alternative housing tenures?

- housing that is affordable to households on low-to-moderate incomes? 


\section{(For relevant organisations) Examples of diverse housing models being developed by industry (morning panels)}

- What alternative types / tenures of housing or residential development / financing processes has your organisation demonstrated or explored?

- What factors most impacted the viability of your project(s)?

- Have projects resulted in housing that is affordable to low- or moderate-income households?

- Does your organisation plan to replicate or scale your project(s) in the future?

\section{(For relevant organisations) Examples of initiatives to enable diverse housing (afternoon panels)}

- What planning reforms, policies or incentives, demonstration projects or other programs has your organisation implemented to support diverse housing supply, and what have been the outcomes?

\section{Potential role of the public sector in enabling diverse housing}

- How could federal, state and local governments facilitate the delivery of diverse housing projects?

- Is there a role for the public sector (including development agencies) in supporting access to sites to facilitate diverse housing development?

- Could planning-based incentives (such as density bonuses, fee waivers, etc) play a role in improving the feasibility of diverse housing projects or enabling deeper affordability?

- How could the benefits of delivering diverse and more affordable housing in local areas be sold to residents?

\section{Key terms and definitions}

- Diverse housing: housing that differs to the majority of housing stock in terms of its:

- structure-offers an alternative to detached housing or high-rise apartments

- tenure-offers an alternative to traditional ownership and rental tenures

- affordability - has a price or rent that is affordable for low- to moderate-income households using a defined benchmark, or is lower than traditional housing products or other housing available in the same locality.

Examples of diverse housing models that have recently been demonstrated in Australia and or are gaining traction with policy makers include:

- Medium density: housing that is neither low density (i.e. a single detached dwelling on a suburban block) nor high density (i.e. high-rise apartment). It typically includes semi-detached houses, terraces or townhouses, dual occupancies and manor homes-two-storey dwellings that contain multiple units.

- Cohousing: housing with shared facilities and communal spaces, typically accompanied by more modest private space.

- Shared equity/ownership housing: housing in which the value of a dwelling is divided between more than one legal entity - typically the occupying household and an equity partner. Equity partners can be private investors, government agencies or not-for-profit organisations.

- Purpose-built rental / build to rent: housing, typically in the form of apartments, that is purpose-built for rental tenancies, held in single ownership as a revenue-generating asset and is professionally managed.

- Rent to buy: housing that is offered under a lease agreement giving the occupant the option to purchase after a fixed period at a price that is set prior to entering into the agreement.

(Note: The panel was not limited to discussing just these models.) 
- Affordable housing: housing that is subsidised and is subject to access and affordability requirements set by government. It encapsulates both housing for rent and purchase by eligible very-low, low- and moderateincome households. It is distinct from market-rate housing that can be offered at a low price due to size, design, location or construction method.

- Very-low-income household: households earning incomes of less than 50 per cent of the median income for their metropolitan region-for example, working households in minimum wage and low paid jobs, as well as households on government pensions and other government benefits.

- Low-income household: households earning incomes between 50 per cent and 80 per cent of the median income for their metropolitan region.

- Moderate-income household: households with incomes between 80 per cent and 120 per cent of median income for their metropolitan region-for example, essential public service providers such as teachers, nurses and emergency service workers, particularly those at an early career stage.

- Alternative models / processes: land acquisition, development financing, construction processes or occupancy processes and arrangements that differ to the conventional approach in Australia-where developers acquire land and development finance, undertake subdivision or dwelling construction and sell residential lots or units to owner-purchasers or investors.

- Urban regulation: legislation, policies and processes governing the development of urban areas.

- Planning: the legal rules governing land use and development. This includes land-use zoning and controls to regulate built form, design and amenity, as well as processes for obtaining consent to undertake development.

- Infrastructure funding mechanisms: the means by which infrastructure to support new development is funded and provided.

Note that the panels and the wider project also considered other factors impacting the feasibility and affordability outcomes of different housing models, including financing arrangements, taxation arrangements and incentives, as well as housing market variables and factors internal to the development industry. 


\section{AHURi}

Australian Housing and Urban Research Institute Level 12, 460 Bourke Street

Melbourne VIC 3000

\section{Australia}

+61396602300

information@ahuri.edu.au

ahuri.edu.au

(2) twitter.com/AHURI_Research

f facebook.com/AHURI.AUS

in Australian Housing and Urban Research Institute 